\title{
5.2 DIE FRANZÖSISCHSPRACHIGEN WOCHENSCHRIFTEN
}

In diesem Abschnitt wird den (stereotypen) Geschlechterdiskursen innerhalb der französischsprachigen Moralischen Wochenschriften nachgegangen. Bevor jedoch die einzelnen Wochenschriften in den Blick gerückt werden, werden die historischen Eckpunkte und die mediale Verbreitung der französischen Aufklärung sowie die prävalenten Geschlechterdiskurse der Zeit summarisch in Erinnerung gerufen.

Hiernach erfolgen die quantitative Korpusauswertung der mit Frauen- und Männerbild ausgezeichneten Wochenschriften sowie die chronologisch aufgebaute Analyse der Einzelnummern. Zu Beginn jeder Detailanalyse wird jede Zeitschrift kurz mit ihren Basisinformationen (Herausgeber*innen, Erscheinungszeitpunkte, Gesamtnummernzahl) eingeführt und die absolute und relative Häufigkeit der in ihr angetroffenen Frauen- und Männerbild-Markups angegeben. Ebenfalls werden die Verfassungsinstanz und ihre dezidierten Ziele, die sie mit ihrem Schreiben verfolgt, vorgestellt. Im Anschluss wird auf das innerhalb der Zeitschrift verhandelte Geschlechterwissen sowie auf die medienspezifischen und narrativen Strategien zur Konstruktion des spectatorialen Wissens über die Geschlechter eingegangen.

\section{Historische Eckpunkte der Aufklärung in Frankreich}

In Frankreich erstreckt sich die Aufklärung über das gesamte 18. Jahrhundert, auch wenn sie mitunter erst mit 1750 angesetzt wird, da um die Jahrhundertmitte zahlreiche Schriften und Schlüsseltexte der Aufklärung entstehen. Das gesamte Jahrhundert ist von einem zunehmenden Machtverlust der Monarchie geprägt, die (gemeinsam mit Adel und Klerus) auf dem Rücken des Dritten Standes einem verschwenderischen Lebensstil frönt, und kulminiert in der Französischen Revolution von 1789. Die Ideen der in England entstehenden Aufklärungsbewegung erreichen bereits nach dem Tod von Ludwig XIV. (1715) die französischen ,philosophes“ (cf. Geier 2012, 93-94), die sich durch einen ,systematischen, an den empirischen Naturwissenschaften geschulten Vernunftgebrauch, durch [...] ]eine Ablehnung traditioneller Vorurteile und durch [...] ein intensives Sozialleben“ (Gipper 2015, 57) auszeichnen. Unter Berufung auf die menschliche Vernunft, die ihnen als oberstes Prinzip allen Denkens und Handelns gilt, ziehen sie in ihrer Gesellschaftskritik überkommene Traditionen ,wissenschaftlich' in Zweifel und machen dabei vor der Infragestellung des absolutistischen Staates, der Herrscherfigur des Königs sowie der kirchlichen Autoritäten nicht Halt. Das Ziel der ,philosophes“ ist es dabei, ihren Mitmenschen zu eigenständigem Denken zu verhelfen. Sie setzen sich dafür ein, dass sich die Menschen nicht mehr auf die althergebrachten, von den Autoritäten sanktionierten Traditionen stützen. Stattdessen sollten sie sich ihres eigenen Verstandes bedienen, um sich aus ihrer selbstverschuldeten Unmündigkeit zu befreien, wie Kant (1724-1804) mit ,sapere aude! ' - dem Leitspruch der Aufklärung - resümiert. Nur durch die Benutzung des Verstandes könne der Mensch erkennen, was wahr und falsch sei, weshalb auch seine Vernunft und seine Urteilsfähigkeit zu schulen sei - ein Desiderat, das in den Moralischen Wochenschriften durch die Vermittlung des empirischen Verfahrens des Beobachtens gestützt wird, aus dem sich eine Beurteilung der beobachteten Objekte ableitet. 


\section{Verbreitung}

Verbreitung finden die aufklärerischen Positionen vor allem durch die immer einflussreicher werdenden Printmedien, die den Intellektuellen zum Ideenaustausch dienen. Unter den französischsprachigen Druckerzeugnissen des Jahrhunderts stellt die Encyclopédie (1751-1772) von Denis Diderot (1713-1784) und Jean-Baptiste le Rond d'Alembert (1717-1783) mit ihren 17 Bänden und zahlreichen Neuauflagen das bedeutendste Werk dar, aber auch Bücher und periodisch erscheinende, weniger umfangreiche Publikationen zirkulieren zunehmend unter den Adeligen und dem Großbürgertum. Die Erzeuger*innen dieser Werke sind oft ein und dieselben Personen, die als ,écrivains-journalistes‘ breitenwirksam auftreten und sich wie Voltaire (1694-1778), Abbé Prévost (1697-1763) oder Marivaux (1688-1763) einen Namen machen (cf. Pinson 2016, 19-28). ${ }^{8}$ Von besonderer Bedeutung sind in Frankreich die seit dem Spätmittelalter geführten Debatten über die Geschlechterverhältnisse (Querelles des sexes), die sowohl in Text- als auch in Bildform stattfinden und anfänglich um die Ehe, im 17. und vermehrt noch im 18. Jahrhundert um die weibliche Bildung und Gelehrsamkeit sowie um Mode und Körperpflege kreisen. Das Hin und Her unzähliger Kontroversen ist oft in Form von offenen oder subtilen Polemiken, in Dialogform innerhalb einer Schrift oder als Ironie, Parodie, Paradox oder Sarkasmus gekleidet und endet mit der Französischen Revolution, die wiederum den Beginn des Streits um Qu'est-ce qu'une femme des 19. Jahrhunderts einleitet (cf. Bock/Zimmermann 1997, 9-38; Hassauer 2008, 11-46).

\section{Geschlechterdiskurse}

Die Geschlechterdebatten der Aufklärung sind in der ersten Hälfte des 18. Jahrhunderts von einem Gleichheitsdiskurs dominiert, der die traditionellen Argumente des 17. Jahrhunderts weiterführt. Dabei wird von einer natürlichen Gleichheit von Frau und Mann ausgegangen, die durch die gesellschaftliche Praxis jedoch zu einer Ungleichheit führe (Höfer/Keilhauer 1996, 39). In der zweiten Jahrhunderthälfte wird dieser Gleichheitsdiskurs immer mehr von einem Komplementaritätsdiskurs abgelöst, ${ }^{9}$ der durch eines der zentralen Ideale der Aufklärung, der Nützlichkeit (utilité), gestützt

8 Voltaire ist Autor einer Vielzahl von Artikeln der Encyclopédie und heute vor allem bekannt für seine Theaterstücke und Erzählungen. Abbé Prévost, der mit seinem Roman Manon Lescaut (1731) sehr erfolgreich ist, schreibt für verschiedene Zeitschriften und publiziert zwischen 1733 und 1740 selbst die Zeitschrift Le pour et contre. Marivaux, dessen Theaterstücke bis heute aufgeführt werden, ist darüber hinaus Autor von drei Spectator-Schriften, von denen zwei in diesem Abschnitt näher behandelt werden (cf. Pinson 2016, 25).

9 Zum Geschlechterdiskurs im Frankreich der Aufklärung siehe beispielsweise die Artikel von Bock/Zimmermann (1997), Brink (2008), Höfer/Keilhauer (1996), Honegger (2011) und Sieuzac (2009).

Zur Präsenz von Frauen in Gesellschaft und Literatur siehe den Sammelband von Eva Jacobs et al. (1979). Zum theoretischen und literarischen Diskurs über die Frau als das ,moralische Geschlecht‘ im 18. Jahrhundert, siehe die Monografie von Lieselotte Steinbrügge (1987). Zur Repräsentation von Frauen in der französischen Presse des Aufklärungszeitalters siehe Suzanna van Dijk (1988) und zur Geschichte der ,presse féminine“ in Frankreich siehe Evelyne Sullerot (1966). 
wird. Der Nützlichkeitsdiskurs erstreckt sich auf alle Bereiche des individuellen wie des kollektiven Lebens, wobei die partikularen Interessen unter jene des Gemeinwohls zu stellen sind. Als Frau oder als Mann gilt man dann als nützlich für die Gesellschaft, wenn man nach den Regeln der Tugendhaftigkeit lebt und gleichzeitig den weiblichen (i. e. reproduktiven) beziehungsweise den männlichen (i. e. produktiven) Pflichten innerhalb dieser Gesellschaft nachkommt. Während für die Frau das dreifache Idealbild der Ehefrau, Hausfrau und Mutter gilt, ist es für den Mann das Ideal des Honnête homme (cf. Höfer/Keilhauer 1996, 37; Höfer/Reichardt 1986). Damit einher geht eine Zuordnung der Frau in die häusliche und des Mannes in die öffentliche Sphäre, wobei sich anfangs nur Ehepaare aus der Mittelschicht einen solchen Lebensstil leisten können. Im 19. Jahrhundert schließlich machen sich die Weiblichkeits- und Männlichkeitsideale, die zuerst innerhalb der bürgerlichen Schicht auftreten, zunehmend auch in anderen Klassen breit (cf. Schaufler 2002, 164).

Während der Honnête homme für sich allein ein eigenständiges Individuum darstellt, wird die Frau stets im Verhältnis zum Mann definiert. Kognitive Fähigkeiten sind im Lernprogramm für die Frau - gleichgültig welcher sozialen Schicht - nicht vorgesehen, es müssen lediglich ihre ,nützliche[n], über die Institution der Familie dem gesamtgesellschaftlichen Gefüge dienliche[n] Fertigkeiten geschult werden: Rechnen, landwirtschaftliche Kenntnisse, Handarbeiten und vor allem sparsame Haushaltsführung“ (Höfer/Keilhauer 1996, 15). Eine Frau hat weder politische Rechte noch Ausbildung oder Beruf, und bleibt somit während ihres gesamten Lebens vom Ehemann und dessen sozialer Stellung abhängig (cf. ibid., 19). Die Natur dieses Verhältnisses drückt sich auch am Ende des 18. Jahrhunderts in folgenden Begrifflichkeiten aus, die in der Encyclopédie méthodique (1791) unter dem Begriff ,femme‘ Erwähnung finden: ,femme mariée', ,femme naturelle', ,maîtresse', ,concubine', ,femme entretenue', ,courtisane' und ,prostituée‘ (cf. Peuchet 1791, 180-182). Die Anordnung dieser Begrifflichkeiten

[...] drückt dabei eine doppelte Rangfolge aus; je dominanter die sexuelle Komponente der Beziehung zwischen Mann und Frau, desto niedriger das Ansehen und die soziale Stellung der Frau. Darüberhinaus [sic] zeigt diese Aufzählung, daß andere soziale Existenzformen der Frau, ausgenommen noch die des Jungmädchendaseins und der Witwenschaft, nicht im kollektiven Bewußtsein verankert waren; so wurde z. B. der Titel femme d'affaire als reine Persiflage in Anlehnung an den homme d'affaire gebraucht und besaß pejorativen Charakter [kursiv im Orig.]. (Höfer/Keilhauer 1996, 13)

Gesellschaftliche Achtung wird einer Frau im 18. Jahrhundert letzten Endes nur zuteil, wenn sie ihre Rolle als tugendhafte Tochter, liebende Ehefrau und fürsorgliche Mutter den Ansprüchen der Gesellschaft gemäß zu erfüllen weiß (cf. Höfer/Keilhauer 1996, 19). 


\subsubsection{Quantitative Analyse der französischsprachigen Moralischen Wochenschriften}

Diagramm 1: Frauen- und Männerbild-Markups in den französischsprachigen Moralischen Wochenschriften (chronologische Reihung).

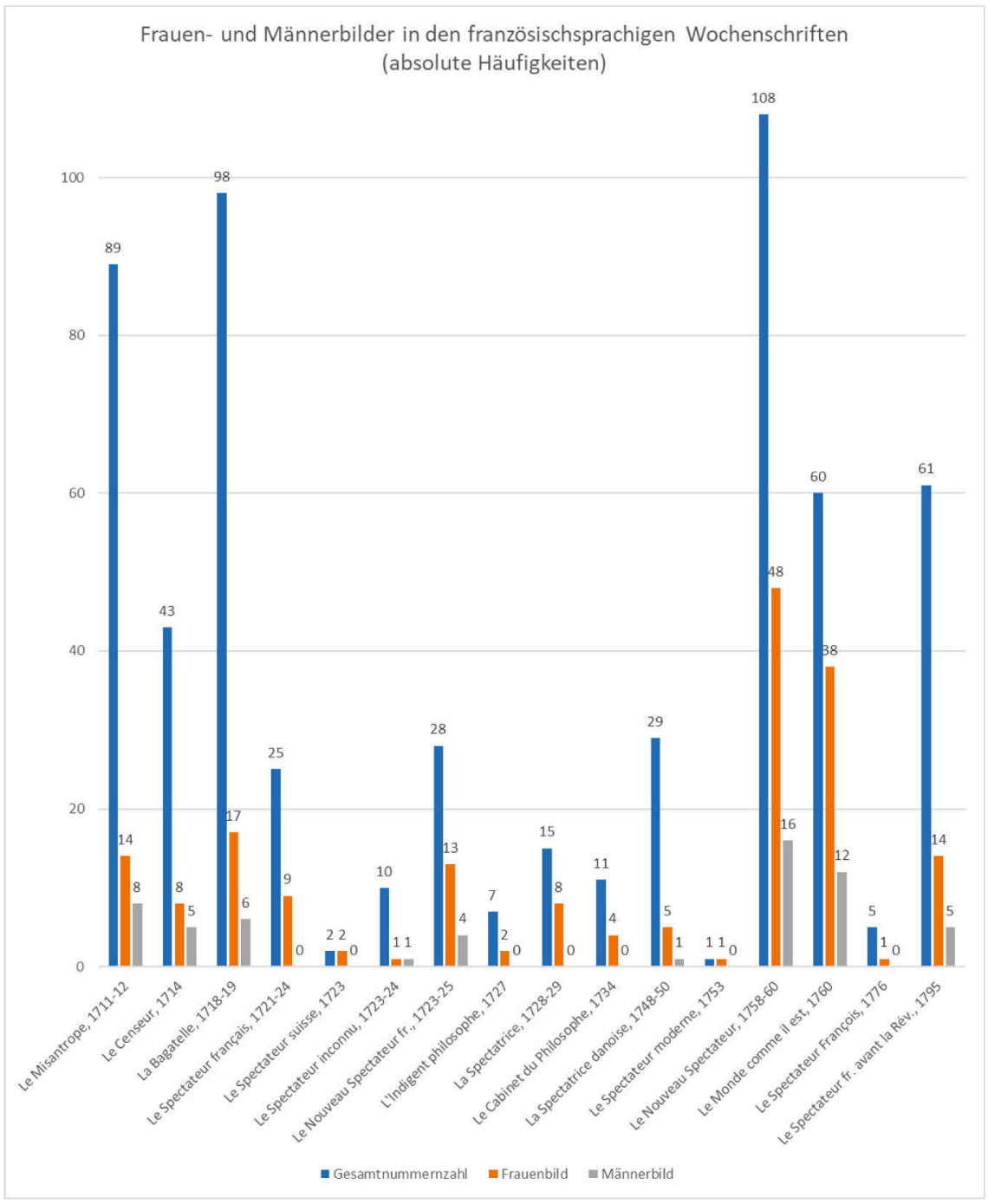

Quelle: Eigene Darstellung.

Für die quantitative Analyse der französischsprachigen Wochenschriften wurde in die erweiterte Suchmaske des Repositoriums gemeinsam mit der Themensuchoption Frauenbild (im ersten Suchdurchgang) und Männerbild (im zweiten Durchgang), das Land (Frankreich) und die Jahreszahl der jeweils zu durchsuchenden Zeitschrift eingege- 
ben. ${ }^{10}$ Aus Diagramm 1 lassen sich demnach die absoluten Häufigkeiten der digital in den jeweiligen Zeitschriften ausgezeichneten Themen ablesen. ${ }^{11}$ Während die blauen Balken die Gesamtnummernanzahl der jeweiligen französischsprachigen Wochenschriften im digitalen Repositorium darstellen, repräsentieren die orangen Balken die Anzahl der Nummern (absolute Häufigkeit) mit Frauenbild-Markup und die grauen Balken jene mit Männerbild-Markup in diesen Zeitschriften. So weist zum Beispiel die Bagatelle (1718-1719) bei einer beachtlichen Gesamtnummernanzahl von 98 Einzelnummern lediglich in 17 Nummern mindestens eine Codierung mit Frauenbild und in 6 Nummern mindestens eine Codierung mit Männerbild auf.

Anhand des Diagramms lässt sich erkennen, dass Frauen- und Männerbilder in den französischsprachigen Wochenschriftennummern in stark variierendem Ausmaß anzutreffen sind. In fast allen französischsprachigen Periodika und über das gesamte Jahrhundert hinweg finden sich Einzelnummern, die Frauen und Männer thematisieren. Insbesondere bestimmte Autor*innen, zu denen Van Effen (Le Misantrope, La Bagatelle, Le Nouveau Spectateur français), Bastide (Le Nouveau Spectateur, Le Monde comme il est) und Delacroix (Le Spectateur français avant la Révolution) sowie jene/r anonyme Autor*in der Spectatrice zählen, scheinen die zeitgenössischen Geschlechterdiskurse intensiver in ihren Blättern zu inkorporieren als andere Kolleg*innen. Implizit sind Geschlechterdiskurse dagegen in allen französischsprachigen Periodika anzutreffen, sie treten allerdings in vielen Nummern nur als eine von vielen Thematiken auf und dominieren diese nicht, weshalb sie in den Dublin-Core-Metadaten auch nicht extra mit Frauen- oder Männerbild ausgewiesen worden sind.

Wie aus der quantitativen Analyse hervorgeht, übertrifft die Anzahl der Frauenbild-Markups generell die Anzahl der Männerbild-Markups meist um mehr als das Doppelte. Daraus lässt sich zum einen ableiten, dass die Moralischen Wochenschriften nicht nur in England, sondern auch im französischsprachigen Europa stark an eine weibliche Zielgruppe gerichtet sind, die im 18. Jahrhundert zunehmend aktiviert wird. Zum anderen zeigt dies, dass das weibliche Publikum im aufklärerischen Reformierungsprojekt der moralischen Periodika eine bedeutendere Rolle als das männliche Publikum einnimmt und somit die Leserinnen gegenüber den Lesern auch am europäischen Festland stärker im Fokus der Spectator-Produzent*innen stehen.

Um eine mögliche Verschiebung der Argumentationslinien innerhalb der Spectator-Gattung über das Jahrhundert aufzeigen zu können, wird im Folgenden die diskursanalytisch informierte Textanalyse der Periodika mit Frauen- und MännerbildMarkups für den französischsprachigen (wie auch im darauffolgenden Abschnitt für den spanischprachigen) Raum chronologisch vorgenommen. Aufgrund der großen Zahl an Wochenschriften werden jene Periodika genauer unter die Lupe genommen,

10 Eine detaillierte Beschreibung der quantitativen Analyse kann in Kapitel 3 unter „Methoden und Vorgehen" nachgelesen werden.

11 Eine tabellarische Auflistung der Treffer kann in Anhang 2 eingesehen werden.

In den Fällen, in denen die Suchanfrage ein und dieselben Treffer doppelt angezeigt hat, wurden diese Dubletten aus der Trefferanzahl herausgerechnet. Durch Kongruenzen bei den Treffern zum Frauen- und Männerbild zeigt sich bereits bei der quantitativen Analyse, dass das Wissen um Frauen und Männer mitunter auch gemeinsam, d. h. innerhalb einer Nummer, verhandelt wird. 
die eine relative Häufigkeit von mehr als $15 \%$ an Frauenbildern ${ }^{12}$ bei einer Gesamtzahl von mehr als zehn Nummern pro Wochenschrift aufweisen. Das birgt den Vorteil, dass ein Gesamteindruck von den in der Zeitschrift vorhandenen spectatorialen Geschlechterdiskursen entsteht und aussagekräftige Befunde über ihre ästhetisch-narrative Ausgestaltung getroffen werden können.

\subsubsection{Le Misantrope (1711-12) - der philantropische Ratgeber}

Die erste französischsprachige Spectator-Nachahmung stammt aus der Feder des Holländers Justus van Effen (1684-1735), der mit seinem Misantrope. Contenant des Réflexions Critiques, Satyriques et Comiques, sur les défauts des hommes (1711-1712) die Gattung bereits einige Monate nach dem Erscheinen des Spectator ${ }^{13}$ auf das europäische Festland überführt. In den insgesamt 89 als ,Discours‘ (Diskurse) bezeichneten Nummern des Misantrope ergibt die Suche 14 Thementreffer für das Frauenbild (Préface, II, IV, XVI, XVIII, XLV, XLVII, L, LXI, LXX, LXXX, LXXXV, LXXXVIII) und 8 Treffer für das Männerbild (Préface, II, XVI, XVIII, LXI, LXX, LXXXV, LXXXVIII), wobei alle Männerbildtreffer gleichzeitig auch Frauenbildtreffer sind, die Treffer also deckungsgleich sind. Damit enthalten circa $16 \%$ der Nummern mindestens eine Frauenbild-Codierung und $9 \%$ mindestens eine MännerbildCodierung.

Wilhelm Graeber (1986) und Alexis Lévrier (2013a) halten fest, dass die Verfassungsinstanz des selbsternannten ,Menschenfeindes', die somit denselben Namen wie die Zeitschrift trägt, direkt in den Fußstapfen ihres englischen Vorbilds schreitet. Wie Mr. Spectator nimmt Monsieur le Misantrope trotz seines negativ konnotierten Pseudonyms die Haltung eines moralischen Wortführers mit „philanthropischen Motiven“ (Graeber 1986, 23) ein. Er vertritt „eine rationalistische Tugendauffassung, die sich auf die Fähigkeit des Menschen zur Einsicht gründet und in französischsprachiger Literatur dieser Zeit fremd anmutet, da die Moralistik-Tradition wenig Vertrauen in die Selbstverfügbarkeit hatte“ (ibid., 24). Im Vorwort der konsultierten Neuauflage von 1742 erklärt der Misantrope seine reformerische Absicht, indem er sich auf den Publikumsgeschmack (goût du Public) bezieht, den er prüfen will, um ihn schließlich mit seinem Werk ansehnlicher zu machen, also zu verbessern: ,[M]on but [est] de tâter le goût du Public, afin de lui donner après quelque bon Ouvrage plus considérable“ (M Préface, xvi). Der Fokus auf den Geschmack erklärt sich dadurch, dass für die Verbesserung der Sitten die Kultivierung des Geschmacks - verstanden ,als ein Vermögen

12 Da die Treffer zum Frauenbild stets weit über jenen zum Männerbild liegen, wird für die Auswahl der zu analysierenden Periodika die Frauenbildauszeichnung herangezogen, auch wenn es - wie sich herausstellen wird - immer wieder zu Überschneidungen kommt, Weiblichkeits- und Männlichkeitsdiskurse also gleichzeitig auftreten.

13 Die erste Nummer des englischen Spectator erscheint am 1. März 1711, die erste Nummer des Misantrope wird zweieinhalb Monate später am 19. Mai 1711 in Den Haag veröffentlicht. Bis zu diesem Tag sind bereits 69 Spectator-Nummern erschienen. In den Jahren $1712-$ 1713, 1726 und 1742 kommt der Misantrope in Sammelbänden heraus, von denen letzterer für die digitale Edition im Repositorium herangezogen wurde. $\mathrm{Zu}$ den formal-inhaltlichen Unterschieden der Neuauflagen siehe Fischer (2014, 55). 
zur Beurteilung ganz bestimmter Sachverhalte auf den Gebieten der Lebensführung, der Mode und der Kunst" (Schümmer 1955, 120) - im 18. Jahrhundert ganz wesentlich wird. Nur wer mit dem Geschmack der Zeit vertraut ist, könne beurteilen, welche Verhaltensweisen, Handlungen und (Charakter-)Eigenschaften angemessen und welche verwerflich seien. Der Verfasser spricht hier zwar vom ,goût' seines gesamten Publikums. Da aber der Geschmack aufgrund seiner Wahrnehmung über die Sinne im Laufe des 18. Jahrhunderts immer mehr mit dem weiblichen Geschlecht assoziiert wird während das männliche mit ,raison' (Vernunft) verbunden wird - kann bereits am Beginn der Zeitschrift davon ausgegangen werden, dass der Verfasser ebenso ein weibliches Publikum im Auge hat. Zudem spricht er im Vorwort auch beide Geschlechter direkt mit „vous autres Messieurs, \& Mesdames [kursiv im Orig.]“ (M Préface, ix) an. Die Inklusion des weiblichen Publikums ist insofern bemerkenswert, als Frauen bis zu diesem Zeitpunkt vom Pressewesen als Zielpublikum noch gar nicht bedacht werden, ${ }^{14}$ da nur wenige Frauen über Lesekompetenz verfügen. ${ }^{15}$

Im weiteren Verlauf der Wochenschrift offenbart sich, dass der Misantrope ebenso wie Mr. Spectator - sein Publikum nach dem Geschlecht in einen weiblichen und einen männlichen Teil untergliedert, wobei er vorgibt, das weibliche Publikum in einigen allein ihm gewidmeten Blättern erziehen zu wollen (cf. Lévrier 2013a, 240): „Je reviens encore à vous, Mesdames; je sai [sic] que vous avez goûté les conseils que j'ai pris la liberté de vous donner, $[\ldots]$ “. $(\mathrm{M} \mathrm{L}, 65)$. Durch die dezidierte und wiederholte Anrede der Frau als Zielgruppe erfährt die Figur der Leserin im Misantrope - die nur in dieser französischsprachigen Wochenschrift direkt adressiert wird - „eine

14 Später als in Deutschland oder England entwickelt sich in Frankreich eine an Frauen gerichtete ,presse féminine‘ erst ab Mitte des 18. Jahrhunderts, die mit dem Journal des Dames (1759-1778) ihren Anfang nimmt (cf. Sullerot 1966; Van Dijk 1988, 5-8). Als Vorläufer französischsprachiger Damenalmanache erscheint bereits in der ersten Jahrhunderthälfte der Almanach des dames savantes françaises (1728-1742) (cf. Lüsebrink/Haß 2013, 279).

$15 \mathrm{Im}$ 18. Jahrhundert nimmt die allgemeine Alphabetisierung zwar zu, allerdings bestimmen die Determinanten der Region, des Verstädterungsgrades, des Geschlechts und des Wohlstandes ihren Grad. Allgemein gesprochen ist die Alphabetisierungsrate bei Männern höher als bei Frauen und in Städten höher als am Land. Im Frankreich der 1740er-Jahre können $40 \%$ der städtischen Frauen im Vergleich zu $13 \%$ der Frauen in ländlichen Gebieten lesen (während die entsprechenden Zahlen für Männer $60 \%$ im urbanen und $35 \%$ im ländlichen Raum betragen) (cf. Melton 2001, 85-86).

Mit der Zunahme des weiblichen Lesepublikums, das anfangs hauptsächlich den aristokratischen und bürgerlichen Kreisen entstammt (cf. Sullerot 1966, 5), erlangt auch das Bild der Frau als Leserin im Laufe des 18. Jahrhunderts eine außergewöhnliche Entwicklung: „Les scènes de lecture féminine du début du siècle insistent tout d'abord sur les plaisirs de la formation à la lecture de jeunes filles et s'attachent à décrire les effets de la lecture sur le corps et l'esprit des innocents. Dans la seconde moitié du siècle, ce sont les programmes de lectures qui assurent cette formation et qui sont au centre des écrits : quels livres sélectionner pour une éducation saine et vertueuse ou à contrario une éducation libertine“" (Aragon 2004, 242-243)? 
Aufwertung und wird dadurch zur kompetenten Rezipientin stilisiert. ${ }^{16}$ Die Figur der Leserin verkörpert jene, die ein Buch oder veröffentlichte Manuskripte liest und aufnimmt und deren Lektüreaktivität in Texten beschrieben ist“" (Fischer 2014, 205). Darüber hinaus führt die werkimmanente Lektürebeschreibung ,,von der weiblichen Adressatin hin zur weiblichen Rezipientin, welche durch die textinterne Inszenierung die an sie gerichtete Botschaft aufnehmen soll“ (ibid.).

Thematisch kreisen die ermittelten Einzelnummern des Misantrope - wie im Untertitel Réflexions Critiques, Satyriques et Comiques, sur les défauts des hommes angedeutet - um menschliche, vermehrt weibliche, Laster (défauts, vices), wobei der Verfasser ,sich die der Moralphilosophie entstammende[n] Konzeption des Lasters als einer geistigen Verirrung zu eigen [macht]“ (Graeber 1986, 23). ${ }^{17}$ Diese werden in variierenden Wiederholungen in mehreren Blättern aus unterschiedlichen Perspektiven besprochen, wobei in allen Fällen, wie im Spectator, jeder Nummer ausschließlich ein Thema gewidmet ist. Zu den in den Treffern aufgefundenen Lastern können insbesondere Schönheitskult und Eitelkeit (XVIII, XLVII, LXXXIII), Egoismus (LXI) und Liebestollereien (II, IV, XVI, XVIII, L, LXXX, LXXXV) - wie das stereotype Bild des verliebten alten Mannes (XVIII) - gezählt werden. Ebenfalls wird explizit die Frage aufgeworfen, wie die Rolle der Frau in der Gesellschaft aussehen solle und wodurch eine Frau gesellschaftliches Ansehen erhalte (LXXXIII). Um den Menschen ferner dabei zu helfen, die moralischen Beweggründe für die Hinwendung zur Tugendhaftigkeit zu verstehen, fügt der Verfasser philosophische Diskussionen ein, und zwar ,[...] on modesty (XXXII), almsgiving (XXXIX), justice and generosity (LXIII), self-esteem (LXXVII), and so on" (Schorr 1986, xiii), wobei die von Schorr angeführten Nummern nicht zu den Frauen- und Männerbildtreffern der vorliegenden Studie zählen. Als Ausgangspunkt für seine Überlegungen dienen Monsieur le Misantrope meist persönliche Erlebnisse (II, IV, XLV, XLVII, LXI), Gelesenes (XVI) oder verallgemeinernde Aussagen, die seine Meinung zu einem bestimmten Thema widerspiegeln (XVIII, LXX, LXXXIII, LXXXV). An diese Expositionen schließt der Verfasser in den 14 Treffern schließlich vor allem narrativ ausgestaltete Verhaltensratschläge an.

16 In den mit Frauenbild und Männerbild ausgezeichneten Nummern des Misantrope wird das weibliche Publikum ab der 45. Nummer mehr als 20 Mal direkt mit ,Mesdames', d. h. als kollektive Gruppe, angesprochen. In den weiteren französischsprachigen Wochenschriften des Korpus, die aber kein Frauen- oder Männerbild-Markup aufweisen, ist diese direkte Anrede nur im Cabinet du Philosophe (CdP IV, V), in der Spectatrice danoise (LaSd III) und im Nouveau Spectateur français (NS2 VII, 13) vorzufinden.

17 ,Défaut` wird überwiegend synonym mit ,vice` gebraucht, wie es gegen Mitte des Jahrhunderts auch der Encyclopédie-Eintrag zu DEFAUT, VICE, IMPERFECTION (Gramm. Synonym.) nahelegt, wobei gleichzeitig auch feine Bedeutungsunterschiede hervorgehoben werden: „Ces trois mots désignent en général une qualité repréhensible, avec cette différence que vice marque une mauvaise qualité morale qui procede de la dépravation ou de la bassesse du cœur ; que défaut marque une mauvaise qualité de l'esprit, ou une mauvaise qualité purement extérieure, \& qu'imperfection est le diminutif de défaut. Exemple. La négligence dans le maintien est une imperfection ; la difformité \& la timidité sont des défauts ; la cruauté \& la lâcheté sont des vices [kursiv im Orig.]“ (Diderot/D’Alembert 2016, 4:731). 
Die spectatorialen Geschlechterdiskurse, die in der ersten Spectator-Nachahmung auftreten, betonen wiederholt die ,natürlichen “ Vorzüge beider Geschlechter und stehen durch die Skizzierung einer ,natürlichen' charakterlichen und körperlichen Geschlechterdifferenz zwischen Frau und Mann ganz in der Tradition ihres englischen Vorbilds. So wird vom ,tour d'esprit aisé \& naturel [qui] est [...] le caractere de son sexe [féminin]“ (M IV , 34), von den ,maniéres polies [...] naturelles au Beau Sexe“ (M XLV, 26-27) oder vom „Sexe timide“ (M LXXXV, 359) ausgegangen. ${ }^{18}$ Die Männerwelt hingegen sei ,en général [...] inaltérable, à l'égard de ses sentimens \& de ses inclinations; il [l'homme] a été, \& sera toujours ce qu'il est, vain, ambitieux, amoureux de l'autorité, porté à se distinguer parmi ses semblables“ (M LXXXV, 358). ${ }^{19}$ Da hier Männer, von Natur aus` zu einem autoritären Verhalten neigen würden, geht Van Effen im Misantrope von einer, natürlichen' Geschlechterhierarchie aus. Diese Superiorität des Mannes tritt ebenfalls in den Ratschlägen des Verfassers an die Frauenwelt zutage: In regelmäßigen Abständen erteilt er der Frauen- wie der Männerwelt Anweisungen, die an die Unterweisungen für Frauen und Männer aus Ovids Ars amatoria angelehnt sind und aus denen hervorgeht, dass der Fokus einer Frau stets auf die Männerwelt gerichtet sein solle (cf. XLV) und nicht etwa auf die Bildung oder wissenschaftliche Tätigkeiten, die das weibliche ,Naturell“ verbergen würden: „Le naturel est votre partage, il fait votre mérite; $\&$ vous devez apliquer uniquement à mettre ce naturel dans tout son jour, \& non pas à l'affaisser \& à l'ensevelir sous la science“ (M XLV, 28-29). Dagegen rät der Verfasser jungen Männern in der 88. Nummer dezidiert zur gemeinsamen Lektüre mit ihren (männlichen) Lehrern, und zwar beispielsweise von Molières Komödien, deren Inhalte nachträglich gemeinsam besprochen werden sollen. Viele Ratschläge, die der Misantrope erteilt, sind dabei eingebettet in direkte Appelle an die (weiblichen) Leserinnen, wie zum Beispiel:

- $\quad$ „[N]e sortez pas de la Sphére de vos connoissances, croyez-moi“ (M II, 15).

18 Weitere ,natürliche“, weibliche" Eigenschaften und Vorlieben, die ebenfalls in Formulierungen verwendet werden und das unveränderbare, weibliche ,naturel' betonen (sollen), sind beispielsweise: ,[I]l serait assez difficile à un Epoux impertinent par raison, de gagner le dessus sur une femme impertinente par naturel“ (M XVI); ,[L]'infamie des Hommes [...] est entiérement éloigné de votre caractére naturel“ (M XLVII); „[E]lles n'ont qu'à suivre leur naturel“ (M LXX); „Ce talent est aussi naturel qu'inimitable“ (M LXX); ,[L]a nature a donné des charmes au Beau Sexe“ (M LXXX); ,,[L]es Femmes ont tant de goût pour les gens de guerre“ (M LXXXV); „On sait qu'une imagination vive, un esprit brillant, \& un tour d'expression aisé \& délicat, sont particuliers à ce Sexe“ (M LXXXVIII).

19 Auch wird von Männern und ihren unabänderlichen ,männlichen' Eigenschaften berichtet, wobei mit „homme“ wie „Homme“ stets auf die männliche Gesellschaft verwiesen wird: „[L]a liberté qui leur est naturelle [aux hommes]“ (M L); „L'Homme hait naturellement la servitude“ (M L); ,A proportion qu'il [1'Homme] avance en âge, il voit devant lui des occupations plus graves, qui excitent dans son ame des passions plus mâles que l'amour" (M LXXXIII); „L'Homme en général est inaltérable, à l'égard de ses sentimens \& de ses inclinations; il a été, \& sera toujours ce qu'il est, vain, ambitieux, amoureux de l'autorité, porté à se distinguer parmi ses semblables“ (M LXXXV); ,,[L]'envie de plaîre aux Belles, si naturelle à l'homme“ (M LXXXVIII). 
- „Montrez à votre Amant tantôt une petite fierté qui réveille, tantôt une complaisance qui touche ; [...]“ (M XLV, 27).

- „Ne croyez pas, Mesdames, que les Hommes changent d'ordinaire par une trahison concertée ; [...]“ (M XLV, 27-28).

- „Ne consultez que votre amour-propre sur mon sentiment“ (M XLVII, 40).

Mit dem vermehrten Rückgriff auf Beispiele und Zitate aus der Antike versucht der Misantrope seine Positionen und die dargebrachten Geschlechterverhältnisse mit historischen Autoritäten - also so, als ob die Verhältnisse schon immer so gewesen wären - zu begründen. Er nimmt Anleihe am Gedankengut von Ovid (XLVII, LXXX, LXXXIII, LXXXV), Horaz (LXXXIII) oder Boccaccio (XVI) sowie seiner unmittelbareren Vorgänger (La Fontaine, Molière). Entgegen seiner englischen Vorgänger nutzt der Verfasser des Misantrope kaum häusliche und überhaupt keine exotischen Erzählungen, vielmehr packt er seine Ratschläge häufig in die folgenden narrativen Erzählformen, die in den Einzelnummern ausgewiesen sind: allgemeine Erzählungen (II, XVIII), mehrere Fremdporträts (II, LXI, LXXXVI) sowie einige wenige Briefe (XVIII, L). Ebenfalls baut er Selbstporträts (Préface, XLV) und einen Dialog (II) ein. Zur Illustration von gutem und schlechtem Verhalten dienen ihm drei Exempla (im Discours II). Um seine Argumente zu untermauern oder zu erklären, gebraucht er in beinahe allen Nummern Zitate (II, IV, XVI, XVIII, XLV, XLVII, L, LXXX, LXXXIII, LXXV) und metatextuelle Reflexionen ${ }^{20}$ (II, XVI, XLV, XLVII, LXXX, LXXXIII, LXXXV, LXXXIII), denn, um gezielt gegen die ,Dummheiten des Jahrhunderts“ vorzugehen, behandelt er die Laster (gemäß dem Untertitel der Zeitschrift) in kritischer, satirischer wie komischer Weise, wodurch er sich hin und wieder in Erklärungsnot sieht. So bekämpft Monsieur le Misantrope insbesondere durch Lächerlichmachung die Laster seiner Zeit. Wie aus der nachfolgenden Analyse einzelner Inhalte der Einzeldiskurse hervorgeht, treten einige narrative Erzählformen auch in weiteren angetroffenen Einzelnummern des Misantrope hervor, wo sie allerdings nicht als solche ausgewiesen sind.

Obwohl Monsieur le Misantrope von Beginn an die Absicht hegt, auch sein weibliches Publikum zu adressieren, wendet er sich erst in der 45. Nummer vom 25. Januar 1712 direkt an die Frauenwelt - also vom ursprünglichen Publikationsrhythmus ausgehend acht Monate nach der ersten Nummer. Aus der Perspektive seines eigenen Geschlechts und seiner Erfahrungen als Mann mit der Frauenwelt erteilt der Misantrope hier eine Palette an Verhaltensratschlägen an die Frauen, die alle darauf gerichtet sind, die Liebe eines „Amans d'un mérite distingué“ (M XLV, 26) zu (er-)halten und in einer späteren Nummer (L) über den Verlust eines Liebhabers hinwegzukommen. Diese Teile verdeutlichen anschaulich, dass die Verwirklichung einer jungen Frau nicht abseits eines Mannes liegen kann, denn schließlich seien Frau und Mann ,von Natur aus' füreinander bestimmt (cf. LXXXIII, 339). Mit dieser Fokuswahl, die den Mann in den Fokus der Frau rückt, die sich um die Gunst dieses Mannes bemühen muss, wird eine Aufwertung des Mannes und eine gleichzeitige Abwertung der Frau

20 Im Repositorium ist diese Erzählform mit dem Begriff ,Metatextualität‘ ausgezeichnet. Sie wird in weiterer Folge der vorliegenden Arbeit meist als ,metatextueller Kommentar' oder ,metatextuelle Reflexion` bezeichnet. 
vollzogen. Um beim anderen Geschlecht nun auf Wohlwollen zu stoßen, sollen die Frauen nicht zu ehrlich, kapriziös oder monoton sein; sie sollen etwas Intelligenz zeigen, aber wiederum nicht zu viel: ,[I] $]$ vous faut un peu de réflexion, un peu de lecture. [...]. Gardez-vous bien pourtant de faire les Philosophes“ (M XLV, 28). Mit dieser Meinung spricht sich der Verfasser hier gegen die gelehrte Frau (femme savante) aus, die im Übrigen auch in den weiteren französischsprachigen Wochenschriften nicht als positives Frauenbild gezeichnet wird beziehungsweise überhaupt unerwähnt und somit von der kollektiven Wahrnehmung ausgespart bleibt. Anstatt zu philosophieren, sollten sich Frauen ihrem Charme und ihrer Schönheit widmen und ja kein zu männliches Temperament (robuste \& viril) an den Tag legen, sondern stets ein bisschen schwach (un peu foible) und dabei freundlich (aimable) sein. Falls sie von Natur aus hässlich sein sollten, dann sollten sie ihr Aussehen nicht mit Schmuck kompensieren, sondern „supléer au défaut d'un extérieur revenant, que par les sentimens généreux de l'ame, par l'agrément de l'esprit, par la facilité de l'humeur, \& par la politesse des maniéres“ (M XLV, 31).

Generell wird die Empfehlung für, ein bisschen weibliche Bildung' über die gesamte Wochenschrift in unterschiedlichen Variationen eingestreut. So spricht sich Monsieur le Misantrope in Nummer IV dafür aus, dass die Bildung von Frauen mehr Aufmerksamkeit erhalte - jedoch mit einer Einschränkung: Er folgt Molières (16221673) Einstellung gegenüber gelehrten Frauen aus dessen Stück Les Femmes savantes (1672), wonach diese zwar eine gute Bildung haben sollten, aber gerade nur so viel, um ihren ,natürlichen' Charme nicht zu verlieren. ${ }^{21}$ Zumal eine Frau nur gefallen solle, bestehe keine Notwendigkeit für einen besonderen Grad an Bildung, wobei der Misantrope gleichzeitig konzediert, dass sie, wenn sie schon Verstand besitze, auch nicht als unwissend auftreten müsse: ,[J]e ne vois pas qu'étant faite pour plaire, elle ait besoin de l'ignorance pour remplir sa destinée, \& qu'elle soit obligée à cacher comme un crime la supériorité de son génie“ (M IV, 35). ${ }^{22}$ Eine ähnliche kausale Argumentation wird in den Nummern XLVII und LXXXIII verfolgt: In der 47. Nummer räsoniert Monsieur le Misantrope, dass nicht nur die äußere Schönheit einer Frau gesellschaftliches Ansehen verschaffe, sondern auch innere Qualitäten wichtig seien. Zu diesen zählen in leichter Abwandlung der 45. Nummer „l'esprit adroit, le cœur bien placé, \& l'humeur agréable" (M LXVII, 46), die von unattraktiven Frauen meist mehr kultiviert würden. In der 83. Nummer greift er das Thema Schönheit erneut auf und beschreibt anhand mehrerer kurzer Bespiele, die Koketterie im Alter als lächerlich erscheinen lassen, das vergebliche Bemühen von Frauen um jugendliches Aussehen, ohne jedoch einen Ausweg über die Bildung zu weisen.

21 Molière ist insgesamt, so Simone de Beauvoir (cf. 1976, 184), kein Feind der Frauen, denn er attackiert in seinen Werken arrangierte Ehen, fordert Freiheit für junge Mädchen in ihrem Liebesleben sowie Respekt und Unabhängigkeit für Ehefrauen.

22 Hier ist noch nicht die Rede davon, dass eine Frau eine gute Ehefrau oder Mutter sein soll. Sie soll dem Mann gefallen: „étant faite pour plaire“ (M IV, 35). Mit dieser Aussage wird sie jedoch schon darauf vorbereitet, dass sie nur als Schmuckstück des Mannes fungieren soll. Genau dieser hat im Zentrum ihres Universums zu stehen und nur er allein ist es, der ihr Wert verleihen kann. 
Wie auch im 70. Diskurs zutage tritt, geht der Verfasser von einer ,natürlichen“ körperlichen Geschlechterdifferenz aus, wobei er die geistigen Kapazitäten der Frau nicht von vornherein hierarchisch unter die des Mannes stellt. In seinen Reflexionen über Frau und Mann schließt er in anthropologischer Manier vom unterschiedlichen Körperbau auf den Verstand/Geist (génie):

Nous avons d'ordinaire le corps plus grand \& plus majestueux, les Femmes l'ont plus gracieux \& plus aimable ; nos mouvemens sont plus vigoureux, mais ils sont plus contraints, \& les nerfs \& les muscles rendent nos efforts sensibles. Les mouvemens des Femmes, au contraire, ont moins de vigueur, mais ils ont quelque chose de plus délicat $\&$ de plus aisé. [...]. Pour faire sentir la justesse de ma comparaison, je suivrai le génie différent des deux sexes dans toutes les opérations de l'esprit ; \& je ferai voir que si notre génie l'emporte sur celui des Femmes pour la grandeur \& pour l'élevation, nous leur sommes inférieurs pour la grace \& pour la délicatesse. (M LXX, 231-232)

Auch in dieser Gegenüberstellung (nous [les hommes] vs. les femmes) weisen Frauen und Männer Vorzüge auf: Der männliche ,génie‘ zeichne sich durch Größe (grandeur) und Erhöhung (élévation), der weibliche durch Anmut (grâce) und Zartheit (délicatesse) aus. Was der Verfasser dabei mit ,grandeur' und ,élévation“ sowie mit ,grâce‘ und ,délicatesse ' meint, verdeutlicht er im restlichen Discours anhand illustrativer Beispiele: Frauen könnten besser den Räsonnements anderer Menschen folgen, Männer besser eigene Überlegungen anstellen; Frauen folgten eher ihrem Herzen, Männer eher ihrem Verstand. Frauen würden zudem mehr Empathie für andere Menschen zeigen und hätten eine ausgedehntere und lebendigere Einbildungskraft (imagination) als Männer und könnten daher auch besser erzählen als diese.

Der Geschlechtervergleich reicht im Misantrope bis zur Gegenüberstellung der literarischen Tätigkeiten, die trotz der Ablehnung der gelehrten Frau (cf. XLV) aufgezählt werden. Durch das spezifisch ,weibliche‘ Naturell seien Frauen geeigneter, in Briefform zu schreiben, ${ }^{23}$ nicht aber Maximen, Reflexionen oder Charakterporträts zu verfassen. Um die Vorzüge des ,génie‘ beider Geschlechter hervorzuheben, bemerkt Monsieur le Misantrope ferner, dass unter Frauen wie Männern exzellente Poet*innen (poëtes) zu finden seien, die sich jedoch durch ihre Denk- und Schreibweisen deutlich voneinander unterscheiden würden:

23 Die Zuschreibung des Briefes als Gattung, die der Frau besonders liege, setzt mit der Ausbildung der Textsorte des modernen Privatbriefs ein, der im Kontext der Rhetorik eine männlich konnotierte Textsorte war und seit Mitte des 17. Jahrhunderts immer subjektiver und spontan-natürlicher verfasst werden sollte. Die Auffassung im Misantrope, dass die Briefform die geziemende Ausdrucksform für die Frau sei, wird gleichzeitig durch den aufkommenden Empfindsamkeitsdiskurs begünstigt, mit dem im 18. Jahrhundert einerseits das Empfinden und die Verbalisierung dessen zunehmen und andererseits dem weiblichen Geschlecht eine höhere Empfindsamkeit zugeschrieben wird. Durch diese parallelen Entwicklungen wird der Brief als geeignete Ausdrucksform für Seelenregungen zum geeigneten Medienraum für die Frau, um ihre Gefühle mitzuteilen (cf. Hillesheim 2013, 18; Pabst 2007, 105-106). 
Les vers où il faut de la force, de la majesté $\&$ du sublime, demandent le génie d'un Homme. Ceux où il faut du naturel, de l'imagination, des sentimens $\&$ de la délicatesse, sont plus à la portée du Beau Sexe qu'à la nôtre : mais je crois que le Poëme Epique \& la Tragédie ne sont nullement son fait. [...]. La Comédie seroit plutôt de leur ressort, puisqu'il s'agit d'y dépeindre les maniéres qui sont en vogue : mais elle demande une connoissance trop méditée du cœur humain, [...]. (M LXX, 236-237)

Am Ende des Diskurses geht der Verfasser erneut auf die Versbildung ein und verdeutlicht dezidiert die Vorzüge der weiblichen (,donne plus de plaisir“ [M LXX, 238]) wie jene der männlichen Versifizierung (,est plus propre à inspirer de l'admiration“ [M LXX, 238]). Das heißt, auch wenn er von einem körperlich-geistigen Unterschied zwischen Frau und Mann ausgeht, so sieht er beide zur Literaturproduktion fähig und folglich - zumindest in diesem Diskurs - als gleichwertige Individuen an, da er Frauen hier nicht abspricht, auch gute Autorinnen sein zu können.

Neben den (pseudo-)wissenschaftlich untermauerten Ratschlägen für Frauen birgt der Misantrope Ratschläge für Männer (LXXXVIII) sowie Charakterbeschreibungen unterschiedlicher lasterhafter Männertypen, welche die Männerwelt nicht nachahmen und die Frauenwelt meiden solle. Es finden sich zum Beispiel Beschreibungen über die verschiedenen Liebhabercharaktere (LXXX), über den verliebten alten Mann (XVIII) oder über Männer, die Frauen nur ausnutzen möchten (IV, LXI, LXXXV). Gegen die weibliche Koketterie, die hier noch nicht als genuin lasterhaft erscheint, wird dagegen nur am Rande gewettert.

Gemäß James Schorr sei Van Effen im Misantrope „,something of a feminist in his attitude toward women“ (Schorr 1982, 31 und 1986, xiii im selben Wortlaut). So weit ist nach der vorliegenden Lektüre des Misantrope jedoch nicht zu gehen, wenngleich die Verfassungsinstanz einmal - allerdings eher beiläufig - bemerkt, dass die Unterschiede zwischen den Geschlechtern nicht ausschließlich der Natur geschuldet seien, sondern auch aufgrund der ungleichen Erziehung zustande kommen: „La cause de cette différence [entre femme et homme] n'est qu'en partie dans le naturel des deux sexes ; leur éducation y contribue beaucoup“ (M LXX, 232). Für eine gleichwertige Erziehung/Bildung spricht er sich dennoch nicht aus - wie im Übrigen auch keine der nachfolgenden spectatorialen Verfassungsinstanzen.

$\mathrm{Zu}$ einem sehr ähnlichen Befund kommt auch Suzanna van Dijk (1988, 21-55) in ihrer Lektüre des Misantrope und der Bagatelle. Innerhalb der beiden von Van Effen angefertigten Wochenschriften ermittelt sie ebenfalls einen Überhang an negativen Porträts und Beschreibungen von Frauen. Allerdings konzediert auch sie, dass der Verfasser - hinter dem sie Van Effen vermutet - einige wenige Male sehr wohl aufzeigt, dass Frauen gegenüber Männern im Nachteil seien, und schreibt ihm aufgrund dessen ,eine gewisse feministische Seite' (cf. ibid., 52) zu:

Il [Van Effen] sait être galant en effet, mais on retrouve chez lui des traces importantes de toute une idéologie négative concernant les femmes. Elle est étrangement contre-balancée par des remarques où il s'accuse lui-même - remarques peut-être indirectement inspirées de Poulain de la Barre, mais manquant tout à fait de la rigueur de celui-ci. (Van Dijk 1988, 54) 


\subsubsection{Le Censeur (1714) - der unparteiische Meinungsbildner}

Der Censeur ou Caractères des Mcurs de la Haye wird zwischen 2. März und 31. Dezember 1714 einmal wöchentlich am Montag anonym in Den Haag herausgegeben. Alexis Lévrier (2007, 217-231) geht davon aus, dass der Gründer dieser Wochenschrift Jean Rousset de Missy (1686-1762) ist. Der Dictionnaire des journaux-Eintrag zum Censeur (cf. Sgard 1999a) geht ebenfalls von Rousset de Missy als Herausgeber aus, erwähnt aber auch einen gewissen Nicolas de Gueudeville (1652-1719), dessen Tätigkeit als Herausgeber dieser Wochenschrift unter Forscher*innen jedoch immer fragwürdiger erscheint. Der Eintrag zu Nicolas de Gueudeville im Dictionnaire des journalistes (cf. Rosenberg 1999) bezweifelt seinen Beitrag zur Herausgabe des Censeur ebenfalls. Aufgrund dieser unklaren Forschungslage führt die digitale Edition des Censeur Rousset de Missy und Gueudeville als Herausgeber an.

In den 43 Nummern (numéros) des Censeur befinden sich acht Nummern (18,6 \%) mit einem Frauenbild-Markup (IV, XVI, XXII, XXIII, XXV, XXVII, XXXVI, XLIII). $11,6 \%$ der Nummern sind mit einem Männerbild ausgezeichnet, wobei sich die Nummern XVI, XXII, XXIII und XLIII mit dem Frauenbild-Markup überschneiden; einzig mit Männerbild codiert ist hingegen nur die Nummer XVII.

Der Einfluss des Misantrope sowie des Spectator auf den Censeur liegt aufgrund inhaltlicher und formaler Ähnlichkeiten der Periodika klar zutage. Lévrier (2007, 217 220) vertritt die These, dass sich Rousset de Missy zu Beginn ausschließlich auf den Misantrope als Vorlage stützte, denn passagenweise kommen die Inhalte des Misantrope und des Censeur sogar einem Plagiat gleich. Erst später sei Rousset de Missy mit dem Spectator in seiner französischen Übersetzung, dem Spectateur, ou le Socrate moderne in Berührung gekommen, der zwischen 26. April 1714 (Datum der Approbation durch die Zensurkommission) und 1726 in Amsterdam auf den Markt kam. Durch den Untertitel - Caractères des Mcurs de la Haye - wird ferner eine explizite Nähe zum klassischen Moralisten Jean de La Bruyère (1645-1696) und seinen Caractères (1688) hergestellt. Der Wunsch der Verfassungsinstanz, des Monsieur le Censeur, als unparteiischer Moralist tätig zu sein, zeigt sich auch darin, dass er über weite Strecken die gesellschaftlichen Sitten beschreibt - dabei aber andere Themen (wie die Literatur) vernachlässigt, die seine Vorgänger sehr wohl aufgriffen. Das deklarierte Ziel seiner Zeitschrift deutet zudem über die moralistische Absicht hinaus auf eine moralische Zielrichtung hin, wenn der Censeur - wie auch sein Name andeutet - bezweckt, die lasterhaften Neigungen seiner Mitmenschen, wenn schon nicht zur Gänze auszumerzen, so zumindest für eine gewisse Zeit zu unterbinden: „Néanmoins, quoi qu'on ne doive point espérer de coriger absolument les vices, ne peut-on pas se flâter d'en arêter pour quelqu'instant le penchant aussi général que pervers“" (CCM I, 2)? Die Verfassungsinstanz des Monsieur le Censeur, der sehr wenige Details von sich preisgibt, fungiert somit zielgerechter als Mr. Spectator oder Monsieur le Misantrope als Erziehungs- und Führungsinstanz, die - zumindest dem Anschein nach - „frequemment la posture d'un observateur impartial de la vie sociale“ (Lévrier 2007, 222) einnimmt. Trotz seines Namens hält er sich auch tatsächlich zurück, Schiedssprüche zu tätigen.

In den angetroffenen Nummern geht der Censeur - wie sein Vorgänger Monsieur le Misantrope - von einer ,natürlichen' charakterlichen und körperlichen Geschlechterdifferenz aus. Während er allen Menschen einen Hang zur Scheinheiligkeit/Heuchelei (hypocrisie) (XVII) nachsagt, sieht er ein ,natürliches' ${ }^{6}$ Laster der Männer in 
ihrem unverschämten und frechen Verhalten gegenüber Frauen, wie das der sogenannten ,lorgneurs' (Gaffer/Spanner) (XXII). Die ,natürlichen` Schwächen (,foiblesse naturelle“ [CCM IV, 25]) der Frauen seien dagegen ihr Stolz (orgueil), ihr Ungestüm (impétuosité), ihr wechselhaftes Gemüt (humeur changeante) und ebenso eine ausgeprägte Neigung zur Scheinheiligkeit. Aus den Nummern 25 und 27 erfahren die Leser*innen zudem die Haltung des Censeur zur weiblichen Erziehung/Bildung, die er anders als jene der Männer konzipiert, das heißt, er nimmt auch ihre geistigen Fähigkeiten anders als die von Männern wahr. Er glaubt, dass Frauen und Männer ,von Natur aus` verschieden und somit zu unterschiedlichen Tätigkeiten geboren seien. Bereits aufgrund der ,natürlichen' Geschlechterdifferenz könnten unter dem weiblichen Geschlecht demnach keine gelehrten Frauen (femmes savantes) zu finden sein. Zudem hätten ,fast alle Frauen` ${ }^{\circ 4}$ ein schwächeres Gehirn (cerveau plus faible) als Männer, dafür eine größere Einbildungskraft und einen hochmütigeren Geist, was sie wiederum dazu bringe zu glauben, sie würden bereits nach ein paar Wochen Studium alle anderen übertreffen. Insgesamt spricht sich der Censeur hinsichtlich der Erziehung demnach dafür aus, dass Frauen zur Tugendhaftigkeit erzogen werden, worunter vor allem ein sittsames ${ }^{25}$ und schamhaftes ${ }^{26}$ Auftreten (modestie, pudeur) verstanden wird (XXII, XXIII, XXVII). Tugendhaftes Verhalten der Männer dagegen tritt durch ihren Vernunftgebrauch (raison) zutage (XXII), wobei der Honnête homme das männliche Idealbild darstellt (XVII, XXIII).

Für die spectatoriale Vermittlung der Inhalte greift der Verfasser zur im Untertitel (Caractères des Mœurs) bereits angedeuteten literarischen Form des Charakterporträts - also zu einem formalisierten Aufbau à La Bruyère (1645-1696). Ähnlich wie der klassische Moralist und Anciens-Vertreter in seinen Caractères (1688) nutzt der Censeur die drei aufeinander aufbauenden Verfahren der Maxime, der Reflexion (zur Maxime) und des Charakterbilds, um satirische Porträts seiner Zeitgenoss*innen aus Den Haag zu vermitteln. Der Einstieg in eine Nummer mittels Maxime wird jedoch bereits nach wenigen Nummern von einem direkten Themeneinstieg mittels Reflexion der Verfassungsinstanz oder aus dem Lesepublikum abgelöst. Dennoch steht am Beginn

24 Der Censeur schreibt „presque toutes les femmes“ (CCM XXV, 199), nennt aber keine dezidierte Ausnahme. In derselben Nummer zitiert er eine Maxime der Marquise de Sablé (1599-1678), wodurch er sie aus seiner Regel ausnimmt. Auch die Frauen, die er in der letzten Nummer anführt, betrachtet er als hervorragende Femmes savantes. Eine Erklärung, wie es zu diesen ,Ausnahmeerscheinungen“ kommt, bleibt er in den konsultierten Nummern schuldig. Insgesamt allerdings wird Frauen im Censeur - im Unterschied zum Misantrope die Möglichkeit einer geistigen, wissenschaftlich-literarischen Betätigung aufgrund ihrer biologisch-anatomischen Konstitution abgesprochen.

25 Sittsamkeit wird immer mehr zum Alleinstellungsmerkmal der bürgerlichen Frau, mit dem sie sich von anderen Schichten abgrenzen kann. Sittsamkeit wird ,zum Symbol sozialer und moralischer Überlegenheit, die den mittleren Schichten besonders teuer war, da sie sowohl das ungepflegte Äußere der Unterschichten als auch dir zügellose Nachlässigkeit der Aristokratie verurteilten“" (Matthews Grieco 1994, 80).

26 Das Schamgefühl wird zu einer inneren Sanktionsinstanz, das zur Selbstkontrolle und zur Selbstsanktion führt, wenn eine Norm nicht befolgt wird (cf. Tranow 2016, 259). Dieser Mechanismus der Beschämung funktioniert bis heute (cf. Wiesböck 2019). 
einer Nummer meist ein verallgemeinerndes Statement, das - einer deduktiven Vorgangsweise folgend - durch mehrere nachfolgende spezifische Beispiele untermauert und bestätigt wird.

Jede Nummer ist dabei einem spezifischen Thema gewidmet, wobei manche Themen in variierender Form wiederholt, das heißt in unregelmäßigen Abständen aus einem anderen Blickwinkel fortgesetzt werden. Die Themen, die der Censeur in den mit Frauen- und Männerbild ausgezeichneten Nummern aufwirft, drehen sich vorwiegend um die Erziehung/Bildung der Jugend (XXII, XXV, XXVII), die Scheinheiligkeit/Heuchelei (IV, XVII) sowie um eheliche (XVI) oder andere zwischengeschlechtliche Beziehungen (IV, XVII, XXII, XXIII, XXXVI). Diese Themenfelder sind mitunter in häusliche Erzählungen verpackt, die das Familien- oder Paarleben aufgreifen.

$\mathrm{Zu}$ den gängigen - und im Repositorium codierten - narrativen Formen, die der Censeur anwendet, fallen die zahlreichen metatextuellen Kommentare in allen (bis auf Nummer XVI) mit Frauenbild ausgezeichneten Nummern (IV, XXII, XXIII, XXV, XXVII, XXXVI, XLIII) ins Auge. Daneben finden sich - wie bereits erwähnt - fast durchweg Charakterbeschreibungen in Form von stereotypisierten Fremdporträts (XVII, XXII, XXIII, XXV, XXVII, XXXVI, XLIII) und einem Selbstporträt (XVII). Auch allgemeine Erzählungen (XVI, XXII, XXVII), zwei Exempla (XLIII) und ein Zitat/Motto (IV) sind in den Einzelnummern zu finden. Abwesend sind dagegen Dialoge oder Fabeln und bis zur 8. Nummer auch Briefe aus dem Publikum, die erst ab dieser Nummer inkludiert werden (cf. Lévrier 2007, 224-225). Sieben der insgesamt 29 Leser*innenbriefe sind in den Nummern mit Frauen- und Männerbild-Markup anzutreffen (XVII, XXII, XXIII, XXV, XXVII, XXXVI, XLIII). Damit ist der Censeur die erste französischsprachige Wochenschrift, in der ein Briefwechsel zwischen der Verfassungsinstanz und dem Publikum eine essenzielle Rolle einnimmt. Bemerkenswert für die französischsprachigen Periodika ist außerdem, dass im Censeur auch Briefe, die (zumindest vorgeblich) von Frauen geschrieben worden sind, Eingang in die Zeitschrift finden (XVII, XXII, XLIII). Die Inklusion weiblicher Stimmen fördert nicht nur die Sichtbarkeit von Frauen innerhalb der Gesellschaft, sondern wertet gleichzeitig ihre Position als Mitgestalterinnen der Gesellschaft auf. Dabei muss jedoch darauf hingewiesen werden, dass das „Schreiben aus weiblicher Feder, das veröffentlicht wird, gegenläufig zur Verhaltensnorm [steht], die mit der vertu erzeugt und vermittelt werden soll [kursiv im Orig.]“ (Pabst 2007, 104). Mit dem ,weiblichen Schreiben` sollen die neuen für Frauen geltenden Werte, Normen und Praktiken transportiert werden und die Korrespondentinnen den Leserinnen je nach Inhalt als positive Nachahmungs- oder negative Abschreckungsbeispiele dienen. Die „moderne Konzeption vom Privatbrief ist nicht auf die Veröffentlichung, sondern auf die vertrauliche Kommunikation zwischen Absender und Empfänger ausgerichtet“ (ibid., 104-105), weshalb die privaten Inhalte an die Öffentlichkeit gelangen können, ohne die geltenden Anstandsregeln zu verletzen. Auffällig ist im Censeur auch, dass die Briefe namentlich gezeichnet sind: entweder mit einem ausgeschriebenen Vornamen - von dem auszugehen ist, dass es sich um ein Pseudonym handelt - oder zumindest in Form von Abkürzungen, wie M. L. ...Y. (XXVII) oder $A^{*} D^{*} D^{*}$ (XXXVI). Wiederholt wird der Censeur von den Briefschreiber*innen darum gebeten, als Schiedsrichter (juge) zu agieren. Diese Rolle übernimmt er, indem er seine Meinung zum Anliegen der Korrespondent*innen in Beispielgeschichten oder Exempla verpackt, aus denen schließlich sein Urteil hervorgeht. 
Die vierte Nummer, die das Thema der weiblichen Scheinheiligkeit - hier mit , dissimulation' betitelt - behandelt, beginnt in der Manier von La Bruyères Caractères mit einer inhaltlich und stilistisch pointierten Maxime: ,Wer die Kunst der Verschleierung nicht kenne, kenne die Kunst des Regierens nicht.' Im Anschluss an die Maxime stellt der Censeur seine persönliche Reflexion vor: Laut ihm gelte diese Maxime für Könige wie für das weibliche Geschlecht. Diese Hypothese entfaltet er weiter und ,beweist ${ }^{\star}$ sie schließlich durch ein konkretes Beispiel in Form eines individualisierten Fremdporträts der jungen Argire, die zu früh von ihrer Mutter in die Gesellschaft eingeführt worden sei. Argire sei gleichzeitig eine tugend- und lasterhafte junge Frau. Sie habe sich eine Reputation als ,vertueuse“ aufgebaut und glaubt nun gegen das Gerede der Leute abgesichert zu sein, wenn sie zur als lasterhaft angesehenen Koketten (coquette) oder zur Spielerin (joueuse) mutieren würde. Am Ende des Porträts steht ein metatextueller Kommentar mit einigen rhetorischen Fragen, mit denen die Leser*innen dazu angeregt werden sollen, sich selbst Gedanken und eine eigene Meinung zum aufgeworfenen Thema zu machen.

In ähnlicher Weise beginnt die 16. Nummer, allerdings fehlt die am Beginn stehende Maxime, und das Blatt setzt direkt mit den Reflexionen der Verfassungsinstanz ein, die sich fragt, warum viele Ehen unglücklich seien. Laut dem unverheirateten Censeur, der - so die Rechtfertigung für seine diesbezügliche Wortmeldung - genug Eheleute in seinem Bekanntenkreis beobachtet habe, um sich über dieses Thema äußern zu können, liege das familiäre (Un-)Glück bei den Ehemännern. Generell seien Frauen nämlich viel ungestümer (impetueuses) als Männer und letztere müssten auf diese weibliche Schwäche Rücksicht nehmen. Hierauf folgen zwei konkrete Charakterbeschreibungen: Als erstes zeichnet er das Fremdporträt von Carinton, der sich immer nur über seine junge Frau Felice beklagt. Der Censeur , beweist‘ damit, dass Felice nur so ist, wie sie ist, weil sie der Geiz (avarice) ihres Mannes dazu bringt, derart zu handeln. Das zweite Beispiel, ebenfalls als Fremdporträt ausgewiesen, erzählt vom Comte Nanticour und seiner Ehefrau Plotine. Für eine bessere Stelle zog er samt Familie an den Hof, wo die höfische Gesellschaft seine Frau verdorben habe. Darüber hinaus verlor der Comte seine Ehefrau und sein gesamtes Vermögen. Am Ende der Geschichte stellt der Censeur mehrere rhetorische Fragen direkt an den Comte, die ihm die Schuld am Verderben seiner Frau anlasten, immerhin brachte ihn sein beruflicher Ehrgeiz (ambition) an den Hof. Schließlich verleiht der Verfasser dieser Nummer ein moralisierendes Resümee: „[R]ien n'est plus contagieux que l'éxemple, \& que nous imitions les bonnes actions par émulation, \& les mauvaises par la malignité de notre nature, que la honte retenoit prisonniére, \& que l'éxemple met en liberté [kursiv im Orig.]“ (CCM XVI, 128) - Nichts sei , ansteckender' als das vorgelebte Beispiel, das gute wie das schlechte. Diese Form der Herleitung, weiblicher" Verhaltensweisen als bloße Reaktion auf ,männliche" Verhaltensweisen tritt bereits in einigen Nummern des originären Spectator auf, in denen ,weibliche' Eitelkeit und Koketterie aus der Frivolität und anderen Lastern der Männer abgeleitet wird (cf. Pallares-Burke 1994, 423, 433). ${ }^{27}$

27 Im Spectator No. 58 beispielsweise räsoniert der Verfasser über das interdependente Verhalten von Frauen und Männern und plädiert dafür, Männer besser zu erziehen: „one way to make the Women yet more agreeable is, to make the Men more Virtuous“ (Spectator No. 58). 
Auch am Beginn der 17. Nummer findet sich die Rechtfertigung des Censeur dafür, warum er das folgende Thema anspricht: Es handle sich um ein Versprechen, das er 14 Tage zuvor auf einen Brief hin gegeben habe. Hiernach reflektiert er darüber, dass Menschen dazu geboren seien, sich gegenseitig zu täuschen. Wie in Nummer IV behandelt er also auch in dieser Nummer das Thema der Scheinheiligkeit - hier , hypocrisie' benannt. Diesmal handelt es sich aber um die Hypokrisie aller Menschen (hommes), die sich nach außen hin tugendhaft benähmen und nach innen hin den Lastern frönten. Dass das Gros der Menschen heuchlerisch sei, zeigt der Verfasser anhand eines individualisierten Fremdporträts, welches durch den Brief einer Leserin vermittelt wird. In diesem Brief beschreibt Lérine ihren Onkel Témoléne, der zwar auf alle wie ein gütiger Mann wirke, aber so scheinheilig wie Molières Tartuffe sei. So habe ihr Onkel bereits mehrere Frauen, die sie namentlich nennt, in den Ruin getrieben und nun wolle er auch noch die Briefschreiberin selbst heiraten. In ihrem Brief bittet Lérine den Censeur schließlich um einen hilfreichen Ratschlag, um sich aus der Situation zu befreien, denn der Onkel habe es sogar schon geschafft, die Zustimmung der Kirche zur Heirat mit seiner eigenen Nichte (!) zu erhalten. Anstatt ihr jedoch einen Rat zu erteilen, gesteht der Censeur ein, dass es der Betrogenen nicht möglich sein werde, aus den Fängen dieses Tartuffe herauszukommen, zumal der besagte Mann im Auge der Öffentlichkeit über eine makellose Reputation verfüge: „Je lui dirois volontiers, que, peut-être, son Persécuteur rentrera en lui-même \& lui rendra enfin justice : mais qui ne sait que quand les Hommes ont une fois franchi de certaines bornes, rarement ils s'en tiennent-là, ou reviennent sur leurs pas [kursiv im Orig.]“ (CCM XVII, 135-136). Auch wenn der Verfasser das Verhalten des Mannes verurteilt, weiß er keinen Ausweg, da Männer, von Natur aus` unbekehrbar seien, wenn sie einmal den falschen Weg eingeschlagen hätten. Er beendet diese Nummer mit dem Ausdruck seines Bedauerns und hofft, dass zumindest andere Frauen aus dem Unglück Lérines lernen mögen: „L'infortunée Lérine est à plaindre d'être dans ce cas, heureuses celles qui sauront profiter de son malheur" (CCM XXVII, 136).

Die Nummer XXII setzt direkt mit dem Brief einer Frau ein, die sich darin über das aufdringliche Benehmen von jungen Männern gegenüber Frauen beschwert und diese Beschwerde anhand der Geschichte ihrer Freundin illustriert. Nach der allgemeinen Erzählung propagiert der Censeur seine Reflexionen über das unverschämte und freche Verhalten der jungen Männer, das zudem in der Kirche und vor Gott stattgefunden habe. Er rät seinen Leserinnen, solche Männer namentlich zu denunzieren, um sie „exposer à la honte d'être connus publiquement pour Lorgneurs de Temple [kursiv im Orig.]" (CCM XXII, 173), also öffentlich als ,Tempel-Spanner" an den Pranger zu stellen. Gleichzeitig verabsäumt er es nicht, dem weiblichen Geschlecht eine gewisse Mitschuld (!) am frevelhaften Verhalten der Männer zu geben, das er damit jedoch

In der No. 528 beklagt eine Verfasserin, dass das libertäre Leben junger Männer auf das Verhalten der jungen Frauen abfärbe. Da diese jenen hilflos ausgeliefert wären, kämen sie nicht umhin, ihre Tugenden ad acta zu legen: ,[A] general Dissolution of Manners arises from the one Source of Libertinism without Shame or Reprehension in the Male Youth. It is from this one Fountain that so many beautiful helpless young women are sacrificed, and given up to Lewdness, Shame, Poverty, and Disease“ (Spectator No. 528). 
nicht entschuldigen wolle: ${ }^{28}$ „Mais malgré le Zèle de celle qui vient de m'écrire, ne pourroit-on pas avouër, sans excuser les Lorgneurs, que souvent ce qu'on apelle légèreté $d u$ Séxe, donne ocasion à l'impudence des gens dont on se plaint si fort \& si justement [kursiv im Orig.]" (CCM XXII, 174). Zu guter Letzt animiert er die Männer zur Vernunft (raison) und die Frauen zur Sittsamkeit (modestie), um solch mehrdeutige Situationen zu meistern.

Ausgangspunkt der 23. Nummer sind erneut die Reflexionen des Censeur über die Vorbildwirkung von Männern auf das weibliche Geschlecht. Da Frauen nämlich Männer als Vorbilder sehen würden, sei ihr lasterhaftes Benehmen auf das lasterhafte Verhalten der Männer zurückzuführen, die sich besser wie Honnêtes hommes verhalten sollten. Hiernach folgen drei Beispielgeschichten, eine weitere reflexive Passage des Censeur und ein Leser*innenbrief, der seine Reflexion untermauert.

Der Einstieg in die 25. Nummer erfolgt wieder direkt über einen Brief, in dem der Korrespondent namens Polymorphe von einer sogenannten Société des Demoiselles beaux Esprits erzählt, die glaubt, Frauen hätten mehr oder zumindest genauso viel Wissen (savoir) und Geist (esprit) wie Männer: „,[C]ette Inscription étonnera sans doute ceux, qui ne savent pas que le savoir $\&$. $<$ sic $>$ la pénétration d'esprit n'est pas une chose dont nous [les hommes] soïons seuls en droit de nous vanter, $\&$ que le beau Séxe prétend y avoir, sinon plus, du moins autant de part que les Hommes“ (CCM XXV, 193). In einer nächsten Nummer wolle Polymorphe gerne, sofern gewünscht, mehr über die Gesellschaft der gebildeten niederländischen Demoiselles berichten. In seiner Reaktion auf den Brief spricht sich der Censeur gegen die geistige Betätigung der Frauen aus; ihm erscheine es verrückt und widernatürlich, dass sich Frauen zu Schöngeistern (beaux-esprits) erheben würden, und er finde es nur gerechtfertigt, dass sie zu den Akademien nicht zugelassen seien. Als Begründung bezieht er sich auf den Unterschied zwischen ,savoir'/,esprit‘ (Weisheit/Geist) und ,bel esprit' (Schöngeistigkeit). Die positiv konnotierte Weisheit sei das angeborene Talent eines vernünftigen Mannes (Homme raisonnable), das die Wertschätzung, die Verehrung und das Wohlwollen der Mitmenschen anziehe. Die negativ konnotierte Schöngeistigkeit dagegen sei eine verachtenswerte Plage der Gesellschaft, da ein schöngeistiger Mann in einer selbstverliebten Art andere von seiner Brillanz überzeugen will, aber eigentlich dumm sei: „,[O]n apliqueroit à un Homme de ce caractére une des maximes atribuées à la Marquise de sablé [sic], qu'être trop content de soi, est être sot [kursiv im Orig.]" (CCM XXV, 197). Wenn nun schon - so der Censeur weiter - ein Mann mit einem solchen Charakter der Gesellschaft zur Last falle, wie sehr falle dann erst eine Frau zur Last, die mit ihrer (,natürlichen`) Geschwätzigkeit gar nicht mehr aufhöre zu sprechen.

28 Dieselbe Rhetorik findet sich auch heute noch in zeitgenössischen Medien und wird seit den 1970er-Jahren mit ,Victim blaming', zu Deutsch ,Täter*innen-Opfer-Umkehr‘ oder ,Opferbeschuldigung', bezeichnet. Der Begriff bezieht sich beispielsweise darauf, dass nach der Meldung über die Vergewaltigung einer Frau öffentlich in den Raum gestellt wird, die Frau habe das Verhalten des Mannes durch ihr eigenes Verhalten oder ihre äußere Erscheinung (z. B. kurzer Rock) provoziert. Ziel dieser Art von Argumentation ist es, dem Opfer die Schuld an seiner Situation zuzuschreiben, anstatt die Täter*innen für die Straftat zur Verantwortung zu ziehen. 
Viele gelehrte Frauen seien zudem bereits zur Megäre ${ }^{29}$ ihrer Familie geworden oder hätten diese in den Ruin getrieben, und der Himmel bewahre seine Freunde vor einer solchen Plage: „Que le Ciel préserve tous mes Amis de trois fleaux, [...], de Pasteur bigot, de grosse Famille en disette, \& sur tout de Femme savante [kursiv im Orig.]“ (CCM XXV, 199)!

In der 27. Nummer berichtet der Korrespondent Polymorphe nun über eine Versammlung der Société des Demoiselles beaux Esprits, wobei er ein groteskes Bild der gelehrten Frau (femme savante) zeichnet, das an jenes von Molière in Les Femmes savantes (1672) anschließt. Er beendet seinen Brief sogar mit einem (teilweise adaptierten) Zitat aus der Tirade von Chrysale (2. Akt, 7. Szene), in dem sich der Vater des Hauses gegen die höhere Bildung der Frau ausspricht:

Il n'est pas bien honnête, \& pour beaucoup de Il n'est pas bien honnête, et pour beaucoup de causes, causes,

Qu'une Fille étudie \& sache tant de choses. Qu'une femme étudie, et sache tant de choses.

Former au bien ses mœurs de ses plus tendres Former aux bonnes mœurs l'esprit de ses enans, fants,

Etudier ses devoirs, sur tout choisir les gens, Faire aller son ménage, avoir l'œil sur ses gens,

Qu'elle veut fréquenter, vivre avec modestie Et régler la dépense avec économie,

Doit être son étude, \& sa Philosophie. Doit être son étude et sa philosophie.

[kursiv im Orig.] (CCM XXVII, 214) (Molière 1672, 2. Akt, 7. Szene)

Auch wenn der Briefschreiber die Verse 3 bis 5 - wie aus der Gegenüberstellung der beiden Versionen ersichtlich - leicht abändert, sodass nicht mehr explizit von den mütterlichen und hauswirtschaftlichen Pflichten einer Frau die Rede ist, kann davon ausgegangen werden, dass das zeitgenössische Publikum mit dem Stück vertraut ist und die implizite Botschaft sehr wohl zu verstehen weiß. Die Erziehung zum anständigen Benehmen vom zarten Mädchenalter an (,Former au bien ses mœurs de ses plus tendres ans') sowie die Hinwendung zum Studium der frauenspezifischen Aufgaben und $\mathrm{zu}$ einem Leben in guter Gesellschaft und in Sittsamkeit führen schließlich ebenso zu Mutterschaft und Hausarbeit.

In seinem Kommentar zum Brief untermauert der Censeur erneut die Absurdität von weiblicher Gelehrtheit. Da er aber nicht selbst über die Femmes savantes richten wolle, überlässt er es (vorgeblich) seinem Publikum darüber zu entscheiden, wie widersinnig es sei, wenn eine Frau ihren Spinnrocken (Teil eines Spinnrads) mit einem Physik- oder Theologiekurs eintausche: „Pour ne point tomber moi-même dans le défaut des faiseurs de Remarques, je laisse volontiers au Public le soin de juger jusqu'à quel excès d'impertinence ne va pas une Femme qui change sa quenouille pour un cours de Phisique ou de Théologie“ (CCM XXVII, 216).

Am Beginn der 36. Nummer steht der Brief eines anonymen Mannes, der Monsieur le Censeur bittet, die Position eines unparteiischen Schiedsrichters in einer dringenden Frage einzunehmen. Im Aufbau folgt der Korrespondent dem Bruyère'schen Grundschema. Der Brief beginnt mit der folgenden (Maxime-ähnlichen) Behauptung, die der

29 Das Wort ,mégère für eine rachsüchtige Frau leitet sich von der gleichnamigen Rachegöttin aus der griechischen Mythologie ab. 
Censeur bestätigen soll: „N'aprouveriez-vous pas qu'on dît de ce Païs-ci, qu'il est pour les humeurs ce que Babel étoit pour les Langues [kursiv im Orig.]" (CCM XXXVI, 281). Als Beispiel dafür, dass die Niederlande für die menschlichen Charaktere so wie Babel für die Sprachen wäre, zieht der Korrespondent das weibliche Temperament heran, das je nach Nationalität variiere, nur in den Niederlanden würden die Frauen alle Temperamente gleichzeitig aufweisen. ${ }^{30}$ Im nachfolgenden Fremdporträt zeichnet er seine Liebesangelegenheit mit der jungen Palmine, die ihn mit ihrem wechselhaften Gemüt (humeur changeante) in die Verzweiflung treibe, habe sie ihm doch plötzlich ihre erst eben zugebilligte Liebe wieder entzogen. Die ironisch gemeinte Antwort des Censeur fällt kurz aus, denn da Frauen schließlich ,von Natur aus' einen wechselhaften Charakter hätten, müsse der Briefschreiber nur darauf warten, bis Palmine ihre Meinung wieder ändere.

Die letzte Nummer (numéro XLIII) beginnt wieder mit einem kurzen Brief einer Frau, die Monsieur le Censeur ebenfalls darum bittet, die Rolle eines objektiven Richters in einer Frage einzunehmen, die sie vor kurzem in einer recht großen Runde diskutiert habe, und zwar in der Frage, welches der zwei Menschengeschlechter edler (plus noble) sei: „Il s'agit [...] de savoir lequel est le plus Noble de l'Homme ou de la Femme [kursiv im Orig.]" (CCM LXIII, 337). Auch hier umgeht der Censeur eine direkte Antwort, indem er zuerst den biblisch-antiken-naturrechtlich abgeleiteten Standpunkt der Überlegenheit des Mannes präsentiert und anschließend seine Überlegungen als Honnête homme darlegt, der niemals negativ über Frauen sprechen würde. Mit dieser Argumentation greift er die Idee aus der 16. Nummer auf, in der er behauptet, die Männer seien für das lasterhafte Verhalten der Frauen verantwortlich: „[S]i elles [les femmes] ont tant de défauts qui semblent les placer au dessous de nous [les hommes], nous devons reconnoître que nous en sommes la cause“"(CCM XLIII, 342). Wenn die Frauen nun die Laster der Männer übernähmen, dann - so der Censeur weiter - gelte das auch für die Tugenden und Talente. Immerhin kenne man einige Frauen, die in unterschiedlichen Wissenschaftsbereichen Hervorragendes geleistet hätten und dadurch in die Geschichte eingegangen seien:

Ce que je viens de dire de ces [...] défauts, on le peut dire de tous les autres : \& ce qu'on peut dire à l'avantage des Talens par lesquels les Hommes veulent l'emporter sur les Femmes, peut s'apliquer aux Femmes mêmes. On a coûtume, par éxemple, de vanter le Savoir, la Sience, l'éloquence, comme propre aux Hommes; y a-t-il quelque Art où quelque Femme n'ait excellé. La Sience des Langues a eu les Desroches, les Gournais, les Dauchis, les Daciers. La Philosophie a eu les Aspasies, les Rohans, les Aubeterres. l'Astrologie une Hipatie, l'Art Oratoire une Cornelie Mére des Graches, \& une Tullie Fille de Cicéron. La Poësie une Sapho, trois Corines, deux Deshoulliéres. La Peinture, une Calipso, une Irenée.

30 Der Korrespondent verbindet hier Geschlechtscharakter mit Nationalität, geht also von der Übereinstimmung von geschlechtlicher und nationaler Identität aus: „En Espagne je les ai trouvées fiéres, mais tendres \& peu cruelles; en Italie elles sont tout Amour, toute intrigue $\&$ toute trahison : en Allemagne elles passent pour grossiéres en toute leur conduite, \& pour trop impérieuses ; enfin, en France elles sont autant sujètes du changement que de l'Amour. Mais en Hollande on les trouve tout ensemble fiéres, tendres, cruelles, amoureuses, changeantes, \& impérieuses“ (CCM XXXVI, 281-282). 
Enfin, ne voïons-nous pas parmi nous une du Noyer, la gloire de son Siécle [kursiv im Orig.]. (CCM XLIII, 343-344)

Die namentliche Nennung der gelehrten Frauen zeigt, dass das Postulat einer weiblichen Bildungsunfähigkeit, von der der Censeur in den vorangehenden Nummern ausgeht, ein Konstrukt seiner Zeit darstellt. Er scheint auch nicht daran zu zweifeln, dass Frauen ebenso großartige Geschichten schreiben würden wie Männer, wenn man ihnen das Recht dazu einräumte: „En un mot, si les Femmes s'étoient aproprié, comme les Hommes, le droit d'écrire les Histoires, peut-on douter qu'on ne lût bien plus de grandes Actions faites par les Femmes que par les Hommes“"(CCM XLIII, 344). Mehr will der Censeur am Ende der letzten Nummer jedoch nicht über den Status von Frau und Mann kundtun, viel lieber überlasse er dieses Urteil seinen Leser*innen: „J'en demeure-là, laissant au Lecteur à porter son jugement, content de n'avoir pas quité la plume sans avoir pris le parti d'un Séxe dont les charmes \& les agrémens méritent toute notre estime [kursiv im Orig.]" (CCM XLIII, 344).

Es zeigt sich in allen Nummern, dass der Censeur die Urteilsfähigkeit seiner Leser*innen bis zur letzten Nummer schulen möchte. Gleichzeitig mit der Aufforderung der Korrespondent*innen an den Censeur, als Schiedsrichter (juge) zu fungieren, wird nämlich auch das Publikum dazu aufgefordert, sich eine Meinung zu den porträtierten Verhaltensweisen zu bilden. Die rhetorischen Fragen des Censeur sollen zudem zu weiteren Gedanken über die aufgeworfenen Themen anregen.

\subsubsection{La Bagatelle (1718-19) - der ironisierende Kritiker}

Die zweite von Justus van Effen herausgegebene Wochenschrift trägt den Titel La Bagatelle und kommt zwischen dem 5. Mai 1718 und dem 13. April 1719 in Amsterdam heraus. Diesen Einzelnummern folgen gesammelte Neuauflagen in den Jahren 1718/1719, 1742, 1743 und am Ende des Jahrhunderts (1792) (cf. Fischer 2014, 56), wobei im digitalen Repositorium die Bandausgabe von 1742 vorzufinden ist.

In ihren 98 Nummern - die jeweils mit ,Bagatelle` (Kleinigkeit, Lappalie) übertitelt sind - befinden sich 17 mit Frauenbild ausgezeichnete Nummern $(17,3 \%),{ }^{31}$ in denen auch die sechs Markups zum Männerbild zu finden sind (6,1\%). ${ }^{32}$ Wie bereits im Misantrope (1711-1712) hat der fiktive Verfasser der Bagatelle, der sich ,Bagatellist‘ (bagatelliste) nennt, auch hier immer sein männliches Publikum im Hinterkopf, wenn er sein weibliches Publikum anspricht - und umgekehrt.

James Schorr (2014) legt dar, dass die Inhalte dieser Wochenschrift vor allem vom bekannten und beliebten Werk Le Chef-d'oeuvre d'un inconnu (1714) von Thémiseul de Saint-Hyacinthe (1684-1746) inspiriert sind. Das Chef-d'oeuvre ist ein geistreicher, ironischer Kommentar auf ein kurzes Gedicht und verfolgt den Streit zwischen den Anciens gegen die Modernes, wobei zu erwähnen ist, dass sich die Modernes - deren

31 Bagatelle-Nummern mit der thematischen Auszeichnung Frauenbild: X, XI, XXII, XXIV, XXVI, XXIX, XXXVIII, XLV, XLVI, XLVIII, LXX, LXXVII, LXXIX, LXXXIII, LXXXIX, XCI.

32 Bagatelle-Nummern mit der Auszeichnung Männerbild: X, XXIV, XXVI, LXX, LXXXIII, LXXXIX. 
Anhänger Van Effen ist (cf. Graeber 2005, 7) - für die Egalität von Frauen einsetzen. ${ }^{33}$ Ebenfalls sieht Schorr die Bagatelle von Jonathan Swifts (1667-1745) Werken sowie von französischen, griechischen und lateinischen Quellen beeinflusst, wobei sich Van Effen natürlich auch von seinen englischsprachigen Zeitgenossen Addison, Defoe, Mandeville und Shaftesbury inspirieren ließ, deren Werke er ins Französische übersetzte (cf. Schorr 2014, 2).

Die kurzen Nummern der Bagatelle, mit der Van Effen zu seiner Zeit wenig erfolgreich war, ähneln den spectatorialen Geschlechterdiskursen des Misantrope. Auch der Bagatellist geht von einer ,natürlichen“ charakterlichen Geschlechterdifferenz aus, wenn er von der ,natürlichen ' Bestimmung der Geschlechter und einer ,gleichmäßigen Verteilung' der Tugenden spricht: „A considérer les deux Sexes dans leur naturel, \& relativement au but pour lequel ils ont été créés, je crois que les Vertus leur ont été distribuées par un partage fort égal“" (B LXXVII, 170). Die Geschlechterhierarchie erachtet der Verfasser, der mitunter als Frauenfreund auftritt (LXXVII), dagegen als gesellschaftliches Konstrukt: Da er der Meinung ist, das männliche Geschlecht sei bei weitem lasterhafter als das weibliche, könne die Superiorität der Männer nur konstruiert sein. Die Männerwelt, zu der sich der Verfasser durch die Verwendung des Pronomens ,wir' (nous) im nachstehenden Zitat bekennt, würde all ihre eigenen verwerflichen Laster (nos vices infames) einfach unter den Tisch kehren, dieselben jedoch am weiblichen Geschlecht kritisieren. Dagegen würden die Männer ihre Liebe zum Wein, zum Spiel und zu Frauen sowie ihre Sprunghaftigkeit, ihre Oberflächlichkeit und sogar ihre Untreue mit größtmöglicher Nachsicht behandeln:

Mais un injuste préjugé des hommes, fondé sur les plus fausses idées de l'Honneur, nous a rendus infiniment plus vicieux que le Beau-Sexe. Abusant de notre prétendue supériorité, \& nous rendant les maîtres des maximes qui passent pour incontestables parmi le Beau-Monde, nous retranchons tout d'un coup de la liste de nos vices infamans, un grand nombre de ces mêmes défauts que nous trouvons les plus infames dans l'autre partie du Genre-humain. Nous nous faisons quartier avec toute la charité possible, sur l'amour du Vin, du Jeu, des Femmes ; sur l'inconstance, sur la légéreté, sur infidélité même. (B LXXVII, 170)

Wenn der Bagatellist allerdings davon spricht, dass eine unverheiratete 35- oder 36jährige Frau, die noch nicht ihrem tristen Zölibat (triste célibat) entgehen konnte, verbittert die Schuld dafür in der Gesellschaft suchen würde (XLVIII), dann geht daraus deutlich hervor, dass auch der dem weiblichen Geschlecht durchaus wohlgesonnene Verfasser - gemäß seiner Zeit - den Platz einer Frau an der Seite eines Mannes sieht.

In den ersten Nummern tritt das Ziel des Bagatellisten zutage, der mit seiner Zeitschrift soziale und moralische Kritik an seinem weiblichen und männlichen Publikum üben will. Immer wieder hebt er den negativen Einfluss der Gesellschaft, zum Beispiel

33 Die Fürsprechenden der Querelle des Anciens et des Modernes führen nicht nur einen Streit um den Vorrang der sich wandelnden ästhetischen Normen, sondern auch einen Streit um die Teilhabe von Frauen am Kulturleben. Als Vorredner der Modernes und der Frauen verfasst Charles Perrault (1628-1703) als Antwort auf die Verssatire Contre les femmes (1694, X. Satire) seines Gegners, des Anciens-Vertreters Nicolas Boileau-Despréaux (1636-1711), die Apologie des femmes (1694) (cf. Köhler 2006, 36). 
auf Mode $\left(\mathrm{XXII}^{34}\right)$, Ehe (XLVI) sowie Verhalten hervor. Seine Blätter thematisieren wiederholt Schönheit(skult) gepaart mit Eitelkeit (XXVI, XXXVIII, XLVI, XLVIII, LXX) und Eifersucht (XLVI, XLVIII). Sie kritisieren den Machtmissbrauch von Männern gegenüber Frauen (LXXVII), die negativen Folgen von Vorurteilen (LXXXIX) oder von übermäßiger Neugier (XCI). Das Ziel der Bagatelle wird in der 11. Nummer im Leserbrief eines Mannes expliziert, der eine mitgehörte Konversation zwischen zwei Frauen über die Bagatelle wiedergibt: „Son but est d'attaquer le mauvais Goût, l'Erreur,/ Et la fausse Délicatesse ;/ Sur-tout de nous guérir de ces Préventions,/ Qui visent à l'Extravagance./ Lisez-le [journal] donc, Madame, \& vous verrez, je pense,/ Que l'on peut profiter de ses Corrections [kursiv im Orig.]“ (B XI, 64). Aus dem Munde der Gesprächspartnerin geht hervor, dass sich die Bagatelle dezidiert auch an das weibliche Publikum richtet - immerhin müssten ,wir (Frauen) ‘ vom ,schlechten Geschmack`, der insbesondere mit dem weiblichen Geschlecht in Verbindung gebracht wird, ,geheilt‘ werden.

Um dem Publikum seine unsittlichen Verhaltensweisen vor Augen zu führen und es zu einer Verhaltensreform zu animieren, beliefert es der Bagatellist mit zahlreichen ironischen Essays, mit denen er es dazu herausfordert, zwischen Wahrheit und Unwahrheit abwägen zu lernen, sprich seine Urteilsfähigkeit zu schulen. Mitunter erscheint es dem Bagatellisten aufgrund des mit der Gattung noch ungeübten Publikums jedoch notwendig, auf die Ironie in seinen Beiträgen in (Meta-)Kommentaren hinzuweisen: „Je me crois obligé en conscience d'avertir le Lecteur pénétrant, qu'il y a un peu d'ironie dans la Lettre qu'il vient de voir" (B XXIV, 141); oder seine Absichten, die er mit dieser oder jener Beispielgeschichte verfolgt, zu verdeutlichen: „Mais ce n'est pas-là le seul but que j'ai en allégant cette histoire : j'ai voulu surtout $[\ldots]^{\text {“ }}$ (B LXXVII, 176). Der übermäßige Explikationsbedarf erklärt sich aus dem umfänglichen Untertitel der Wochenschrift: Discours ironiques. Où l'on prête des sophismes ingénieux au vice et à l'extravagance, pour en faire mieux sentir le ridicule. Die zahlreichen kommentierenden Passagen lassen sich folglich darauf zurückführen, dass der Bagatellist zur Belehrung seines Publikums auf raffinierte und irreführende Argumentationslogiken (sophismes ingénieux) zurückgreift, um für das Publikum die Lächerlichkeit bestimmter Laster und Extravaganzen hervorzukehren. Die Verfassungsinstanz des Bagatellisten, eines geistreichen, welterfahrenen Dilettanten, trägt außerdem dazu bei, dass das Publikum die vernünftigen Argumente akzeptiert, anstatt den leeren Sophismen Glauben zu schenken (cf. Schorr 2014, 3). Darüber hinaus kann die Lächerlichmachung als Strategie der Absicherung gegenüber der Zensur verstanden werden, mit der die Inhalte abgeschwächt werden, um nicht als direkter Angriff gegen die Obrigkeiten gewertet werden zu können.

Für die Kritik und Reformierung seiner Leser*innen greift der Verfasser zu allgemeinen Erzählungen (X, XXII, XXVI, XXIX, XLVI, LXXVII, LXXIX, LXXXIX,

34 Die allgemeine Erzählung in der 22. Bagatelle lässt sich der exotischen Erzählung (conte oriental; , oriental tale“ bei Kay 1975) mit satirischer Absicht zuordnen. Indem der Bagatellist davon erzählt, wie ihm im Halbschlaf eine Dschinn-Figur erscheint, wird anhand dieser exotischen Erzählung Kritik an den neuesten Modetrends geübt. Der Rückgriff auf den im Traum erscheinenden Dschinn, also die Überlappung von Traumvision und exotischer Geschichte, ermöglicht dem Bagatellisten eine doppelte Distanzierung. 
XCI), zu metatextuellen Kommentaren (XI, XXIV, XXVI, XXIX, XLV, XLVI, LXXXIII, LXXXIX, XCI) und Dialogen (XI, XXVI, XXIX, LXXVII, XCI) sowie zu einigen Leserbriefen aus männlicher Feder (XI, XXIV, XLVI), wobei in der 24. Bagatelle der kurze Auszug aus dem Brief einer Frau innerhalb des Briefes eines Mannes vorzufinden ist. Darüber hinaus verwendet der Bagatellist Utopien (XXII, LXXVII), Zitate/Motti (XXIV, XLVI), Exempla (zwei in Nummer LXXIX) und einen Traum (XXII). Als besonders nützlich beschreibt er die moralische Instruktion über das Stilmittel der Allegorie (LXXXIII), die er selbst jedoch in den untersuchten Nummern nur dreimal anwendet (XXII, LXXXIII, LXXXIX).

Um sein Publikum zu tugendhaftem Verhalten zu führen, nutzt Van Effen in der Bagatelle nicht mehr die dezidierte Ratschlagerteilung aus dem Misantrope, sondern verfolgt zwei neue Strategien: Zum einen setzt er noch stärker auf die Wirksamkeit der variierenden Wiederholung von Inhalten, indem er in unregelmäßigen Abständen dieselben Themen aus einem anderen Blickwinkel aufgreift. Zum anderen nutzt er die Wirkmächtigkeit (meist lasterhafter) emotionsschürender Beispielgeschichten, die das Publikum innerlich bewegen und somit reformieren sollen, was an den Katharsis-Effekt der aristotelischen Tragödie erinnert. Der Bagatellist selbst bringt seine Vermittlungsstrategie indirekt in die Nähe der klerikalen Kanzelpredigten, deren Erfolg und Überzeugungskraft er auf die Redegewandheit und den „ton doux, suppliant, insinuant" (B XXIX, 167) des Predigers zurückführt, womit dieser direkt in die Gefühlswelt seiner Zuhörenden vordringt. Ähnlich den Kanzelrednern eröffnet der Bagatellist seine Blätter mit einleitenden, eher theoretisch gehaltenen Statements, die das Thema der Einzelnummer darlegen. In deduktiver Vorgehensweise verdeutlicht er im Anschluss das Thema über abstrakte und schließlich ein oder mehrere konkrete Charakter- oder Situationsbeispiele (in Form von Binnenerzählungen). Mit diesen Beispielgeschichten, die Menschen in unterschiedlichen Situationen beschreiben und vorgeblich wahre Begebenheiten wiedergeben, können sich die Leser*innen mit den Protagonist*innen identifizieren und werden so gezielt vor der Hinwendung zu diesen Lastern gewarnt. Um nicht zu langweilen, bedient sich der Bagatellist ferner der zarten, blumigen und anmutigen Sprache der beliebten Prediger:

Que feront-ils pour se faire goûter? Se mettront-ils dans l'esprit d'être solides, simples \& clairs ; de plaîre à deux Auditeurs, \& de faire bâiller tout le reste ? Point du tout. S'ils veulent m'en croire, ils se tourneront du côté du délicat, du fleuri, \& du gracieux [kursiv im Orig.]. (B XXIX, 170) ${ }^{35}$

Daneben betont der Bagatellist immer wieder die Notwendigkeit einer guten Erziehung/Bildung der jungen Generation sowie die wichtige Rolle der Eltern dabei, da die ,richtige‘ Erziehung/Bildung den Weg von jungen Frauen und Männern zur Tugend-

35 Der Vergleich der Zeitschrift mit den Kanzelpredigern verwundert nicht, übernehmen doch die Moralischen Wochenschriften immer mehr ,die traditionellen Steuerungs- und Orientierungsfunktionen des früheren Mediums Prediger“ (Faulstich 2002, 75), wobei deren (Medien-)Konkurrenz „ein Auseinanderklaffen konträrer Teilöffentlichkeiten und demzufolge die Anpassungsbemühungen einer immer noch oralen, emotional bestimmten Religionskultur an die neue literale, rational bestimmte Bürgerkultur [bewirkt]“ (ibid.). 
haftigkeit maßgeblich mitbestimme (X, LXXIX, LXXXIII). Als Ideal des jungen Mannes gilt dem Verfasser einmal mehr der Honnête homme, dessen Erziehung zum vorbildlichen Verhalten an mehreren Stellen angesprochen beziehungsweise in Beispielgeschichten oder Porträts verdeutlicht wird. So mahnt der Bagatellist in der 79. Bagatelle sein männliches Publikum, dass eine universitäre Ausbildung für junge Männer noch nicht ausreiche, um in der Gesellschaft als Honnête homme auftreten zu können. Als Beispiel nennt er die vielen Studenten, die sich mit ihrem Wissen lediglich brüsten und fernerhin lächerlich machen würden, anstatt sich an die Gesprächskonventionen zu halten. Wie die Gesprächs- und Verhaltenskonventionen für den Honnête homme aussehen, wird zuvor in der 45. Bagatelle demonstriert, in der die Statuten einer „Société d'honnêtes-gens [kursiv im Orig.]“ (B XLV, 257) an einer „célébre Université d'Deutschland [kursiv im Orig.]“ (ibid.) bekundet werden. Zu den Anstandsregeln zählen neben einem respektvollen Umgang unter den rein männlichen Mitgliedern auch Kleiderordnungen, Vorschriften zu Gesprächsinhalten und Verhaltensnormen im Kontakt mit dem weiblichen Geschlecht. Die Tatsache, dass diese Statuten - deren normativer Charakter allein durch ihre Bezeichnung als ,Statuten' gegeben ist - an einer deutschen Universität eingeführt worden seien, verweist auf die Vorbildwirkung anderer Länder. Damit soll das Publikum gleichzeitig zur Nachahmung gebracht und ihm die ehrbaren Verhaltensweisen der Honnêtes-gens vermittelt werden.

Wie bereits angedeutet, exemplifiziert der Bagatellist die Laster und Tugenden seiner Zeit gerne anhand von abstrakten und konkreten ${ }^{36}$ Charakterbeschreibungen, wobei nur in drei Nummern dezidiert das Fremdporträt-Markup anzutreffen ist (X, XLVIII, LXXVII). In der 10. Bagatelle vergleicht er das Verhalten und den Charakter dreier angesehener Personen, um an ihnen das Zusammenspiel von ,esprit‘ (Geist) und ,âme' (Seele) in einem Menschen zu verdeutlichen. Das erste Porträt berichtet von einem Mann namens Lycidas, der durch das Studium zu einem großen Theologen wurde. Als ,homme savant" sei er zwar allwissend, aber nicht fähig, anregende Konversationen zu führen, weil ihm eine ,âme raisonnable‘ (Vernunftseele) fehle. Ihm stellt der Bagatellist im zweiten Porträt einen gewissen Eraste gegenüber, der dank seines Geistes und seiner Seele die Leute als Schwadroneur gut unterhält. Im dritten Porträt geht es um die charmante Céliméne, die zwar eine Seele (âme), aber kein Denkvermögen (esprit) besitze und deshalb ein wechselhaftes Gemüt aufweise, was er mit einer Liste an Beispielen untermauert. Am Ende der Nummer, die aus diesen drei Porträts besteht, lässt er diese kommentarlos stehen und auf die Leser*innen wirken. Es bleibt ihnen hier also eigenverantwortlich überlassen, ob und welchem der drei Charaktere sie sich eher zurechnen würden. Damit wird jedenfalls suggeriert, dass Frauen gar keinen Geist hätten und deshalb stets wankelmütig wären.

Etwas anders verfährt der Bagatellist in der 48. Bagatelle, in der er anhand eines abstrakten und eines konkreten Frauenporträts den Schönheitskult der Zeit entblößt, diese Gesellschaftkritik aber in väterliche Sorge hüllt: „Mon unique but est d'exposer vivement aux yeux de mon Lecteur, les chagrins dont une belle personne est sans cesse accablée, par l'injustice \& par la jalousie de son propre Sexe“ (B XLVIII, 277). Hier

36 Während konkrete Porträts mit einer namentlich genannten Person verbunden werden, folglich individualisiert sind, werden abstrakte Porträts allgemein gehalten und beziehen sich auf alle Personen aus einer porträtierten Gruppe. 
kritisiert er, dass schöne Frauen meist in Eitelkeit verfielen, anstatt ihr attraktives Antlitz mit einem guten Charakter zu verbinden, und dass Frauen anderen Frauen gegenüber aufgrund ihres Äußeren oft zu Eifersucht und Verunglimpfungen tendierten.

Die 77. Bagatelle greift erneut das Idealbild des Honnête homme auf und stellt dieses dem weniger schmeichelhaften stereotypen Männerbild des galanten Mannes (homme galant) gegenüber. Anhand der ersten Binnenerzählung porträtiert und kritisiert der Bagatellist den alten und reichen Bankier Lysippe, der mit Frauen ein leichtes Spiel habe, da sich diese aus Geldnot und Hoffnung auf ein besseres Leben von ihm leicht verführen ließen. Als ,Anwalt der Frauen“ warnt der Bagatellist hier sozusagen die Frauenwelt davor, sich mit zunächst galant wirkenden Männern (galants hommes) einzulassen, die er in der 70. Bagatelle noch positiv charakterisierte, und zwar als „Homme[s] du monde, qui [ont] de la politesse \& des maniéres aimables“ (B LXX, 125). Über das exemplifikatorische Charakterporträt erklärt er dem weiblichen wie männlichen Publikum, dass der Galanterie-Begriff neben dem positiv konnotierten Verhaltensideal für Männer auch als Synonym für die als negativ (und sexuell) konnotierte Libertinage verwendet wird, die ein nicht nachahmenswertes Verhalten darstelle. ${ }^{37}$ Gleichzeitig wendet sich der Bagatellist mit seinen Ausführungen in der 76. Nummer direkt an das männliche Publikum, dem er nahelegt, sich als tugendhafte Honnêtes hommes zu verhalten, wobei er dieses Idealbild (noch vor der Geschichte über Lysippe) folgendermaßen beschreibt:

Pour être honnête-homme, il suffit d'être poli, brave, \& d'observer avec ceux de notre sexe, les devoirs de la Probité, de la Justice, \& de l'Amitié. Mais avec toutes les dispositions imaginables à la Vertu, avec le meilleur cœur du monde, on n'est pas honnête-homme, si l'on est convaincu d'avoir succombé une seule fois à certaines tentations. (B LXXVII, 170-171)

Nach dem Porträt Lysippes nimmt der Bagatellist mit einem direkten Appell Kontakt zu den Männern seiner Leser*innenschaft auf, mit dem er sie zum Nachdenken über ihre falsche Ehrbarkeit beziehungsweise falsche Aufrichtigkeit (faux point d'honneur) bewegen will: „Que les Hommes fassent pendant un moment abstraction de leur faux point d'honneur, [...] \& qu'ils examinent s'ils devroient attendre quelque résistance de la prétendue force de leur esprit, si elle étoit attaquée de tous côtés par la faim, par la disette, par les desirs naturels, [...] [kursiv im Orig.]“ (B LXXVII, 173). Anhand einer zweiten Binnenerzählung, in welcher der Bagatellist einen hedonistischen Edel-

37 Die positive und negative Konnotation von ,Galanterie“ wird auch in den Encyclopédie-Artikeln GALANT (Grammaire) und GALANTERIE (Morale) von 1757 erwähnt. Im Eintrag zu GALANT (Grammaire) wird der semantische Unterschied an der Wortstellung festgemacht: „Un galant homme [est] un homme à nobles procédés. Un homme galant [...] se rapproche plus du petit-maître“ (Diderot/D’Alembert 2016, 7:427). Aus dem Eintrag zur GALANTERIE (Morale) geht zudem hervor, dass davon ausgegangen wird, dass galantes Verhalten angeboren sei. Die Opposition zwischen Verhaltensideal und Libertinage wird ebenso angesprochen.

Die (ebenfalls negativ konnotierte) weibliche Galanterie kommt dagegen erst im 17. Band (1765) in den „Articles omis“ in Abgrenzung zur Koketterie im Artikel COQUETTERIE, GALANTERIE (Langue françoise) zur Sprache. 
mann porträtiert, veranschaulicht er, dass jedem Mann die Achtung der Jungfräulichkeit einer jungen Frau langfristig mehr Zufriedenheit bringe als ein sexuelles Abenteuer mit ihr. In der Geschichte lässt der Edelmann eine junge Frau auf ihr herzerwärmendes Bittgesuch hin unbeschadet gehen, anstatt sie ihrer verarmten Mutter abzukaufen. Zudem hilft er der Mutter mit finanziellen Mitteln und veranlasst sogar, dass die Frau ihren Geliebten heiraten kann, der als armer Honnête homme bezeichnet wird, wodurch sich hier bereits die Verschiebung des Honnêtété-Ideals Richtung Bürgertum zeigt. Durch dieses moralisch-ethische Verhalten, so der Bagatellist, könne sich der Edelmann nun damit rühmen, dass alle Beteiligten glücklich leben würden: „Ajoutez à tous ces sentimens délicieux, le plaisir inexprimable de pouvoir se dire à soi-même, c'est à moi que toutes ces personnes doivent tout le bonheur de leur vie [kursiv im Orig.]" (B LXXVII, 176-177). Mit dieser Geschichte beabsichtigt der Bagatellist, wie er selbst notwendig erachtet zu erläutern, tugendhaftes Verhalten bei Männern zu wecken: ,[J]'ai voulu surtout réveiller le goût pour la Vertu, dans les ames engourdies par les plaisirs“ (B LXXVII, 176). Bemerkenswert ist hier auch, dass die Bagatelle in dieser Nummer die Beschreibung des bürgerlichen Verhaltensideals im Artikel zu HONNÊTE, adj. (Morale) des Encyclopédie-Bandes von 1765 vorwegnimmt, in dem die „Bürgertugenden [...] eine gewisse Schicklichkeit (bienséance, délicatesse, décence) bei der gesellschaftlichen Interaktion“ (Höfer/Reichardt 1986, 38) enthalten, ,aber vor allem Gerechtigkeit (justice), Sittlichkeit (bonnes mæurs) und gesellschaftlichen Nutzen [...] [kursiv im Orig.]“ (ibid., 38-39) des Honnête homme hervorheben, „denn wichtiger als der je eigene Lebensgenuß ist jetzt das Glück der Mitmenschen“ (ibid., 39):

L'honnête est un mérite que le peuple adore dans l'homme en place, \& le principal mérite de la morale des citoyens; il nourrit l'habitude des vertus tranquilles, des vertus sociales; il fait les bonnes moeurs, les qualités aimables ; \& s'il n'est pas le caractere des grands hommes qu'on admire, il est le caractere des hommes qu'on estime, qu'on aime, que l'on recherche, $\&$ qui, par le respect que leur conduite s'attire \& l'envie qu'elle inspire de l'imiter, entretiennent dans la nation l'esprit de justice, la bienséance, la délicatesse, la décence, enfin le goût \& le tact des bonnes moeurs [kursiv im Orig.]. (Diderot/D’Alembert 2016, 8:286)

Darüber hinaus liefert der Bagatellist in den Einzelnummern, die mit Frauen- und Männerbild-Markups ausgewiesen sind, viele weitere (nicht im Markup-Prozess als solche gekennzeichnete) Charakterporträts, anhand derer ein umfassendes Bild der zeitgenössischen Gesellschaft und Sitten dargeboten wird, und greift somit eine typische Vermittlungsstrategie des Spectator auf. In der 26. Bagatelle werden beginnend mit Beispielen von eitlen Männern verschiedene Ausprägungen von Egoismus (amour propre) dargebracht. Darauf folgt eine generelle Beschreibung der Eigenschaften eines Narzissten und ein Appell an die Leserinnen, sich vor diesem Männertyp zu hüten. Abschließend wird zudem auf narzisstische Variationen hingewiesen, wie sie in Form des eitlen Gecken (fat) oder des Dummen (imbécile/sot) erscheinen können. ${ }^{38}$

38 Ein weiteres Charakterporträt in der Bagatelle, das jedoch nicht in den hier analysierten Nummern vorkommt, ist laut Schorr $(2014,4)$ jenes des Pedanten (B LXXII). 
Nach der aufgrund ihrer Position im Gesamtgefüge der Bagatelle dringlicher erscheinenden Porträtierung stereotyper Männerbilder instruiert der Verfasser das Publikum in der 70. Bagatelle über die gängigen stereotypen Frauenbilder. Als Rahmung dient ihm sein (angebliches) Gespräch mit einer nicht mit den Begrifflichkeiten der Zeit vertrauten jungen Frau, ${ }^{39}$ die sich irritiert darüber zeigt, dass ein ,galant homme“ und eine ,femme galante' nicht dieselbe Bedeutung aufwiesen. In diesem Dialog tritt ein für diese Textsorte charakteristisches Ungleichgewicht zwischen den beiden Kommunizierenden zutage: „Es gibt einen Wissenden und einen Unwissenden, der sich belehren läßt, oder einen moralisch kompetenten und einen inkompetenten Kommunikanten; einen Sprecher, der sich [...] auskennt, und einen, der sich nicht auskennt“ (Niefanger 1997, 201). In dieser dialogisch aufgebauten Nummer erklärt der kundige Bagatellist, dass sich hinter der Bezeichnung, galant homme' ein Mann von Welt voller Höflichkeit und guter Manieren verberge (cf. B LXX, 125); hinter ,femme galante‘, „une Femme qui a des Galans, avec lesquels elle ne reste pas dans les bornes étroites d'une innocente tendresse“ (B LXX, 125). Während sich also hinter der männlichen Galanterie hier eine positive Konnotation ablesen lässt, ist die weibliche Galanterie negativ konnotiert. Hierauf grenzt er die ,femme galante“ von der Prostituierten (débauchée de profession) ab. Die erstere opfere ihr Ansehen für die Liebe, könne aber ihrem Liebhaber treu und eine ehrbare Person sein; die zweite sei per se eine ehrlose Frau, die von den Einnahmen ihrer Reize lebe. Nachdem nun die Gesprächspartnerin des Bagatellisten die ,femme galante“ in die Nähe der Koketten (coquette) bringt, erklärt er auch noch diesen Begriff: ${ }^{40}$ Er impliziere nicht zwangsläufig eine Lasterhaftigkeit, denn es gäbe zwei Arten von Koketten, ${ }^{41}$ die jedoch beide für die Gesellschaft

39 Ebenso hätte hier ein junger Mann die Frage nach der Begriffserklärung stellen können. Der Rückgriff auf eine weibliche Figur festigt jedoch die Erscheinung des gebildeten, fürsorglichen Mannes, der seine Weisheit gerne mit anderen, insbesondere mit Frauen, teilt.

Insgesamt pflegt sich dieser Dialog in die Tradition der Gesprächsliteratur ein, die als Instrument der Erkenntnisgewinnung und Wissensvermittlung in der Antike ihren Ursprung hat und in die aufklärerische Literatur Eingang findet. Die Beliebtheit des schriftlich fixierten Dialogs lässt sich mitunter darauf zurückführen, dass er eine formale Unparteilichkeit des Autors/der Autorin ermöglicht und somit „das unabhängige Urteilen und das selbstbestimmte Reflektieren demonstrativ“ (Niefanger 1997, 200) darstellen kann. „Gerade das duale Gespräch eignet sich vorzüglich dazu (etwa im Rahmen einer Erzählung, mit der die Wahrheit eines moralischen Satzes belegt werden soll), gegensätzliche Positionen zu konturieren. Diese werden personalisiert und den Protagonisten in den Mund gelegt. So wird eine klare Profilierung von Gut und Schlecht, von Richtig und Falsch möglich, [...]“ (ibid.).

40 Eine abwechselnde Erklärung der Begriffe ,coquette‘ und ,galante“ präsentiert bereits La Bruyère (1645-1696) in seinen Caractères (1688), und zwar im Fragment über die Frauen („Des femmes“). Dieses Fragment findet 77 Jahre später in nur leicht abgewandelter Form Eingang in den Band 17 (1765) der Encyclopédie unter dem Eintrag COQUETTERIE, GALANTERIE (Langue françoise).

41 „Les unes ont le cœur véritablement tendre, elles sont susceptibles d'estime \& d'amour pour un Homme de mérite ; mais elles ne se contente $<$ sic $>$ pas d'un cœur bien placé, elles veulent charmer tout le monde, $\&$ voient avec un souverain dépit un seul cœur qui échappe à leur empire. Les autres sont incapables d'aimer, elles adorent leurs propres charmes, leur seul 
gefährlich seien, weil sie tugendhafte Männer verführen und Kummer unter die Honnêtes-gens brächten. Kurz gesagt sei die Kokette das Gegenteil der Prüden (prude). Nach diesen theoretischen Begriffserklärungen folgt ein Beispiel (,Supposons ...“ [B LXX, 127]), wie es einem solchen tugendhaften jungen Mann ergehen würde, wenn er sich in eine kokette Frau verlieben sollte. Damit soll Mitleid für den armen Mann geweckt werden, da er einer koketten Frau schlichtweg hilflos ausgeliefert sei. Das Blatt endet mit einer Warnung des Bagatellisten an seine junge Gesprächspartnerin. Er warnt sie vor der Koketterie und schildert, dass er selbst oft Zeuge davon gewesen sei (,J'ai vu souvent“ [B LXX, 130]), wie eine kokette Frau von einem ehrlosen Mann an der Nase herumgeführt worden sei, für den sie schließlich alles aufgegeben habe, „son innocence, \& même sa réputation“"(B LXX, 130).

Auch wenn die Bagatelle mehrere allgemeine Erzählungen enthält, so steht am Beginn der 46. Bagatelle die einzige häusliche Erzählung in den mit Frauenbild ausgewiesenen Nummern. Aus diesem Grund wird die ebenfalls dialogisch aufgebaute Erzählung nach einer kurzen Erläuterung des formalen Aufbaus der Nummer näher beleuchtet. Die Geschichte handelt von einem Liebhaber (un homme galant), der auf den Ehemann seiner Mätresse eifersüchtig ist. Auf diese Geschichte reagiert zuerst der Freund des Liebhabers, dann der Bagatellist selbst. Beide philosophieren über die eheliche Liebe, die in Frankreich erst in der zweiten Hälfte des 18. Jahrhunderts eine bedeutende Aufwertung erlangt, und üben Kritik an den gängigen Formen der Eheschließung. Diese Bagatelle endet schließlich mit dem Gedicht eines verständigen und tugendhaften Offiziers, ,[un] homme de bon-sens \& d'esprit sans étude, \& vertueux sans bigotterie“ (B XLVI, 266), das dieser am Vorabend seiner Hochzeit geschrieben habe. Mit dieser stilistischen Variation des thematischen Blattinhaltes werden schließlich ein weiteres Mal, und zwar von einem Mann aus dem einfachen Volke, die Vorzüge ehelicher Liebe untermauert.

In der häuslichen Erzählung berichtet der Liebhaber davon, dass er ,zufällig' durch das Schlüsselloch wahrgenommen habe, wie seine Geliebte ihren Ehemann liebkoste. Es handelt sich hierbei um eine sehr private Geschichte, die öffentlich kundgetan wird und zudem eine Variation des klassischen Motivs des heimlichen Belauschens eines Gesprächs durch eine verschlossene Tür hindurch darstellt. Mit folgenden Worten entrüstet sich der Liebhaber nun bei seinem Freund über das zärtliche Liebesgeplänkel der Eheleute: „Morbleu! [...], mon Cher, vous ne sauriez croire jusqu'à quel point Madame d'Olonne porte la coquetterie ? Je l'ai vue de mes propres yeux, la Diablesse aime jusqu'à son mari [kursiv im Orig.]" (B XLVI, 263-264). Der Freund zeigt sich zwar mitfühlend mit dem enttäuschten Liebenden, kritisiert allerdings nicht - wie eventuell anzunehmen - die Verletzung ihrer Privatsphäre, sondern die Missachtung des ,heiligen Ehebündnisses“ („liens sacrés du Mariage“ [B XLVI, 264]), das für ihn

orgueil est la source de leurs minauderies, \& de leurs petits airs agaçans. Tant quelles sont jeunes \& belles, elles n'ont pas le loisir de sentir les impressions de la Nature, qui ne se déclare souvent chez elles, que lorsque leur orgueil est privé de leur nourriture ordinaire, \& que leur beauté flétrie par les années, fait déserter la plupart de leur Idolâtres“ (B LXX, 126). 
die Basis sozialen Friedens darstelle (,une des plus considérables bazes de la tranquilité de la Société Civile“" [B XLVI, 265]). ${ }^{42}$

Das Liebesverständnis, das hier aufgegriffen wird, ist jenes, das durch die Herausbildung der bürgerlichen Kleinfamilie und eines bürgerlichen Wertekanons ins Wanken gerät. Es handelt sich um die Auffassung, dass romantisch-zärtliche Liebe (als Gefühl) innerhalb der Ehe nicht existiere, denn Ehen werden - vor allem in aristokratischen Kreisen, aber auch unter Bauersleuten - aus wirtschaftlichen oder politischen Gründen geschlossen und körperliche Liebe, also Geschlechtsverkehr, wird als ,eheliche Pflicht' ${ }^{\star}$ angesehen. Zärtliche Liebe und Ehe werden bereits in der TroubadourLiteratur im 12. Jahrhundert als zwei voneinander unabhängige Elemente betrachtet, die nicht miteinander in Zusammenhang stehen können. Eine romantisch-zärtliche Liebe - die in der Bagatelle erst mit Zärtlichkeit (tendresse) und später mit dem dafür üblicherweise verwendeten Begriff der Freundschaft (amitié) umschrieben wird - sei demzufolge nur außerhalb der Ehe möglich. In der adeligen Gesellschaft stehen solche außerehelichen, erotisch-sexuellen Beziehungen bis in die zweite Hälfte des 18. Jahrhunderts an der Tagesordnung und gehören gleichsam zum guten Ton. Schließlich gilt eine adelige Frau ohne Geliebten als unattraktiv und einen adeligen Herrn ohne Mätresse glaubt man impotent oder finanziell mittellos (cf. Bernos 1997; Faulstich 2002, 108-109; Matthews Grieco 1994, 85).

Der Freund des Liebhabers, der einen Repräsentanten des Bürgertums verkörpert, spricht sich gegen diese noch wirksame gesellschaftliche Norm aus. Für ihn stellt die außereheliche Liebe in Form von stetig wechselnden Affären, mit denen die Leidenschaften (passions) befriedigt werden - weil die Individuen es nicht bewältigen, diese zu kontrollieren -, eine gesellschaftliche Unsitte dar. Er plädiert dafür, dass zwei vernünftige und tugendhafte Menschen ihre ganze Kraft dafür investieren sollen, die eheliche ,Pflichtliebe‘ mit einer zärtlichen Liebe zu verbinden, damit eine anhaltende Beständigkeit in der Ehe erwachsen kann. Um diese zärtliche und partnerschaftliche Liebesbeziehung zu erreichen, solle das Paar daran arbeiten, die Pflichtliebe mit einer gefühlvollen Liebe, die hier nun als wahre und weise Freundschaft (véritable \& sage amitié) bezeichnet wird, zu stützen und die (körperlichen) Freuden durch die (eheliche) Pflicht zu beleben:

Il est pourtant certain que rien n'est plus possible qu'une constance matrimoniale entre deux
personnes raisonnables \& vertueuses, qui n'ont pas gâté la simplicité de leurs idées natu-
relles. Si elles se font une étude de soutenir leur amour par une véritable \& sage amitié, \&
d'animer, [...], le plaisir par le devoir, elles ne peuvent que goûter longtems les délices d'un
amour mutuel, d'autant plus douces qu'elles sont exemtes de crime. Comme Baucis \& Phi-
lémon, elles peuvent, dans une vieillesse extrême, n'attendre la fin de leur tendresse que de
la mort. (B XLVI, 265)

Hier wird die so entstehende ,eheliche Liebe‘ (amour mutuel/amour conjugal) weiter aufgewertet, indem die außereheliche Liebe gleichzeitig (und bereits zum zweiten Mal in dieser Nummer) als Verbrechen (crime) abgewertet wird. Zum Schluss zieht der

42 Die Ehe fungiert hier als Mechanismus, mit dem die Affekte und Umgangsformen der Menschen modelliert werden (cf. Elias 1997, 9). 
Freund das alte Ehepaar der griechischen Mythologie Philemon und Baucis als Paradebeispiel des sich liebenden Ehepaares heran, denn die beiden liebten sich so sehr, dass sie von Zeus erbaten, zum selben Zeitpunkt sterben zu dürfen, um jeweils nicht den Verlust der anderen Person ertragen zu müssen.

Nach dem Ende der häuslichen Erzählung erklärt der Bagatellist selbst, dass das Laster der außerehelichen Liebe gerade bei Hofe in Mode sei: „A la Cour d'un Peuple inconstant, \& amateur outré du plaisir, le vice ne peut que briller“ (B XLVI, 265). Dieser Einfluss verstelle den Weg zur ehelichen Liebe, obwohl es viele Werke gebe, die den bürgerlichen Ehemann dazu auffordern, seine Ehefrau zu lieben. Diese bürgerliche Art und Weise zu lieben, missfalle jedoch sogar den Bürgerlichen selbst sehr:

Historiettes, Comédies, Lettres Galantes, toutes sortes d'Ouvrages d'Esprit nous prêchent, qu'il y a un air bourgeois à aimer sa Femme : \& l'air bourgeois est une chose qui est en horreur aux Bourgeois mêmes. Où est l'homme assez ennemi de sa réputation, pour oser être un sot avoué de la Raison, plutôt qu'un homme de mérite en dépit du Bon-Sens ? Quand il s'agit d'opter entre la Vertu \& les Belles Maniéres, on ne balance pas longtems ; sur-tout dans un Pays où tout le monde, du plus au moins, naît glorieux, \& où la Mode met en vogue, au gré de ses caprices, tantôt la Dévotion, \& tantôt le Libertinage. (B XLVI, 265-266)

Der Bagatellist verurteilt schließlich den gesellschaftlichen Einfluss sowie die Angewohnheit der Menschen, mehr auf die Meinung und Anerkennung anderer Menschen als auf die eigene Vernunft und Tugendhaftigkeit zu hören. Diese Schlussfolgerung ist insofern bemerkenswert, als der Bagatellist selbst danach strebt, eine kulturelle Praxis (außereheliche Liebe) durch eine andere kulturelle Praxis (eheliche Liebe) zu ersetzen und sich damit - ähnlich wie der Censeur - zum Meinungsbildner erhebt, der andere Menschen zu beeinflussen strebt. Da er die angestrebte bürgerliche Praxis allerdings unter das Siegel der Vernunft und Tugend stellt, erscheint die eheliche Liebe als natürliche Veranlagung und die außereheliche Liebe als korrumpierte Praxis des Adels.

\subsubsection{Le Spectateur français (1721-24) - der ,normale“ Mitmensch}

Die erste eigenständige (also nicht übersetzte) Wochenschrift, die den Begriff des Beobachters im Titel trägt, ist jene von Pierre Carlet de Chamblain de Marivaux (16881763) unter dem Titel Spectateur français (1721-1724) herausgegebene Zeitschrift. Trotz des ursprünglich konzipierten zweiwöchentlichen Erscheinungsrhythmus erscheinen die 25 als ,Blätter' (feuilles) bezeichneten Nummern des Spectateur français in sehr unregelmäßigen Abständen. Zwischen den von Juli 1721 bis August 1724 in Paris erscheinenden Publikationen liegen oft mehrere Monate. Diesen Umstand führt Lévrier (cf. 2007, 250-251) unter anderem auf Marivaux' intensive Tätigkeit als Theaterproduzent in diesen Jahren zurück. Nach seiner ersten Wochenschrift verfasst Marivaux zwei weitere: L'Indigent philosophe ou l'homme sans souci (1727) und Le Cabinet du philosophe (1734). Diese drei Periodika werden gemeinsam in den Jahren 1752, 1754, 1755 und 1761 in Bandausgaben veröffentlicht (cf. Lévrier 2007, 60), wobei für die digitale Edition der drei Marivaux'schen Periodika und somit auch für die vorliegende Arbeit die Bandausgabe von 1752 herangezogen wurde. Die Anhäufung von Neuauflagen in den 1750er-Jahren lässt Rückschlüsse auf eine große Beliebtheit von Marivaux' Spectator-Schriften zu. Aber auch generell scheint gegen Ende dieses 
Jahrzehnts eine Begeisterung - oder zumindest ein gesteigertes Interesse - für die Spectator-Gattung vorzuherrschen, zumal auch Jean-François de Bastide (1724-1788) zwischen 1758 und 1767 seine vier moralischen Periodika veröffentlicht: Le Nouveau Spectateur (1758-1760), Le Monde comme il est (1760), Le monde (1760-1761) und Le Journal de Bruxelles ou le Penseur (1766-1767).

In den 25 Nummern des Spectateur français befinden sich neun Nummern, in denen mindestens ein Frauenbild codiert ist (I, VIII, X, XI, XII, XVII, XVIII, XIX, XX), und keine einzige Nummer mit Männerbild-Markup. Somit sind $36 \%$ der Nummern mit dem Frauenbild-Markup versehen.

Wie im Vorwort des Drucklegers (Avis de l'Imprimeur) der Bandausgabe von $1752 \mathrm{zu}$ lesen ist, führt Marivaux mit seiner ersten Wochenschrift die sittenreformerische Intention seiner Vorgänger fort: „Entre les ouvrages de M. de Marivaux, le Spectateur doit être regardé comme la production d'un Philosophe agréable qui connoit le monde \& qui sçait donner à la vertu cet air d'agrément qui la fait aimer, $\&$ au vice les couleurs qui effarouchent la probité" (SF, ii-iii). Seine Reformierungsmaßnahmen ergreift Marivaux über die Verfassungsinstanz des Spectateur français, der von den Leser*innen respektvoll als Monsieur le Spectateur adressiert wird, allerdings nicht aus der Position eines Vordenkers oder Schulphilosophen, ,sondern als Mitmensch - welterfahren und leidgeprüft, mit sozialer Empathie und ironischer Distanz" (Jüttner 2011, 56). Monsieur le Spectateur situiert sich dezidiert - wie später der Verfasser des Pensador - innerhalb des Wertesystems der Gesellschaft und will als „Philosophe agréable“ (SF Avis, ii) seinen Mitmenschen mit seinen Reflexionen nützlich sein: ,[J]e souhaitte que mes réflexions puissent être utiles“ (SF I, 8). Mit Marivaux wird in den frankofonen Moralischen Wochenschriften erstmals Nützlichkeit zum Ziel erhoben. Während Van Effen in seinen beiden ersten Wochenschriften den nützlichen Charakter der Zeitschrift für das Publikum noch nicht hervorhebt, verweist er erst in seiner letzten (teilweise zeitgleich mit dem Spectateur français herauskommenden) Wochenschrift Le Nouveau Spectateur français (1723-1725) explizit darauf, und stellt sich schlussendlich in eine Linie mit den englischen Prototypen: „Je ne prends leur tître [celui de Spectateur], que parce que j'ay resolu d'écrire dans leur gout, $\&$ de rendre mon ouvrage aussi utile aux hommes, qu'il me sera possible [Hervorhebung der Verfasserin]“ (NS1 I, 8).

In einem amikalen Kommunikationsstil beginnt nun der Verfasser von Marivaux’ Spectateur français mit seiner Abgrenzung von den unliebsamen ,philosophes', die es gewohnt seien, künstliche, realitätsferne und somit für die Gesellschaft unnütze Reflexionen in hochtrabenden Worten anzustellen. Ihn hingegen interessierten die natürlichen und unverfälschten Gedanken, die seinen Beobachtungen entspringen und die er in seiner Zeitschrift im Sinne einer Ästhetik des Zufalls wiedergeben möchte:

$[\mathrm{M}]$ on dessein [est] de recueillir fidélement ce qui me vient d'après le tour d'imagination que me donnent les choses que je vois ou que j'entends ; \& c'est de ce tour d'imagination, 
ou pour mieux dire, de ce qu'il produit, que je voudrois que les hommes nous rendissent compte, quand les objets les frappent. (SF I, 2-3) ${ }^{43}$

Um den Denkprozess möglichst authentisch abzubilden, werden als weitere Vermittlungsstrategie Inhalt und Ton seiner Zeitschrift vom Zufall (hazard) geleitet sein und unstrukturiert auftreten: „[C]'est le hazard qui leur donne le ton : de-là vient qu'une bagatelle me jette quelquefois dans le sérieux, pendant que l'objet le plus grave me fait rire : \& quand j'examine après le parti que mon imagination a pris, je vois souvent qu'elle ne s'est point trompée“ (SF I, 9). Es geht Monsieur le Spectateur darum, wie er in der achten Nummer erneut hervorhebt, ,natürlich zu denken“: ,[...] penser naturellement, c'est rester dans la singularité d'esprit qui nous est échûe" (SF VIII, 87). Er will seine Gedanken weder den Geschmäckern und Schreibregeln der Anciens noch jenen der Modernes anpassen, sondern sie in ihrer einzigartigen Natürlichkeit und Wahrheit aufschreiben, weil es für ihn eben nicht nur eine vorgefertigte Art des Denkens gibt. ${ }^{44}$ Wie Jüttner (2011) ausführt, hat das vorgeblich impulshafte Schreiben, das den Anschein von Zufall und Laune erwecken soll, nichts wirklich Zufälliges an sich, sondern lässt sich auf die Tradition der „Form des Formlosen“ zurückführen, „die über Wurzeln in der Rhetorik des celare artem, in der des humoristischen Romans und in der barocken Ästhetik eines je ne sais quoi verfügt. In der Aufklärung gewinnt sie einen heuristischen, einen experimentell exploratorischen Charakter [kursiv im Orig.] (ibid., 60). Marivaux' Vermittlungsstrategie ist also ein

[...] strategisches Kalkül [und] Ergebnis von vier Strategien zur Anordnung des Fragmentarischen, die im Zusammenwirken dann heuristisch ein Sinnpotential für den Leser bereitstellen: durch harte Schnitte und chaotische Reihung, ${ }^{45}$ durch variierende Wiederholung und emotionalisierende Kontraste. (Jüttner 2011, 62)

Zusätzlich greift der Verfasser bei der Vermittlung seiner Inhalte zu einer Verzögerungsstrategie (oder Retardierung), mit der er vorgeblich dringendere Inhalte einfügt

$43 \mathrm{Zu}$ dieser Distanzierungsstrategie der Spectator-Figuren von der Existenz als Schriftsteller*in in den frankofonen Moralischen Wochenschriften, die insbesondere bei Marivaux auftritt, siehe Fischer (2014, 195-197).

44 Anhand eines Analogieschlusses, der ihn von den verschiedenartigen Denk- und Schreibweisen auf die verschiedenen Schönheitszüge (von Frauen wohlgemerkt) bringt, verdeutlicht er (in Form eines Exemplums), dass es nicht nur eine einzige Art der Schönheit gibt, gleich wie es nicht nur eine einzige Art des Denkens bzw. Schreibens gibt.

45 Als ,harte Schnitte ' bezeichnet Jüttner jene thematischen Wechsel, deren Übergänge abrupt vonstattengehen und somit „tradierte Lesererwartungen durchbrechen“ (Jüttner 2011, 62). „Harte Schnitte und abrupte Übergänge [...] fragmentarisieren das Material, um es zugleich mit einem abschließbaren Netz möglicher Sinnbezüge neu zu überziehen. Unterstützt wird diese implizite Semantisierung des Textes durch das Verfahren der chaotischen Reihung. Sie hilft unterschiedliche, in der Alltagswahrnehmung getrennte Bereiche der Gesellschaft unvermittelt nebeneinander zu stellen [sic], um Absurditäten freizulegen und so die Frage nach den ausgesparten Zusammenhängen neu zu stellen, Ursachen und Erklärungsgründe des Beobachteten sichtbar zu machen“ (ibid., 64-65). 
und andere nach hinten verlagert: „J'ai promis, dans la derniere Feuille du Spectateur un rêve [...] ; mois [sic] je ne puis m'empêcher de le differer : j'ai quelque chose de plus pressant à dire. Je cede à des réflèxions moins amusantes, mois [sic] plus instructives" (SF IV, 34). An diesem Beispiel lässt sich erkennen, dass sich die leselenkenden Strategien immer wieder auch gegenseitig verstärken, wobei die ,[h]arten Schnitte und [die] chaotische Reihung [...] als Stimuli für die Aufmerksamkeit der Leserschaft“ (Jüttner 2011, 66) dienen. Auch wenn in diesem Beispiel noch keine emotionalisierenden Kontraste gebracht werden, mit denen ein ,leidenschaftliche[r] Appell nach grundlegender Umkehr“ (ibid.) im Publikum entstünde, so werden durch die Enttäuschung der Leseerwartung - immerhin wird das Angekündigte nicht erzählt - Emotionen bei den Leser*innen geweckt. Neben der Enttäuschung entsteht vor allem Neugier: Was kann so viel lehrreicher sein, dass es anstatt der angekündigten Geschichte erzählt werden muss?

Diese Vermittlungsstrategien verbindet die Verfassungsinstanz mit den folgenden Textsorten: Beliebt für die Vermittlung der frauen- und männertangierenden Inhalte erscheinen die allgemeine Erzählung (I, VIII, X, XI, XII, XVII, XVIII, XX), der Dia$\log$ (I, VIII, X, XI, XII, XVII), das Selbstporträt (I, XII, XVII, XVIII, XX) und das Fremdporträt (I, VIII, X, XI, XII, XVIII, XIX). Auch einige kürzere und längere Briefe (X, XI, XII, XVIII, XIX, XX) sowie Exempla (I, VIII) sind in den Spectateur français eingebaut. Darüber hinaus befinden sich in den meisten Treffern Markups zu den metatextuellen Kommentaren (VIII, X, XI, XII, XVII, XVIII, XIX, XX) des fiktiven Verfassers.

Hinsichtlich der Vermittlungsperspektivik fällt auf, dass das weibliche Publikum erneut in Form von Briefzusendungen zu Wort kommt. ${ }^{46}$ Durch die Inklusion der Briefe aus weiblicher Hand verschiebt sich die typisch männliche Perspektive (des Verfassers und der männlichen Korrespondenten) und die Innenperspektive von Frauen findet erneut Gehör. Im vorliegenden Fall äußern Frauen aus zwei Generationen ihre Anliegen: zum einen in Form einer jungen geschwängerten Frau (IX, X, XI) und einer weiteren jungen Frau, die unter der frommen Erziehung ihrer Mutter leidet (XII), zum anderen in Form einer alten koketten Dame, die ihre Lebensgeschichte erzählt (XVII-XIX).

Thematisch werden in den mit Frauenbild und Männerbild ausgezeichneten Nummern des Spectateur français die Rollen von Frauen und Männern in der Gesellschaft aufgegriffen, wobei verstärkt auf das Idealbild der Frau als tugendhafte (Ehe-)Frau und fürsorgliche Mutter eingegangen wird. Als Idealbild des Mannes wird das des Honnête homme präsentiert, der jedoch bis dato unter den Reichen kein Ansehen finde, weil er ,nur' ein ehrenwerter Mann - also ohne adelige Abstammung und Reichtümer - sei: „[O]n dit de lui, c'est un honnête homme ; mais ceux qui le disent, le fuyent, le

46 Für Fischer (2012, 107-108) steht der einsetzende geschlechtsspezifische Perspektivenwechsel bei den Briefzuwendungen in Zusammenhang mit der Entwicklung des gesellschaftlichen Frauenbildes sowie mit der ,Entdeckung' der Frau als kaufkräftige Rezipientin. Briefe von Frauen werden allerdings nicht erst mit dem Spectateur français in eine Wochenschrift inkludiert, erste Redebeiträge von Leserinnen finden sich bereits im sechs Jahre zuvor erscheinenden Censeur (1714). 
dédaignent, le méprisent, rougissent même de se trouver avec lui : \& pourquoi ? c'est qu'il n'est qu'estimable“" (SF I, 4).

Die spectatorialen Geschlechterdiskurse der Wochenschrift orientieren sich an einer als ,natürlich“ wahrgenommenen charakterlichen Geschlechterdifferenz. Es wird von vorgeblich geschlechtsspezifischen (Charakter-)Eigenschaften ausgegangen, wobei der Verfasser hauptsächlich ,weibliche' Laster wie Schönheitskult, Eitelkeit, Eifersucht, Frömmigkeit, Geiz und Koketterie (I, VIII, XII, XVII, XVIII, XIX) zur Sprache bringt. Anhand von als authentisch dargestellten Beispielen aus Briefzuwendungen und Lebensgeschichten warnt er vor den negativen Auswirkungen dieser Untugenden. Mit diesen gut gemeinten Ratschlägen präsentiert sich der Verfasser - hinter dem der in der Forschung als Frauenfreund bekannte Marivaux (cf. Mason 1979; Gaudry-Hudson 1991, 36-37) zu vermuten ist - als Frauen wohlgesinnter Zeitgenosse, ohne jedoch die Legitimität der geschlechtsspezifischen Zuschreibungen zu hinterfragen. Während als lasterhaft angesehene Männerbilder wie das des falschen Honnête homme (IX-XI), des ,homme galant“ (XVIII) oder des ,libertin“ (XVII-XIX) in Kombination mit den Frauen attribuierten Lastern zwar auch Erwähnung finden, werden die ,männlichen“ im Gegensatz zu den ,weiblichen` Lastern nicht ausdrücklich verunglimpft.

Der fiktive Verfasser beginnt seine Zeitschrift mit einer anekdotischen Erzählung aus seiner eigenen Jugend, ${ }^{47}$ anhand derer er die generelle Künstlichkeit gesellschaftlicher Praktiken entlarvt und Kritik an den (Selbst-)Täuschungspraktiken des weiblichen Geschlechts übt (cf. Graeber 1986, 111-112). Darin beschreibt er, wie er als junger Mann seine Angebetete dabei überrraschte, als sie gerade mit einem Spiegel in der Hand ihre Natürlichkeit, einübte':

[J]'aperçus la belle de loin, qui se regardoit dans un miroir, \& remarquai, à mon grand étonnement qu'elle s'y représentoit à elle-même dans tous les sens où, durant notre entretien, j'avois vû son visage ; \& il se trouvoit que ses airs de physionomie que j'avois crus si naifs, n'étoient, à les bien nommer, que des tours de Gibeciere : [...]. (SF I, 10-11)

Als der junge Spectateur français ihren Trick (tour de Gibeciere) durchschaut, ist er enttäuscht von der tugendhaft geglaubten Angebeteten und verliert sofort jegliches Interesse an ihr. Um in Zukunft also nicht mehr von ähnlichen Ereignissen verletzt zu werden, „,verschließt sich der Erzähler emotional und zieht sich in einen rationalen Bereich zurück“ (Graeber 1986, 111). Er geht sogar so weit, sich als Opfer ihres ,Charakterbetrugs` zu stilisieren, und bestimmt diese Lebensepisode rückblickend als Schlüsselerlebnis, das ihn fortan dazu veranlasst, die Menschen aufmerksam zu beobachten: ,[C]'est de cette avanture que naquit en moi cette misantropie qui ne m'a point quitté, \& qui m'a fait passer ma vie à examiner les hommes, \& à m'amuser de

47 Während diese Erzählung im 18. Jahrhundert oft als autobiografische Erzählung von Marivaux gedeutet wurde, ist heute bekannt, dass es sich dabei um eine Abwandlung von „La métamorphose de Fidélio en miroir" aus dem Spectateur français ou le Socrate moderne Vol. 4, Nr. 30 handelt, der selbst eine Übersetzung des Spectator No. 392 ist (cf. Lévrier 2007, 263-265). Die Fidelio-Erzählung hat ebenso in den spanischen Pensador (P LXXIX) Eingang gefunden (cf. Hobisch 2017, 119). 
mes réflexions“ (SF I, 12). Das heißt, mit dieser Geschichte rechtfertigt der Spectateur français die Hinwendung zur Menschenbeobachtung und in weiterer Folge die Publikation der Wochenschrift.

Gleichzeitig muss festgehalten werden, dass die Frau in dieser Spiegelsequenz lediglich als Objekt der Begierde dargestellt wird, das vom männlichen Subjekt eine negative Beurteilung erfährt. Der Spiegel als Repräsentant der (männlichen) Gesellschaft dient der Frau dazu, die gesellschaftlichen Gepflogenheiten einzuüben, um von ihrem Liebhaber und in weiterer Folge von der Gesellschaft akzeptiert zu werden. Mit anderen Worten definiert sie sich selbst über den männlichen beziehungsweise den gesellschaftlichen Blick, ohne eine eigene Identität zu entwickeln. Überdies wird ihre ,natürliche“ Identität als eitle Kokette vom Spectateur français als verwerflich dargestellt. Der Maßstab dafür, wer sie ist, und vor allem, wie sie zu sein hat, kommt ganz klar von außen. Im ,Spiegel der Gesellschaft‘ kann die Frau schließlich nie sie selbst sein. Aus weiblicher Sicht müsste das Fazit der Geschichte also lauten: Egal, wer ich bin und wie ich mich gebe, ich kann es der Gesellschaft nicht recht machen - also bin ich wie ich bin. Da es dem Spectateur français als Vertreter der aufklärerischen Gesellschaft aber darum geht, Geschlechterhierarchien zu perpetuieren, wird der Vorgang der Bewertung des weiblichen Objekts durch das männliche Subjekt weder von den Protagonist*innen (dem jungen Spectateur français und seiner Angebeteten) noch vom sich erinnernden Ich-Erzähler in Frage gestellt. Stattdessen wird die Frau beschuldigt, sie würde dem Mann falsche Tatsachen vorspielen und somit zur Degeneration (des männlichen Teils) der Gesellschaft beitragen.

In der 8. Nummer greift der Spectateur français die von ihm als typisch weibliche Eigenschaft angesehene Eitelkeit (vanité) wieder auf und verbindet sie mit der Eifersucht (jalousie). Er erklärt über ein in Dialogform wiedergegebenes erlebtes Gespräch, dass Eitelkeit und Eifersucht von Frauen gegenüber anderen Frauen boshaftes Verhalten und Gerüchte hervorbrächten. Daraus leitet er allgemeinmenschliche Charaktereigenschaften ab, die er über das folgende Exemplum auf den Punkt bringt:

\footnotetext{
Volontiers louons-nous les gens qui ne nous valent pas ; rarement ne censurons-nous pas ceux qui valent mieux que nous : ainsi nous ne louons le mérite d'autrui presque que pour sousentendre la supériorité du nôtre ; \& quand nous le blâmons, c'est la douleur de le sentir supérieur au nôtre qui nous échappe. Mais je laisse là les querelles des Auteurs, \& les réflexions qu'ils me font faire. (SF VIII, 97)
}

Um die Lesenden zum weiteren Kauf seiner Zeitschrift anzuregen, kündigt der fiktive Verfasser im letzten Absatz des achten Blattes an, was in der nächsten Feuille zu lesen sein wird, und beginnt das neunte Blatt mit einer Retrospektive auf das vorangehende. Mit dieser neuen spectatorialen Vermittlungstechnik der Ankündigung und der Rekapitulation kann die Entwicklung hin zu einer Inszenierung der Redaktions- und Editionsarbeit festgestellt werden, die unter anderem mit Marivaux und seinen Zeitschriften ihren Anfang nimmt (cf. Fischer 2012, 112).

Mit den Wochenschriften von Marivaux setzt auch die Tendenz ein, Erzählungen über mehrere Nummern zu strecken - eine Publikumsbindungsstrategie, die er auch in 
seinen anderen Periodika anwendet ${ }^{48}$ und die vier Jahrzehnte später in Bastides Wochenschriften stark ausgebaut wird. Da jede Zeitschriftennummer aus drucktechnischen Gründen eine vorgegebene Länge hat, bettet der Verfasser des Spectateur français die inhaltliche Überschreitung der Blattlänge in eine Fiktion: Er wolle in den Nummern IX bis XI die drei Briefe einer jungen Frau einfügen, die ihm diese habe zukommen lassen. Um nicht nur das bedauernswerte Schicksal der Frau abzudrucken und somit - so die fiktive Argumentation - Gefahr zu laufen, das Publikum zu langweilen, streut der Verfasser weitere - ganz ähnlich gelagerte - Geschichten in die Nummer X und XI ein. So berichtet er in der 10. Nummer erst von seiner Unterredung mit einem Mann, in der zwei kontradiktorische Frauenbilder gegenübergestellt werden. Darin beleuchten die beiden Männer die Verhaltensweisen einer zerstreuten Koketten (une femme coquette $\&$ dissipée) und einer klugen und tugendhaften Frau (une femme sage \& vertueuse), wobei der Fokus auf den Mechanismen liegt, wie man(n) das Herz einer tugendhaften Frau gewinnen könne. Diese Vorgehensweise, die sich wie eine theoretische Anleitung zur Eroberung eines Frauenherzens liest, wird durch den Perspektivenwechsel auf die junge Frau und ihre Geschichte sozusagen in der Praxis vorgeführt. In ihrem Brief erzählt sie, wie sie durch ihr ungeschultes Urteilsvermögen ihre Tugendhaftigkeit - hier Jungfräulichkeit - an einen hinterlistigen Geliebten verloren hat, der hinter der Fassade eines Honnête homme verborgen lag. Die Feuille endet schließlich mit ihrem Brief an den ehemaligen Geliebten, der sie schwanger im Stich gelassen hat. Die 11. Nummer setzt ebenfalls mit einer anderen, aber ähnlich gelagerten Liebesgeschichte ein und erklärt anhand dieser die Hintergründe, warum ein Mann seine Geliebte vor der Ehelichung verführte und sie nach dem Liebesbeweis nicht mehr heiraten wollte:

[C]ette maîtresse si aimable n'est plus ; il [l'amant] ne voit plus à sa place qu'une fille imprudente, dont la présence l'ennuie, dont les sollicitations l'importunent, dont la tendresse lui est à charge, \& qui parle un langage qu'il n'entend plus. Elle est encore folle ; il se trouve libre : elle le poursuit ; il est naturel qu'il la laisse là. (SF XI,140)

Erst hiernach folgt der letzte Brief der jungen Frau an ihren Vater, der seine entehrte und mittlerweile todkranke Tochter aus dem Haus gejagt hat, womit die Erzählung endet und das Schicksal der jungen Frau unbekannt bleibt. Trotz ihrer Reuebereitschaft ist ihr Ableben jedoch aufgrund der gängigen Doktrin der ,poetic justice', womit die Vorstellung einhergeht, dass gutes Verhalten belohnt und böses bestraft wird, sehr wahrscheinlich. ${ }^{49}$

$48 \mathrm{Zu}$ den Techniken der Unterbrechung in Marivaux’ Periodika siehe Lièvre (2003).

49 Die Auffassung, das Schicksal fiktiver Figuren müsse sich mit den etablierten Normen und Werten decken, geht auf Platon (ca. 427-348/347 v. Chr.) zurück und findet auch im Spectator No. 40 Erwähnung, wo Joseph Addison die Doktrin der „equal Distribution of Rewards and Punishments“ jedoch angreift (cf. Zach 2017, 26-38). Der Begriff ,poetic justice“ kursiert bereits im 18. Jahrhundert in der Bedeutung der gerechten Belohnung des Guten und der Bestrafung des Bösen in der Literatur und verbreitet sich aufgrund der großen Popularität des Spectator in ganz Europa, wobei ,in Frankreich ausschließlich von der Belohnung der Tugend und Bestrafung des Lasters in der Literatur gesprochen [wird] [...]“ (ibid., 33; cf. 
Die Strategie des steten Perspektivenwechsels zwischen Frauen und Männern in diesen drei Nummern trägt nicht nur zur abwechslungsreichen Unterhaltung für das Publikum bei, sondern verfolgt auch eindeutig edukative Ziele. Anstatt jedoch durch die Illustration des unwürdigen männlichen Verhaltens die Leser dazu aufzufordern, die Tugend einer Frau zu respektieren, verstehen sich die drei Nummern unmissverständlich als ernst zu nehmender Ratschlag an die Leserinnen mit einem vergleichbaren koketten Charakter: ,[...] pour l'instruction de toutes les femmes de son caractere“ (SF X, 120). Die bedauernswerte Liebesgeschichte der jungen Frau, die an das Mitgefühl, das heißt Empathievermögen des weiblichen Publikums appelliert, soll folglich gemeinsam mit der Darstellung des männlichen Kalküls (aus männlicher Perspektive) als Warnung oder abschreckendes Beispiel für alle tugendhaften Frauen mit einem weichen Herzen (,un cœur sensible“ [SF X, 120]) dienen, die versucht sind, dem Drängen ihres Geliebten nachzugeben. Gemäß diesem Beispiel liegt die Sittlichkeit der gesamten Gesellschaft deutlich in der Verantwortung der tugendhaften Frauen, die auf Männer und andere Frauen in gleicher Weise eine Vorbildwirkung ausüben sollen.

Der edukative Effekt dieser drei Nummern wird jedoch nicht nur durch den Perspektivenwechsel erzielt. Der Abdruck der drei Briefe, die (zumindest vorgeblich) aus weiblicher Hand stammen, ist insofern bemerkenswert für die französischsprachigen Periodika, als mit diesen Briefen (nach denen im Censeur) wieder eine weibliche Stimme in den Wochenschriften zu Wort kommt. Obwohl die junge Frau hier als scheinbar eigenständiges Subjekt ihre Stimme erhebt, darf nicht übersehen werden, dass ihre Erzählung ständig unterbrochen wird, um letztendlich in der Rolle des (geläuterten),Anschauungsobjekts` als Abschreckung für andere Frauen in ähnlichen Situationen zu dienen. Dass also lediglich die Blattlänge und das Abwenden von Lektüremonotonie die Gründe für die fragmentierte Inklusion der Briefe sind, darf bezweifelt werden, denn deutlich lässt sich hier ersehen, wie anhand dieser drei Nummern versucht wird, auf das Sexualverhalten des weiblichen Publikums Einfluss zu nehmen.

In den Nummern XVII, XVIII und XIX des Spectateur français befindet sich ebenfalls eine sich über mehrere Blätter erstreckende Erzählung. Es handelt sich um die handschriftlichen Memoiren einer alten Freundin des Verfassers, die er ihr rücksichtslos entwendet habe. Ohne sich dafür in irgendeiner Weise zu schämen oder zu rechtfertigen, rühmt sich der Spectateur français sogar damit, wie er seiner Freundin im Zuge des Treffens eine Hälfte ihres Manuskripts aus den Händen gerissen und damit die Flucht ergriffen habe. In seiner Zeitschrift veröffentlicht er nun gegen den Willen der Freundin - also indem er ihr jegliche Entscheidungsgewalt über ihr Manuskript abspricht - die Memoiren, die als Textsorte einen nicht öffentlichen Charakter besitzen. Aus dieser Rezeptionsfiktion und der vorgegebenen Blattlänge ergibt sich, ähnlich wie bei der Geschichte der jungen Frau, die Fragmentation der Erzählung. Am Beginn der 19. Nummer nimmt der Spectateur français die anfänglich erzählte Geschichte über den Erhalt eines Teils der Memoiren wieder auf, um sich damit zu brüsten, dass ,man“ (on) ihm nun den Rest geliefert habe („on m’en a fourni la suite“ [SF XIX, 251]) und er diesen hier nun abdrucke (cf. Lièvre 2003, 186-187). Durch die unpersönliche Formulierung des Manuskript-Erhalts mit ,on', die den/die Überbringer*in im Dunkeln 
lässt, darf übrigens durchaus angenommen werden, dass ihm seine Freundin auch den zweiten Teil ihrer Memoiren nicht freiwillig überlassen hat oder dass alles zur Gänze erfunden wurde. Diese Rezeptionsfiktion rechtfertigt ferner die Inklusion einer weiblichen Stimme in die Wochenschrift, die der gängigen Auffassung zufolge im privathäuslichen Bereich angesiedelt und nicht zur öffentlichen Zurschaustellung bestimmt ist.

Inhaltlich geben die Memoiren das Leben der Freundin des Verfassers wieder, wobei die alte kokette Dame Schritt für Schritt ihre markanten Begegnungen mit dem männlichen Geschlecht beschreibt. Mit dieser Fokuswahl bringt sie anschaulich zum Ausdruck, dass die Identität einer Frau nur über die des Mannes gebildet werden könne und von diesem abhänge. Ihre Lebenserzählung beginnt damit, dass sie sich in ihrer Jugend damit begnügte, von ihrem Ehemann und anderen Männern bewundert und umworben worden zu sein. Mit zunehmendem Alter und gesellschaftlichem Umgang wandelte sich ihre Tugendhaftigkeit in Koketterie - sie fand also immer mehr Gefallen daran, Männern zu gefallen. Diese Koketterie ging so weit, dass sie sich ständig um ihr Aussehen und ihre Kleidung sorgte. Was die Männer über sie wohl denken mochten, beeinflusste ihre Stimmung, ihr Selbstbild wie auch ihre Freundschaft zu anderen Frauen. Je mehr die Zeichen der Zeit sichtbar wurden, umso mehr bemühte sie sich um den (vergeblichen) Erhalt ihrer Schönheit, denn auf ihre Umgebung wirkte sie - rückwirkend betrachtet - mit zunehmendem Alter meist nur lächerlich. Im Alter resümiert sie nun reuevoll in einer Maxime, die an La Rochefoucauld (1613-1680) denken lässt, dass Frauen ihr ganzes Leben lang versuchen kokett zu bleiben:

[C]oquettes, quand nous sommes aimables ; coquettes, quand nous ne le sommes plus : dans le premier cas nous travaillons à être aimées, dans le second nous travaillons à montrer que nous avons mérité de l'être ; de façon que souvent je faisois encore l'agréable, \& quelquefois j'osois esperer que je plairois ; [...]. (SF XIX, 256)

So wie die Einführung von Erzählungen über mehrere Blätter hinweg mit Marivaux ihren Anfang nimmt, so beginnt auch die Einfügung von Lebensgeschichten in das Spectator-Genre mit diesem Autor. Durch die Erzählung von lebensumspannenden Geschichten können langfristige Auswirkungen der als lasterhaft angesehenen Verhaltensweisen dargestellt werden. Dadurch, dass die Person, die ihr ,lasterhaftes ' Leben aus ihrer subjektiven Perspektive wiedergibt und dieses am Lebensende auch noch bereut, kann die autobiografische Lebensgeschichte schließlich als Warnung oder abschreckendes Beispiel verstanden werden.

Weitere abschreckende Beispiele sind anhand zweier Leser*innenbriefe in der Nummer XII inkludiert. Hier wird das Rollenbild der Frau als fürsorgliche Ehefrau und Mutter aufgegriffen. Es kommen jedoch weder eine Ehefrau noch eine Mutter zu Wort, sondern die Briefe stammen von ihnen nahestehenden Personen, die unter der unverhältnismäßigen Fürsorge der Ehefrau beziehungsweise Mutter leiden. Über die Darstellung einer geizigen Ehefrau und einer frömmlerischen Mutter wird vorgeführt, wie die ins Extreme gebrachten Verhaltensweisen der Sparsamkeit und der Religiosität, wenn sie von Frauen an den Tag gelegt werden, dem Familienleben und in weiterer Folge der gesamten Gesellschaft schaden. Die Darstellung aus der Ich-Perspektive eines Ehemannes beziehungsweise einer Tochter untermauert zum einen die Dringlichkeit der Anliegen der beiden Briefschreibenden und fördert zum anderen die Empathie 
der Leser*innen für den Ehemann beziehungsweise die junge Frau. Zusätzlich weisen die Briefe, die in Boulards (2000) häusliche Erzählungen einzureihen sind, einen parallelen Aufbau auf: Am Beginn jedes Briefes steht das Selbstporträt des/der Schreibenden. Hierauf folgt die Beschreibung des Problems mit der Ehefrau beziehungsweise der Mutter, das in einem dritten Schritt mit einigen Situationsbeispielen belegt wird. Am Ende jedes einzelnen Briefes steht schließlich die Bitte um Hilfe an den Spectateur français, der die Ehefrau beziehungsweise die Mutter zur Vernunft bringen solle.

Im ersten Brief ${ }^{50}$ beschwert sich nun ein Ehemann über seine überaus geizige Ehefrau, die sich weder um ihn noch um ihre Kinder kümmere und die er lieblos als ,diese unheilbringende Frau“ („,cette femme si fatale“ [SF XII, 145]) bezeichnet. Über den Umweg der Beschreibung der negativen Auswirkungen ihres Lasters auf das gesamte Familienleben werden die Aufgaben der Frau innerhalb der bürgerlichen Gesellschaft kommuniziert. So bewirke ihr Geiz (avarice) nicht nur, dass die Kinder schlecht gekleidet seien, sondern auch, dass bei Tisch nicht genug Essen vorhanden sei, weil sie das Hauswirtschaftsgeld nicht ordnungsgemäß verwende:

[Q]uand je reviens chez moi, je crois rentrer dans un désert ; car il y règne un calme si triste ; la cuisine est si froide ; mes enfans sont si sobres, si sérieux ; leur sang apparemment a si peu d'esprits ; il circule si lentement ; moi-même, à l'aspect de tout cela, je demeure si abattu, si consterné, qu'actuellement en vous racontant seulement la chose, \& quoiqu'absent de chez moi, il me prend, de mélancholie, un engourdissement par tout le corps. (SF XII, 148)

Ohne die Fürsorge der Frau und Mutter, so hier das gezeichnete Bild, gebe es schlichtweg kein Familienleben. Sogar die Syntax erscheint reduziert: Die kurzen und abgehackten Sätze zeugen von der auseinanderfallenden ,familiären Einheit‘, als deren Garant die Ehefrau und Mutter gesehen wird.

Während der erste Brief in der Nummer XII die negativen Auswirkungen von mangelnder mütterlicher Fürsorge bekundet, bezeugt die zweite Zuschrift die ebenfalls negativen Auswirkungen von exzessiver mütterlicher Fürsorge. Der zweite Brief stammt von einem 16-jährigen Mädchen, das sich über die zu fromme Erziehung seiner Mutter beklagt. ${ }^{51}$ Bevor es jedoch zu seinem eigentlichen Anliegen kommt, unterstreicht es in

50 Bei diesem Brief handelt es sich aufgrund inhaltlicher und struktureller Parallelen um eine Abwandlung des Briefes aus dem Spectator No. 328. Marivaux nimmt für seinen Spectateur français jedoch nicht nur Anleihen beim Spectator, sondern auch bei Van Effen und dessen Wochenschriften: „Aux côtés d'Addison et de Steele, l'auteur du Misanthrope [sic] et de La Bagatelle constitue sans nul doute l'un des auteurs auxquels Marivaux, dans son premier journal, est demeuré le plus redevable. Cette influence, [...], transparaît notamment dans les caractéristiques et les fonctions que l'auteur du Spectateur français a prêtées à l'auteur supposé. Mais des rapprochements plus précis peuvent également être proposés. Il semble, ainsi, que Marivaux ait emprunté à certains récits du Misanthrope [sic] ou du ,Bagatelliste‘ leur cadre ou leur trame narrative [kursiv im Orig.]" (Lévrier 2007, 269; cf. ibid., 249-292).

51 Dieser Briefinhalt weist Ähnlichkeiten mit dem Spectator No. 492 auf. Generell finden sich im Spectator und in seinen Nachahmungen immer wieder Briefe von jungen koketten Mädchen, die ,commencent leurs lettres en mettant en avant leur jeune âge et leurs motifs de satisfaction, puis en avouant leur envie de plaire“ (cf. Lévrier 2007, 276). 
plauderndem Ton (babiller) sein hübsches Aussehen. Mit diesem vom angekündigten Thema abschweifenden Selbstporträt wird es einem gängigen stereotypen Weiblichkeitsbild gerecht, das es selbst untermauert, indem es sein Geschwätz mit seiner nicht enden wollenden Morgentoilette vergleicht und beides als ganz ,natürlich' darstellt: „[J]e m'amuse à babiller, sans venir au fait. Il faut me le pardonner, Monsieur : une fille de mon âge, qui parle de sa taille $\&$ de son visage, c'est tout comme si elle étoit à sa toilette : elle ne peut finir [kursiv im Orig.]" (SF XII, 154). An diese ausgedehnte und impulshaft vorgebrachte Einleitung schließt die Tochter ihre Geschichte darüber an, wie sie unter der überaus strengen Erziehung ihrer Mutter leide. Das kokette Verhalten und das abschweifende Erzählen des Mädchens werden demnach der Frömmigkeit (dévotion) der Mutter gegenübergestellt, und zwar so, dass es scheint, das kokette Verhalten der Tochter resultiere aus dem allzu frommen Verhalten der Mutter. Insgesamt geht aus dem Brief somit hervor, dass ein Übermaß an mütterlicher Fürsorge negative Auswirkungen auf die weibliche Nachkommenschaft habe. In beiden Fällen wird also ein Mittelmaß als Verhaltensnorm propagiert.

Auffällig ist am Beispiel des zweiten Briefes auch, dass im Fall des Mädchens das ,natürliche', vom Zufall geleitete Schreiben als negativ dargestellt wird, während der fiktive Verfasser diese ,natürliche Art zu denken“ im ersten und achten Blatt als impulshafte Schreibstrategie positiv hervorhebt. Letzten Endes zeigt sich, dass Monsieur le Spectateur, der sich als gewöhnlicher Mitmensch ausgibt und gutgemeinte Ratschläge an seine Leser*innen zu erteilen weiß, Frauen und Männer nach unterschiedlichen Maßstäben beurteilt, die sich an den geschlechtsspezifischen Differenzdiskursen seiner Zeit orientieren.

\subsubsection{Le Nouveau Spectateur français (1723-25) - der praxisorientierte Sittenmaler}

Zwischen Dezember 1723 und Frühjahr 1725 publiziert Justus van Effen in Den Haag seine dritte Wochenschrift. Um sie von Marivaux' bereits erscheinendem Spectateur français (1721-1724) abzugrenzen, versieht er sie mit dem Titel Le Nouveau Spectateur français; ou, Discours dans lesquels on voit un portrait naïf des mours de ce siècle (cf. Buijnsters 1999b). Kurz nach ihrer Publikation kommt eine Gesamtausgabe der aus 28 Nummern (numéros) bestehenden Wochenschrift heraus, die im digitalen Repositorium zur Verfügung steht. ${ }^{52}$ Diese zweibändige Neuauflage von 1725-1726 setzt sich aus den Nummern 1-20 im ersten Band und den Nummern 21-28 gemeinsam mit den nicht von Van Effen stammenden 25 Veritez Satiriques en Dialogue im zweiten Band zusammen.

Innerhalb der Nummern des Nouveau Spectateur français sind fünf (No. 11, 15, 16, 25, 26) mit Frauenbild und eine mit Männerbild (No. 4) ausgezeichnet. Damit befassen sich circa $18 \%$ der Einzelnummern Van Effens letzter Wochenschrift mit den Geschlechtern. Weitere acht Frauenbild- und drei Männerbild-Treffer stammen aus

52 Eine weitere Neuauflage erfährt Le Nouveau Spectateur français sieben Jahre nach dem Ableben von Van Effen in Euvres diverses (1742), in dem seine Werke gesammelt veröffentlicht werden (cf. Buijnsters 1999b). 
den Veritez Satiriques. ${ }^{53}$ Auch wenn nun die Satiren nicht von Van Effen selbst herrühren, so werden sie aufgrund ihrer generellen Erscheinung innerhalb der SpectatorGattung wie aufgrund ihrer Einbettung in die gebundene Ausgabe des Nouveau Spectateur français (1725-1726), in dessen Kielwasser sie ursprünglich gelesen wurden, in diesem Kapitel mitbehandelt. Zudem erfüllen die satirischen Dialoge dem Bandherausgeber zufolge denselben Zweck wie Van Effens Blatt, das - wie der Untertitel bereits ankündigt - ein ,portrait ${ }^{54}$ naïf des mours de ce siècle“, also ein ungekünsteltes, natürliches Sittenporträt des Jahrhunderts zeichnen möchte. Das Ziel der Dialoge sei schließlich dasselbe, und zwar die Skurrilität menschlicher Handlungen ans Licht zu bringen: „[Ils] tendent au même but que le Spectateur, qui est de faire connoitre aux hommes le ridicule de la plûpart de leurs actions" (NS1 Veritez Satiriques, 139). Mit der Entlarvung lächerlichen Auftretens bezweckt der Nouveau Spectateur français demnach, die Menschen zu tugendhaftem Verhalten und Handeln zu motivieren. Damit wird auch diese Wochenschrift, wie der kurz zuvor erscheinende Spectateur français, in den Dienst der Allgemeinheit gestellt. In der ersten Nummer expliziert der fiktive (und ebenfalls als Monsieur le Spectateur adressierte) Verfasser die Intention, sein Werk so nützlich wie möglich für die Menschen zu gestalten, mit folgenden Formulierungen: „rendre mon ouvrage aussi utile aux hommes, qu'il me sera possible“ (NS1 1,8) und,,pouvoir être de quelque utilité à mon prochain“ (NS1 1, 14). Dieses Bestreben sei jedoch eine sehr undankbare Arbeit (travail ingrat), wie Monsieur le Spectateur in der elften Nummer erklärt. Hier lässt er erneut die Motivation für die Abfassung seiner Zeitschrift anklingen, als er davon spricht, was Autor*innen generell dazu antreibe, ihre Mitmenschen bessern zu wollen, obwohl es sich hierbei um ein verhältnismäßig aussichtsloses Unterfangen handle. Sollten aber immerhin zumindest vier oder fünf Personen am Ende des schriftstellerischen Lebens zu vernünftigen Gedanken (idées saines) und tugendhaften Handlungen (actions vertueuses) inspiriert worden sein, so könne man bereits zufrieden sein:

Je $[\ldots]$ sens $[\ldots]$ qu'il n'y a pas de travail plus ingrat que celui qu'on employe à inspirer aux hommes du goût pour les idées saines, \& pour les actions vertueuses. D’où vient donc, [...],

53 Durch die Konsultation der Bandausgabe des Nouveau Spectateur français zeichnet sich auf den ersten Blick die folgende Auseinandersetzung mit den Geschlechtern ab: Von den insgesamt 53 Nummern der zwei Bände verfügen in etwa ein Viertel über die Themenauszeichnungen Frauenbild und/oder Männerbild. 13 Nummern weisen das Thema Frauenbild und vier das Thema Männerbild auf (davon sind zwei Nummern deckungsgleich, zwei neu). Auf den zweiten Blick handelt es sich hier jedoch um ein verfälschtes Bild, denn ursprünglich besteht Van Effens Nouveau Spectateur français aus lediglich 28 Nummern. Die Aufstockung auf 53 Nummern ergibt sich aus seiner erneuten Publikation (1725-1726) als zweiteilige Bandausgabe. Aufgrund seiner Kürze und um den Band gewichtiger zu machen, wurde der zweite Band nämlich vom Den Haager Herausgeber Jean Néaulme (1694-1780) mit 25 kurzen (und ursprünglich in Paris veröffentlichten) Veritez Satiriques en Dialogue aus der Feder eines anderen Autors aufgestockt (cf. Schorr 1982, 91).

54 Die Nähe zur Malerei für die Bezeichnung der Sittenbeschreibung findet sich ebenso in Titeln nachfolgender Wochenschriften. Bei Bastide wird das ,Portrait‘ zu ,Le monde comme il est' und bei Delacroix zu ,Peintures des mœurs'. 
que tant d'auteurs prodiguent les efforts de leur genie à un objet si desesperé ? C'est que parmi ces Illustres un grand nombre ne se met gueres en peine du bon-sens $\&$ du bonheur public $;[\ldots]$ chez d'autres l'amour de la réputation ne fait que soutenir un motif plus beau $\&$ plus noble. Ils savent assez que les passions, les préjugés, \& l'habitude forment un retranchement imprenable autour du Corps du genre humain. Ils n'esperent pas l'y forcer, ils sont persuadés qu'il a resolu de s'y défendre jusqu'à son dernier soufle. Tout ce qu'ils peuvent se promettre raisonnablement, c'est de munir des coeurs qui ne sont pas encore gâtés, contre la contagion de l'extravagance publique, $\&$ de fortifier les motifs plus sublimes dans les ames, qui en sont déja touchées. Si tout ce qu'ils écrivent pendant toute leur vie produit cet heureux effet sur quatre ou cinq personnes, ils doivent se feliciter de leur entreprise, \& être contens de leur sort. (NS1 11, 171-172)

Ebenfalls in der elften Nummer führt ein Korrespondent, der dem Nouveau Spectateur bei seinen Sittenporträts zur Hand gehen möchte, die Absichten der Zeitschrift wie den Beruf des Verfassers noch genauer aus und hebt ihn als ,Medecin d'esprit et du cœur mit dem ,Medecin du corps' auf eine Stufe, wobei er von allen ,Geist- und Körperärzten' derjenige sei, der die Theorie stets gekonnt in die Praxis umsetze - sie also an praktischen Beispielgeschichten zu zeigen wisse:

Vous avés choisi une profession, qui a pour but la réforme du ridicule, la correction des défauts, \& la destruction des vices ; par conséquent vous ne courés pas risque de manquer d'occupation ; Depuis que ces maladies sont répanduës dans le monde, elles occupent nombre de Medecins, qui en raisonnent très-bien pour la plûpart, mais qui à l'exemple des Medecins du corps trouvent rarement le secret de faire suivre l'utilité de la Pratique aux plus beaux préludes de la Theorie [kursiv im Orig.]. (NS1 11, 164)

Diese Praxisorientierung, die durch den Einschub von Charakterporträts und Beispielgeschichten auch allen anderen Wochenschriften in unterschiedlichem Ausmaß anhaftet, ist es auch, die Van Effens letzte französischsprachige Wochenschrift prägt. Er packt die Praxisbeispiele, mit denen er trotz der geringen Erfolgschancen die Reformierung seines Publikums vorantreibt, generell in die Erzählformen der allgemeinen Erzählungen $(15,16)$, der Fremdporträts $(15,25,26)$ und Selbstporträts $(15,16)$ sowie in Dialoge $(13,15)$. Daneben lässt er auch sein (fiktives) Publikum über Briefzusendungen $(4,11,16,25,26)$ zu Wort kommen, in denen ebenfalls Erzählungen, Porträts und Dialoge vorzufinden sind. Alle angetroffenen Einzelnummern zum Frauen- und Männerbild sind zudem mit metatextuellen Kommentaren $(4,11,15,16,25,26)$ des Verfassers gespickt, in denen er immer wieder vor den Verhaltensweisen warnt, die Eitelkeit (vanité) und Egoismus (amour propre) befördern. Außerdem sind die Nummern des Nouveau Spectateur français am Kopf des Blattes mit einem lateinischen Motto (samt französischer Übersetzung) übertitelt, das auf den nachfolgenden Inhalt verweist.

Die Geschlechterdiskurse, die in den mit Frauenbild und Männerbild ausgezeichneten Nummern auftreten, weisen darauf hin, dass der Verfasser von einer ,natürlichen' charakterlichen Geschlechterdifferenz ausgeht. Auch wenn das Laster der Eitelkeit Frauen und Männern in gleichem Maße zugeschrieben wird, wird über zwei Beispielgeschichten eine weibliche und eine männliche Eitelkeit (vanité femelle/mâle) konstruiert. Die beiden als Lebensgeschichten einer alten Frau und eines alten Mannes 
präsentierten Erzählungen verdeutlichen anhand praktischer Beispiele aus dem Leben der zwei Individuen, dass eitles Verhalten bei Frauen und Männern ganz anders zutage trete: Während die Eitelkeit in der Geschichte der Frau mit ,weiblicher' Koketterie (coquetterie) zusammengeführt wird, wird sie in der Geschichte des Mannes mit ,männlichem‘ Egoismus (amour propre) verbunden - allesamt unnütze Qualitäten für die Allgemeinheit.

Die beiden (fiktionalen) Lebensgeschichten, die als allgemeine Erzählungen codiert sind, erweisen sich für die Leser*innen demnach als nicht nachahmenswerte Lebensgeschichten. Die Memoiren der ,dame âgée“ in den Nummern 15 und 16 machen dabei den Anfang. ${ }^{55}$ Obwohl schon in Nummer 19 angekündigt, folgt erst einige Nummern später (in 25 bis 28) ${ }^{56}$ die Reaktion auf die Memoiren der Frau samt Lebensgeschichte eines ,homme d'âge', die James Schorr $(1982,91)$ als Van Effens Reflexionen über seine persönlichen moralischen Anliegen (moralistic concerns) wertet, nicht aber als seine eigene Autobiografie. Alexis Lévrier und Jean Sgard sehen die Lebensgeschichte als „en partie au moins une confidence personnelle“ $(2012,504)$. Sie bemerken in dieser dritten Wochenschrift aus den Händen Van Effens seine stärkere Hinwendung zum autobiografischen Schreiben, die er in der Einleitung des Nouveau Spectateur français ankündigt, indem er bewusst beurkundet, hier über seinen eigenen realen Charakter und nicht den Charakter eines fiktiven Verfassers schreiben zu wollen: ,[J]'imiterai ici le Spectateur Anglois \& le Mentor moderne, en traçant mon propre caractere ; mais ce sera un caractere réèl, qui me peindra tel que je me suis trouvé moimême, [...] [kursiv im Orig.]“ (NS1 1, 9). Allerdings sind über diesen einleitenden ,autobiografischen Pakt‘ (Lejeune 1996) keine persönlichen Erzählungen des Produzenten innerhalb der Wochenschrift zu finden, auch der Name Van Effens scheint nirgends auf. Die letzten vier Nummern, die den Brief des alten Mannes enthalten, können allerdings aufgrund der Ähnlichkeiten in den Lebensläufen des namenlos bleibenden alten Mannes und Van Effens als sein autobiografisches (Teil-)Geständnis gewertet werden (cf. Lévrier/Sgard 2012, 506-508). ${ }^{57}$

Die wiedergegebenen Erinnerungen der alten Frau und des alten Mannes thematisieren vor allem die Eitelkeit, die das Leben beider Individuen maßgebend be-

55 Die Geschichte der alten Dame übernimmt Van Effen wortgetreu aus Marivaux' Spectateur français (SF XVII, XVIII, XIX). Diese in sich abgeschlossene Geschichte ist allerdings nicht die einzige, die sich bei beiden Produzenten über mehr als ein Blatt erstreckt. Im Spectateur français zählen hierzu noch die Texte aus dem ,Journal espagnol' (SF 15, 16), die Van Effen auszugsweise übernimmt (NS1 9, 12), und ,Les avantures de l'Inconnu' (SF 21, 22, 24, 25). Bei Van Effen nehmen die Reflexionen über Voltaires Henriade (NS1 12, 18, 19) sowie der ,Lettre d'un homme d'âge' (NS1 25-28) mehr als eine Blattlänge ein (cf. Lévrier 2007, 416).

56 Im Repositorium wurden die Nummern 25 und 26 dem Thema Frauenbild zugeordnet, wenngleich sie den Brief des ,homme d'âge‘ enthalten. Der Vollständigkeit halber muss erwähnt werden, dass der Brief des alten Mannes vier Blätter (NS1 25-28) umfasst.

57 Lévrier und Sgard (2012) zeigen in ihrem Artikel, wie Van Effen die vier Briefe des, homme d'âge', die in einem groben, veralteten Stil mit klarer Anrede an die Leser*innen und didaktischem Ziel verfasst sind, in der Erzählung Reflexions de $T^{* * *}$ sur les égarements de sa jeunesse (1727) in eine elegante, flüssige Fassung bringt. 
stimmte. ${ }^{58}$ Beide Lebensgeschichten sind an ihren Übergängen nicht mehr (wie bei Marivaux) durch metatextuelle Kommentare gerahmt, sondern hören abrupt auf oder sind lediglich durch den Vermerk „Suite de l'histoire d'une dame âgée“ (NS1 16) beziehungsweise „Suite de la Lettre d'un homme d'âge \&c.“(NS1 26, 27, 28) gekennzeichnet (cf. Lévrier 2007, 417). In der Reaktion des alten Mannes, eines ehemaligen Hauslehrers, auf die Memoiren der Pariserin drückt dieser nun zunächst seine Empörung über die ,weibliche Eitelkeit‘ (vanité femelle) dieser Dame aus. Nach eingehender Selbstbeobachtung - eine Strategie, die an den Begründer der Moralistik Michel de Montaigne (1533-1592) denken lässt - gesteht er ein, dass seine eigene ,männliche Eitelkeit‘ (vanité mâle) jener der Pariserin gleicht. Nachfolgend stellt er sich selbst als unnütze, menschliche Kreatur dar, die an einem ,natürlichen' Don-Quichotismus leide und einem Romanhelden gleiche. Wie es dazu kam, zeigt er in seiner Lebensgeschichte, die er mit seinen Erinnerungen aus der Kindheit beginnt. Im Gegensatz zur alten Dame, die sich ihr Leben lang über den Blick von außen definiert, wird ihm eine eigenständige Identität zugestanden. Obwohl ihn Erziehung und Studium zu einem tugendhaften und moralischen Menschen hätten formen sollen, ist er stets von einer Selbstliebe, einer Eitelkeit und einer „envie de plaire au beau sexe“ (NS1 25, 75) besessen. Genauso wie die alte Dame stillt auch er sein Selbstwertgefühl/seine Eitelkeit damit, ständig neue Herzen zu erobern - egal, ob aus adeligem oder bürgerlichem Haus.

Als gewöhnlicher Hauslehrer stellt der alte Mann einen Antihelden dar, dessen Brief im Gegensatz zu den bekannten historischen Memoiren ${ }^{59}$ steht. Mit diesem gewöhnlichen Menschen können sich die Männer aus dem Lesepublikum zudem leichter identifizieren. Seine Vornehmheit erhält er durch die Weisheit, die er aus seiner Lebensgeschichte zieht und die seine misslungene Karriere aufwiegt: „Le récit de carrière malheureuse est ainsi retourné en quête de la sagesse, et l'on se trouve renvoyé à un autre type de récit qui commençait à faire fortune au début du $18^{\mathrm{e}}$ siècle, le récit de conversion ou de repentance“" (Lévrier/Sgard 2012, 508). Der Brief des alten Mannes (bei Van Effen) kann aufgrund der ähnlichen Lebenswege als Variation des Briefes der alten Frau (bei Marivaux) gelesen werden. Der verhinderte soziale Aufstieg des alten Mannes spiegelt die Rückschläge der alten Dame. Beide finden nur langsam und aufgrund vieler Enttäuschungen ihren Weg zur Weisheit, wobei deren Ausgänge wiederum unterschiedlich sind:

58 Zur Beschreibung des Inhalts der Lebensgeschichte der alten Dame siehe den betreffenden Abschnitt zu Marivaux' Spectateur français in diesem Kapitel.

59 ,[L]a narration porte, pour l'essentiel, sur une vie écoulée et vécue tristement, elle est empreinte d'amertume. Elle rappellerait par là les pseudo-mémoires qui se sont répandus à la fin du $17 \mathrm{e}$ siècle. Si l' 'homme d'âge' portait un nom illustre ou simplement noble, on évoquerait les héros les plus malchanceux de Courtilz, ou ces illustres malheureux qui rapportent l'échec de toute une vie dans des mémoires personnels: les Mémoires de la vie du comte D... avant sa retraite (1696), les Mémoires du comte de Vordac, général des armées de l'Empereur (1702), et surtout L'Infortuné Napolitain (1704) [kursiv im Orig.]“ (Lévrier/ Sgard 2012, 508). 
[S]i la dame âgée raconte avoir finalement pris le parti de renoncer à la vie mondaine, les dernières pages de son 'Mémoire' traduisent une amertume grandissante et sont même hantées par l'image de la mort. La conclusion du récit de 'l'homme d'âge' est résolument plus optimiste, puisque le narrateur proclame longuement sa joie d'avoir triomphé de son orgueil et de vivre désormais dans la foi : 'Je me trouve à présent dans un état que je puis appeler heureux. [...]'. (Lévrier/Sgard 2012, 512)

Die beiden Memoiren sind als Warnung oder abschreckende Beispiele zu verstehen. Durch die Veranschaulichung der langfristigen Effekte der als lasterhaft angesehenen Verhaltensweisen werden die Leser*innen darin geschult, das Laster der Eitelkeit in seinen ,lebenslänglichen' Variationen und geschlechtsspezifischen Ausprägungen zu erkennen und zu meiden. Die subjektive Perspektive und der reuige Ton, den die Erzählfiguren in der Erinnerung über ihr lasterhaftes Leben an den Tag legen, sollen aufzeigen, dass sich ein lasterhaftes Leben nicht lohne. Im Gegensatz zu Marivaux wird durch die Präsentation der Lebensgeschichte einer Frau und jener eines Mannes Kritik am Verhalten von Frauen und Männern gleichermaßen geübt. Ein kleiner Unterschied zeigt sich allerdings: Während die Eitelkeit der Frau bis zum Tod anhält, sie also nicht zu Läuterung fähig erscheint, kann der Mann seine männliche Eitelkeit überwinden und optimistisch in die Zukunft sehen.

Die insgesamt 25 Veritez Satiriques en Dialogue führen den Inhalt der von Justus van Effen dargebrachten spectatorialen Geschlechterdiskurse insofern weiter, als sie versuchen, die Affektiertheit aristokratischer Gesellschaftspraktiken zu entlarven und dem Publikum in überspitzter Form zu vermitteln. Im Grunde steigern sie sogar das „portrait naïf des mœurs de ce siècle“ aus dem Untertitel des Nouveau Spectateur français, da sie ganz direkt und unverblümt auf die artifiziellen gesellschaftlichen Gepflogenheiten zu sprechen kommen und so in die Nähe von Juvenals Satiren gerückt werden können, die sich durch ihren gnadenlosen, spöttischen Charakter auszeichnen. Wie bereits erwähnt, wird in den Veritez Satiriques zudem nicht das Bürgertum, sondern der Adel porträtiert, dessen Lebensweise im Laufe des 18. Jahrhunderts generell immer mehr kritisiert wird und von dem sich das aufstrebende Bürgertum abzugrenzen sucht. Ihre Inhalte schelten demnach die aristokratischen Verhaltensweisen, welche die entstehende bürgerliche Gesellschaftsschicht nicht adoptieren soll.

Sämtliche Veritez Satiriques sind in ein Zwiegespräch gekleidet, an dessen Beginn die beiden Gesprächspartner*innen namentlich (und gelegentlich mit Berufsbezeichnung oder bezeichnendem Charaktermerkmal) genannt werden, wobei eine Person mit mehreren naiven Fragen die sozialen Praktiken der anderen Person unter die Lupe nimmt. Die Frage-Antwort-Sequenzen nehmen Bezug auf Eheschließungspraktiken (I., III. Dialogue), Erziehungsfragen (V), modische Verhaltensweisen von ,femmes de qualité (VI, VIII, XIV) - eine Bezeichnung für Frauen, meist adeliger Herkunft, die vor allem im 17. Jahrhundert verwendet wurde - oder von Ehemännern gegenüber ihren Ehefrauen (IX); behandeln Geldfragen (XV) oder demaskieren Frömmlerinnen (XXIV, XXV).

Als Beispiel einer Modesatire sei das Gespräch zwischen Madame Tripode und Monsieur Senrassis (VIII) genannt, in dem sich die beiden darüber unterhalten, warum die gute Dame beim Spaziergang gestützt werden müsse. Im Laufe des Gesprächs stellt sich heraus, dass nach derzeitiger Mode nur bürgerliche Frauen oder Dienerinnen allein gehen und alle Frauen , de qualité‘ gestützt werden müssten. Zusätzlich erfährt der 
Fragende, dass es derzeit schick sei, kleine Füße zu haben. Dies führt zum einen dazu, dass viele ,femmes de qualité' kleinere Schuhe tragen als sie sollten, und zum anderen, dass sie stets daran erinnert werden, Hilfe beim Gehen zu benötigen. Als ihr schließlich der Gesprächspartner erzählt, er kenne einen Schuhmacher, der den Schuh so gestalten könne, dass der Fuß klein aussehe, aber bequem zu tragen sei, lehnt Madame Tripode dieses Angebot mit dem Verweis auf das bestehende Modediktum dankend ab:

Si ces sortes de pantoufles deviennent à la mode, je serai des premiers à m'en servir, pourvû qu'elles ne m'ôtent pas la gloire d'avoir un joli petit pié. Je ne voudrois pas aussi que la pantoufle fût si commode qu'elle m'empêchât de marcher en femme de qualité, nonchallamment appuiée. (NS1 Veritez Satiriques VIII, 207)

Da die meist zwei bis drei Seiten langen satirischen Ausführungen geradewegs den Kern der Problematik ansteuern und diesen - wie eben dargestellt - so überspitzt darstellen, dass man ihn nicht übersehen kann, erzielen die Dialoge ihre gesellschaftskritischen sowie edukativen Absichten umgehend. Die satirische Darstellung lehrt die Leser*innen, bestimmte Verhaltensweisen als lasterhaft wahrzunehmen und zu beurteilen sowie sich mit einem konträren (oder aber zumindest anderen) Verhalten von diesen Lastern zu distanzieren. Die Veritez Satiriques haben also nicht nur zur Folge, dass sich das Publikum über die aristokratischen Gepflogenheiten lustig macht, sondern führen gleichzeitig auch dazu, dass von ihm ähnliche Verhaltensweisen zur klaren Abgrenzung von der missbilligten Oberschicht vermieden werden. Durch die Verbindung von Unterhaltung (plaire) und Belehrung (instruire) reihen sich die satirischen Dialoge demnach gut in das Gesamtkonzept der Wochenschriften ein.

\subsubsection{La Spectatrice (1728-29) - die selbstreflexive Reformerin}

La Spectatrice kommt zwischen März 1728 und März 1729 anonym in Paris heraus. ${ }^{60}$ Einige Forscher*innen sind der Meinung, dass die Spectatrice aus den Händen der Dramatikerin Marie-Anne Barbier (1670-1745) stamme, andere Expert*innen wiederum glauben, dass der weibliche Fokus innerhalb der Schrift zu stark sei, als dass sie von einer Frau herrühren könnte. Ungeachtet der Tatsache, wer die Zeitschrift tatsächlich geschrieben hat, ist die Spectatrice aufgrund der feminisierten Titelendung, die auf eine weibliche fiktive Verfassungsinstanz hinweist, in Frankreich das ,erste[...] Zeugnis einer journalistischen, weiblichen Schreibweise im Kontext der Spectateurs“ (Fischer 2014, 61). Mit anderen Worten ist es das erste Mal, dass eine als Frau inszenierte Verfasserin dem Spectator-Beispiel von Addison und Steele folgt, um die in England begonnene pädagogische Arbeit in Frankreich fortzusetzen (cf. PallaresBurke 1994, 413, 430-431). ${ }^{61}$

60 La Spectatrice wird im Jahr 1730 ein einziges Mal neu aufgelegt. Eine kritische Ausgabe der Spectatrice erscheint im Jahr 2013 unter der Leitung von Alexis Lévrier (2013b) im EpureVerlag.

61 Ein Jahrzehnt früher erscheint in England bereits der Female Tatler (1709-1710), während der Female Spectator (1744-1746) noch weitere eineinhalb Jahrzehnte auf sich warten lässt. 
In mehr als der Hälfte (53,3 \%) der 15 unter der Bezeichnung ,Semaine“ (Woche) herausgegebenen Nummern der Spectatrice befinden sich Markups zum Frauenbild, aber keine zum Männerbild. Zu den acht mit Frauenbild versehenen Nummern zählen die Semaines I, II, IV, V, X, XI, XII und XIV. ${ }^{62}$

Ähnlich wie die Spectator-Produzent*innen vor und nach ihr nutzt die spectatoriale Verfasserin, Madame la Spectatrice (cf. LaS II, 38), ab der ersten Nummer die direkte Anrede, Imperative und rhetorische Fragen, um eine Publikumsnähe und zumindest den Anschein von Dialogizität zu erzeugen. Dabei scheint die Spectatrice durch ihren feminisierten Titel an ein rein weibliches Publikum gerichtet zu sein, sie adressiert allerdings von Anfang an ein gemischtgeschlechtliches Publikum. Um den männlichen Publikumskreis zu aktivieren und dessen Wohlwollen für ihre Zeitschrift zu erlangen, beginnt Madame la Spectatrice ihr Werk mit einer Captatio Benevolentiae. Sie leitet die Spectatrice damit ein, den lesenden Männern zu schmeicheln, nur um gleich darauf die Vorzüge des weiblichen Geschlechtskollektivs hervorzuheben, dem sie sich mit der Verwendung des Personalpronomens ,nous“ (wir) zuordnet: „J'admire quelquefois l'orgueil des hommes, qui nous taxent d'inconstance \& de legereté. Il me semble, qu'en ambition, en amour, \& en autre chose, nous voulons plus fortement qu'eux ce que nous voulons, nous ne perseverons pas moins que les hommes“ (LaS I, 3). Um sicherzustellen, dass sich auch die Vertreter des männlichen Geschlechts von ihrer Zeitschrift angesprochen fühlen, adressiert die Verfasserin diese direkt mit „Lecteurs masculins“ (LaS I, 8) oder „Messieurs les hommes“ (LaS I, 7). Der weibliche Publikumskreis wird dagegen eher implizit über imperativische Formulierungen und rhetorische Fragen angesprochen. Die Anrede der weiblichen und männlichen Geschlechtergruppen gibt somit „l'impression que la lecture est réservée autant à lui qu'à elle. C'est une sorte de rhétorique de lecture qui est utilisée par l'auteur pour mieux s'assurer l'attention du public" (Fischer-Pernkopf 2019, 54-55).

Mit vereinzelten Ausnahmen sind in allen mit Frauenbild gekennzeichneten Nummern allgemeine Erzählungen (bis auf Semaine XI) und metatextuelle Kommentare (bis auf Semaine XII) der Verfasserin anzutreffen. Ihr Selbstporträt präsentiert Madame la Spectatrice über mehrere Nummern hinweg (I, II, XI, XIV) und auch Fremdporträts stellt sie bereit (I, II, X, XIV). Wie bei Marivaux' früher erscheinendem Indigent Philosophe (1727) und dem späteren Cabinet du philosophe (1734) finden auch in der Spectatrice keine Leser*innenbriefe Eingang in die Zeitschrift. Um die verschiedenen Positionen zu den vorherrschenden Themen der Zeit zum Ausdruck zu bringen, fügt Madame la Spectatrice indessen zahlreiche - als sich tatsächlich zugetragen dargestellte - Dialoge (mehrere in IV, V, X, XII, XIV) ein. Auch auf Zitate (V) greift sie zurück und über eine Traumerzählung (XI) führt sie ihre Reflexionen zur Beziehung zwischen Körper und Geist aus.

Im Unterschied zu ihren männlichen Spectator-Kollegen beginnt Madame la Spectatrice ihre Schrift mit einer selbstreflexiven Rechtfertigungsstrategie, mit der sie

62 Diese Anzahl an Frauenbild-Treffern mag angesichts der Vorannahme, die Spectatrice wäre durch den feminisierten Titel ausschließlich an ein weibliches Publikum gerichtet, gering erscheinen. So wie der Spectator und all seine aus vorgeblicher Männerhand erscheinenden Nachfolger jedoch kein exklusiv männliches Publikum im Auge haben, ist auch die Spectatrice an die Vertreter*innen beider Geschlechter gerichtet. 
ihr Frausein - also ihre Geschlechtsidentität - ab der ersten Zeile thematisiert. ${ }^{63}$ Nach der Captatio Benevolentiae fragt sie ihre Leser*innen direkt, ob man in der Gesellschaft nicht auch ,ohne ein Mann zu sein“, erfolgreich sein könne: „[M]ais ne peut-on point réussir [...] sans être homme [...]" $(\mathrm{LaS} \mathrm{I}, 4)$ ? Die Suggestivfrage mit der doppelten Verneinung mit ,ne...point" und ,sans être“ verweist bereits darauf, dass Erfolg ausschließlich mit dem männlichen Geschlecht in Verbindung gebracht wird, denn genausogut hätte die Frage lauten können: Kann man - oder wie kann man - als Frau erfolgreich sein (,peut-on/comment peut-on réussir en tant que femme ${ }^{6}$ )? Daneben beklagt die Verfasserin, dass Männer - auch bei gleichen Leistungen - Frauen stets eine herablassende Nachsichtigkeit (indulgence) entgegenbringen. Dies sei der Meinung geschuldet, Frauen besäßen einen schwächeren Geist: „Les hommes nous trouvent foibles par l'esprit, peu capables de les égaler ; \& en general si inferieures à eux, qu'ils croient nous devoir faire toûjours quelque grace“ (LaS I, 6). Mit der Kritik an der ungleichen Wahrnehmung und Bewertung der physischen Körper und geistigen Fähigkeiten von Frauen und Männern macht die Verfasserin bereits in der ersten Zeitschriftennummer auf die Konstruiertheit der Geschlechterverhältnisse sowie auf ihre Skepsis gegenüber der kursierenden Annahme einer Einheit von Körper und Geist aufmerksam.

Das Geschlechterverständnis, das Madame la Spectatrice zum Ausdruck bringt, ist vom cartesianischen Dualismus und von Poulain de la Barre geprägt. Sie sieht Frauen und Männer, ob ihrer unterschiedlichen Körper, als gleich vernunftbegabt an und geht von einer Egalität (und nicht von einer Komplementarität) der beiden Geschlechter aus. ${ }^{64}$ Vor diesem ideologischen Hintergrund übt sie in ihrer Wochenschrift Kritik am männlichen Teil der Gesellschaft, der es ihr als gelehrte Frau nicht gestatte, mit gleichwertigem Ansehen am öffentlichen Leben (der öffentlichen Sphäre) teilzuhaben. Anstatt aber nun Ratschläge oder Handlungsanweisungen für ein egalitäres Miteinander zu erteilen, zielt sie darauf ab, den Raum der Zeitschrift zu nutzen, um Vorurteile der

63 Ganz anders verfahren jene Wochenschriften aus männlicher Hand, die vom Spectator beginnend ihr eigenes Mannsein (in Abgrenzung zum Frausein) nie thematisieren oder nie auch nur ansatzweise überlegen, ob sie genug Unparteilichkeit und Abstraktionsvermögen für die Menschenbeobachtung besitzen mögen (cf. Pallares-Burke 1994, 418). So zum Beispiel erklärt Marivaux' Spectateur français zwar den initialen Moment, der ihn als ,normalen Menschen' (das heißt als jemand, der kein ,philosophe‘ ist) zur Tätigkeit des Menschenbeobachtens und fernerhin zur Publikation seiner Zeitschrift veranlasste, sieht aber keine Notwendigkeit, seine Schreibfähigkeit als Mann rechtfertigen zu müssen (cf. Abschnitt zu Marivaux' Spectateur français in diesem Kapitel).

64 Als Beispiel für die von Natur aus angenommene Gleichheit von Frau und Mann argumentiert Madame la Spectatrice damit, dass es viele Männer mit ,weiblichen'Attributen und umgekehrt viele Frauen mit ,männlichen“ Attributen gebe: „La nature donne à de certains hommes des visages de femme : à quelques autres, elle en donne les inclinations. Au contraire elle donne à quelques femmes, ou le visage, ou la taille, ou la force des hommes, ou leur caractere d'esprit, ou des inclinations viriles, ou enfin des vices d'hommes. Elle a ses jeux, ses caprices, qui rendent plusieurs femmes égales à vous [hommes] par l'envie ou par la maniere de penser \& de philosopher“ (LaS IV, 79). 
Männer gegenüber Frauen als soziale Konstrukte zu entlarven ${ }^{65}$ und zu beweisen, dass sie als gelehrte Frau ebenso räsonieren und philosophieren kann wie ihre männlichen Kollegen. Selbstbewusst nennt Madame la Spectatrice ein weiteres Ziel, das sie mit dem Schreiben ihrer Spectatrice verfolgt: In der Zeitschrift will sie der Männerwelt nicht ,den Hof machen', also nicht durch Schmeicheleien die Geschlechterrollen invertieren, sondern sie trachtet danach, die Männer von ihrem übermäßigen Stolz zu befreien und somit zu reformieren: ,[L]oin de leur faire ma cour pour obtenir des suffrages, je me prepare à leur dire des verités propres à rabatre leur orgueil“" (LaS I, 7-8). Indem sie jedoch nicht nur die Männerwelt, sondern auch die Frauenwelt und ihre eigene Person zu kritisieren gedenkt, inszeniert sie sich gleichzeitig als unparteiische Beobachterin, die, wie Mr. Spectator oder Monsieur le Misantrope, als moralische Wortführerin fungiert. Darüber hinaus folgt sie der Vorgangsweise ihres erklärten Vorbilds, dem Begründer der Moralistik Michel de Montaigne (1533-1592), der als „spectateur de la vie“ (Van Delft 2005b, 5) zuerst sich selbst und erst danach seine Lebenswelt beobachtete, um diese anschließend zu beschreiben und zu analysieren, und der auch nicht davor zurückschreckte, sich ab und an zu widersprechen (cf. LaS II, 37). Durch das Selbststudium macht sich die Spectatrice - ähnlich wie Montaigne in seinen Essais (1580-1588) - von der ersten Nummer an selbst zum Inhalt ihrer homonymen Zeitschrift. Ebenfalls zeigt sie durch ihr autodidaktisches Vorgehen, dass alle Menschen (inklusive der weiblichen Hälfte) zum Philosophieren geschaffen seien, und weist somit Ähnlichkeiten mit den gewöhnlichen Verfassern von Marivaux’ Periodika auf.

Wie die Schilderung auf den ersten Seiten zeigt, verfolgt Madame la Spectatrice vermittlungstechnisch bei der schriftlichen Umsetzung die Strategie der Abwechslung in der Art der Montaigne'schen Essays - beziehungsweise der chaotischen Reihung mit den Worten Jüttners (2011). Damit trägt sie der Vielfalt der Urteile und Geschmäcker Rechnung: „La suite de mes discours formera un Ouvrage mêlé, souvent sans ordre ; un Ouvrage de pieces raportées, aussi diversifiées que les jugemens \& les goûts, \& qui par consequent ne manqueront point à exciter tour à tour l'approbation \& la critique des Lecteurs“ (LaS I, 26-27). Diese facettenreiche Wiedergabetechnik nützt ihr zum einen, um ihre Leser*innen bei Laune zu halten, zum anderen, um sie zum weiteren Kauf der Spectatrice zu animieren. Als Ich-Erzählerin springt sie assoziativ und scheinbar wahllos von einem Thema zum anderen und schildert ihre Wahrnehmungen, Empfindungen, Gedanken oder Erinnerungen, was bereits das ,stream-ofconsciouness'-Schreiben evoziert, das Ende des 19. Jahrhunderts in Mode kommen wird. Manche der Scharnierstellen - also der Übergänge zwischen den einzelnen Themenblöcken - kennzeichnet sie sogar explizit mit betont kurzen, beinahe schnippisch wirkenden metatextuellen Wendungen, wobei diese häufiger in den ersten Nummern vorkommen, bis die autodidaktische ,Journalistin-Philosophin' scheinbar ihren persönlichen Schreibstil findet:

- Je passe à mon origine.“ (LaS I, 9)

• „En voilà peut-être assez pour me disculper. Parlons d'autre chose.“ (LaS II, 32)

65 In diesem Aspekt weist die Spectatrice starke Ähnlichkeiten mit Marivaux’ Cabinet du Philosophe auf. 
- „Parlons d'une autre espece de Grand : de ces Sçavans [...].“ (LaS II, 49)

- „Parlons à present des beaux Esprits qui nous ont si-bien accommodées.“ (LaS V, 112)

- „[...], je n’y pensois pas, je vais parler d'autre chose.“(LaS XI, 249)

Im Mittelteil von Semaine I, also der ersten Ausgabe von La Spectatrice, kommt Madame la Spectatrice auf ihre eigene Person zu sprechen, wobei ihr Selbstporträt indirekt über die Darstellung ihres Elternhauses erfolgt: ihres Vaters, eines trink- und vergnügungssüchtigen Landadeligen, und ihrer Mutter, einer tüchtigen Frau aus ebenso noblem, aber verarmtem Hause, die sich weder lieben noch miteinander verheiratet sind. Erziehung erhält das wissbegierige Mädchen kaum. Von ihrem Vater lernt sie das Lesen und die Jägerei, vom Pfarrer Latein, doch seine Romane und Moralbücher langweilen sie. Stattdessen beginnt sie das ,Buch der Natur' ${ }^{`}$ zu studieren und erkennt bald, dass sie - wie ihr moralistisches Vorbild - zur Beobachterin geboren war: „[J]e sentis que la nature m'avoit fait Spectatrice“ (LaS I, 20). Beide Elternteile sterben, als sie bereits mündig ist, und hinterlassen ihr ein stattliches Erbe, was ihr heute ermögliche, ein - für Frauen unübliches - selbstbestimmtes Leben zu führen; auf männliche Privilegien müsse sie jedoch nach wie vor verzichten. Im vollen Bewusstsein ihres inferioren Status als intelligente junge Frau, bringt sie diesen für die Leser*innen folgendermaßen auf den Punkt und gleichzeitig zum Ausdruck, dass zu ihrem Trost die meisten Männer ihre Privilegien nicht weise genug zu nutzen wüssten:

[L]'état de fille [célibataire] est une disgrace naturelle pour une ame d'une certaine trempe. Quelle misere d'être attachée à un corps feminin, esclave de tous les usages qui captivent nôtre sexe : O hommes que vous êtes heureux, quand vous sçavez vous servir sagement de vos privileges ; mais que vous le sçavez peu : c'est ce qui me console. (LaS I, 25-26)

Aus dieser Frustration heraus nehme sich die Verfasserin die Freiheit, von Zeit zu Zeit die gesellschaftlichen Grenzen zu überschreiten. Madame la Spectatrice beschreibt, wie sie sich regelmäßig in Männerkleidung unter die Gesellschaft mische, wo sie aufgrund ihrer weder eindeutig weiblichen noch eindeutig männlichen Gestalt scheinbar mühelos als Mann wahrgenommen werde. Durch den geschlechtlichen Rollentausch präsentiert sie sich als androgynes Wesen, das über die Geschlechtergrenzen hinweg denken kann (cf. Pallares-Burke 1994, 420, 429). Nach außen hin soll das als real dargestellte (i. e. in der Realität stattfindende) Maskierungsspiel vor allem dem Lesepublikum zuträglich sein, da die Spectatrice so den weiblichen und den männlichen Teil der Gesellschaft aus der jeweiligen Innenperspektive wahrnehmen und über diesen innerhalb der Zeitschrift reflektieren kann. Ebenfalls versucht sie damit zu zeigen, dass beide Geschlechter dieselben Tugenden und Laster besitzen, und bestätigt damit gewissermaßen Poulain de la Barres Annahme vom geschlechtslosen Geist, auf den sie in Semaine XII (insbesondere 268-269) ausführlich zu sprechen kommt, ohne jedoch Poulain de la Barre beim Namen zu nennen.

Semaine II beginnt Madame la Spectatrice damit, sich explizit in die Tradition von Montaigne zu stellen, woraufhin sie - nach einer Reflexion über den Egoismus (amour propre) und ob man egoistisch sei, wenn man seine eigenen Gedanken aufschreibt erneut auf ihre Geschlechtsidentität zu sprechen kommt und ihren Rechtfertigungsdiskurs aus Semaine I weiterführt. Im nachfolgenden Abschnitt geht sie auf ihren ledigen Personenstand ein und führt mehrere Gründe an, warum sie lieber alleinstehend 
bleiben wolle: So lehne sie es beispielsweise ab, einem Ehemann, den sie als ,maître“ (Meister, Gebieter) und nicht als ,mari` (Ehemann) betitelt, zu gehorchen, mit dem Philosophieren und Menschenbeobachten aufhören und ihre Kinder überall mit sich herumführen zu müssen, womit sie sich in den Diskurs der Preziösen einschreibt (cf. Badinter 1992, 25-29). ${ }^{66}$ Die Absage an die Institutionen der Ehe und Mutterschaft erteilt sie erneut am Ende der Nummer IV, als sie davon spricht, auf die Titel ,Ehefrau“ und ,Mutter' verzichten zu wollen, ungeachtet der Geringschätzung ihrer Mitmenschen, die ohnehin nur dumm sein könnten, wenn sie sie dafür verachten würden. Gemäß ihrem Selbstbild als Philosophin vergleicht sie sich stattdessen mit den ,philosophes' der Zeit, die auch nicht dafür gemacht erscheinen, die Welt zu bevölkern, sondern sie zu verbessern: „La nature n'a pas prodigué aux Philosophes le talent ni le goût de peupler le monde. A quoi sont-ils donc bons ? Je n'ose dire, à le corriger“" (LaS II, 35). ${ }^{67}$ Daraus leitet sie erneut das sich selbst gesteckte Ziel ihres Schreibens ab: „Je dirai donc des veritez \& tirerai sur la turpitude humaine, comme si j'en étois exempte. On m'avoüera que cela est Philosophe“ (LaS II, 39-40).

In den nachfolgenden Nummern beschreibt die Verfasserin immer wieder erlebte Situationen, von denen ausgehend sie ihre eigenen Reflexionen entwickelt. Wie bei Montaigne (und anderen Wochenschriftenproduzent*innen) erscheint ihre Themenwahl augenscheinlich von einer Ästhetik des Zufalls geleitet zu sein. So gibt sie zu Beginn der Semaine IV über das klassische Motiv des heimlichen Belauschens den Dialog von zwei Männern über ihre Zeitschrift wieder, der verrät, dass La Spectatrice die stereotype Erwartungshaltung des männlichen Publikums an eine Schriftstellerin nicht erfülle, weil sie weder Unterhaltsames schreibe noch , wie eine Frau' denke, sondern eben philosophiere. Im Zuge der Beobachtung eines Ehepaars spricht sich Madame la Spectatrice nun allgemein (und nicht nur mehr für sich persönlich) gegen die Institution der Ehe aus, weil sie Frauen zu Sklavinnen ihrer Ehemänner mache. ${ }^{68}$ Auf diejenigen unglücklich wirkenden Frauen, die nur deshalb eine Ehe eingegangen sind, weil es der gesellschaftliche Duktus besage, schaut Madame la Spectatrice zudem zutiefst herab. Sie gelangt zu dem Schluss, dass Frauen nur in Liebesangelegenheiten mit Männern zu tun haben sollten, denn in diesem Fall seien sie für eine Zeit lang die

66 Das Preziösentum als Manifestation der Querelles des sexes in der französischen Klassik hat seinen Höhenpunkt zwischen 1650 und 1660. Unter ,précieuse‘ versteht man eine emanzipierte Frau, die sich gegen die traditionellen gesellschaftlichen Werte stellt und sich für ein neues Frauenideal einsetzt. Dieses umfasst die Selbstbestimmung und die Befreiung der Frau aus festgeschriebenen Rollenzuschreibungen und berücksichtigt die Möglichkeit ihres sozialen Aufstiegs. Um dies zu erreichen, greifen die Preziösen die Ehe als das Herzstück der phallozentrischen Gesellschaft an: „Contre l'autoritarisme du père et du mari, les Précieuses sont résolument hostiles au mariage arrangé et à la maternité“ (Badinter 1992, 26).

67 Madame la Spectatrice greift hier den Diskurs der Mitglieder der République des Lettres auf, die nur aus Männern besteht. Auch die ,philosophes', unter denen in etwa genauso viele Verheiratete wie Junggesellen sind, diskutieren nämlich heftig darüber, ob die Ehe für die intellektuelle Arbeit förderlich sei oder nicht (cf. Bots/Waquet 1997, 102-104).

68 Pallares-Burke $(1994,433)$ erinnert diese Passage an Daniel Defoes (1702) Good advice to the Ladies shewing that as the world goes, and is like to go, the best way for them is to keep Unmarried, 4-11. 
selbstbestimmten Mätressen von Männern; in der Ehe dagegen seien sie auf ewig ihre Untergebenen. ${ }^{69}$ Semaine V beginnt mit ihrer Rezension des frisch gedruckten Buchtitels La méchante femme, ${ }^{70}$ das ihre Leseerwartungen nicht erfüllt habe, denn anstatt die ,boshaften Frauen' zu attackieren, zeige der Autor die positiven Seiten ,boshafter Frauen' auf und mache sich somit zu deren Anwalt. Zudem wiederhole er die Vorurteile gegenüber Frauen, auch wenn er sich von den Vorurteilen distanziere, indem er sie den Vertretern der Anciens zuschreibe: „Ces Auteurs sont la Bruyere, [Boileau-]Despréaux, Moliere, Sarrazin \& autres“ (LaS V, 103). Madame la Spectatrice missfällt daran, dass der Autor es verabsäume, die Unwahrheit der Beurteilungen von La Bruyère, Molière und Co. aufzuzeigen (,,il se réserve à montrer le faux de leurs jugemens" [LaS V, 103-104]). Stattdessen hebe er das Gute einer boshaften Ehefrau für den Ehemann hervor, wobei er dieses Gute am Beispiel der zänkischen Xanthippe festmacht, die Sokrates (469-399 v. Chr.) zu dem Philosophen gemacht habe, der er war.

Neben dem Rollentausch wendet die Verfasserin in Konversationen mit Gesprächspartner*innen und ihren eigenen Reflexionen immer wieder eine weitere Strategie an, um auf die gleiche Verteilung derselben Tugenden und Laster auf beide Geschlechter aufmerksam zu machen. Es handelt sich dabei um die Inversion der geschlechtsspezifischen Sichtweise, ${ }^{71}$ wie sie später auch im Pensador (1762-1767; P VIII) anzutreffen sein wird. So zum Beispiel dreht sie in Semaine IV die Vorurteile des einen Geschlechts über das andere um: In einer Männerrunde erzählt sie als Mann verkleidet die Geschichte einer Frau, die jahrelang als Soldat im Heer diente. Ein Soldatenkollege fand Gefallen an ,ihm', und als er herausfand, dass sein Kumpan eine Frau war, offenbarte er ihr seine Liebe und versprach, sie zu heiraten. Nach langen Bemühungen des Soldaten gab sie nach; sie wurde schwanger; er starb in einem Gefecht, woraufhin sie das Heer verließ und heimlich das Kind gebar; Ende der Geschichte. Da daraufhin einer der Männer am Tisch vehement die Ansicht vertrat, Frauen würden immer schwach, invertierte Madame la Spectatrice die Geschichte und fragte die Runde, ob nicht ein als Frau verkleideter Mann in einem Frauenheer genauso irgendwann schwach würde. In ihrem Plädoyer setzt sie die Weisheit von Männern und Frauen gleich, da beide nur so lange ihren Prinzipien treu blieben, bis sie umgeworfen (renversé) würden: ,[...] nôtre sagesse [celle des hommes] ressemble à celle des femmes [...]. Elle n'est forte que jusqu'à son renversement“" (LaS IV, 93-94).

In den letzten drei Nummern (XI, XII, XIV), die mit Frauenbild ausgezeichnet sind, lässt Madame la Spectatrice trotz oder gerade wegen der Vorurteile ihres männlichen Publikums über das weibliche Geschlecht die Leser*innenschaft an ihren philosophischen Überlegungen und (inneren/monologischen) Konversationen teilhaben. Ihr Bezug zu den zeitgenössischen Wissenschaftsdiskursen ist dabei unübersehbar: In

69 Madame la Spectatrice spricht sich gegen jegliche Form der Ehe aus, ob standesgemäße Vernunftehe, wie unter Aristokrat*innen üblich, oder romantisch-zärtliche Liebesheirat, wie sie unter den Bürgerlichen mehr und mehr propagiert wird.

70 Es handelt sich hierbei um Louis Coquelet (1728) La méchante femme. Paris: Jacques Langlois.

71 Die Methode der Inversion wendet bereits Poulain de la Barre an, um die Gleichheit der Geschlechter zu demonstrieren (cf. Pellegrin 2017). 
Semaine XI gibt sie unter dem Deckmantel eines Traumberichts ihre Überlegungen zum Körper-Geist-Problem preis, erörtert also die Frage nach der Beziehung zwischen Körper und Geist. Am Beginn des Traums hört sie eine Uhr schlagen, die sie an das Schlagen ihres Herzens erinnert, was bereits an Descartes (1596-1650), für den Körper wie Maschinen funktionieren, denken und die darauf folgende cartesianische Argumentation bereits erahnen lässt. In Analogie zum Uhrwerk nimmt sie ihren eigenen Körper (corps) als ,machine naturelle' wahr und kommt von hier auf ihren Geist (esprit) zu sprechen, der für sie keine Maschine darstelle: „Mon esprit qui pense ces choses-là, [...] n'est point machine : ses fonctions sont d'une nature differente de celles des corps“ (LaS XI, 242). Sie argumentiert, dass der Geist (esprit) jedes Menschen von einem höheren Wesen, einer höheren Intelligenz gemacht worden sei und sich diese höhere Intelligenz durch die Menschen selbst und deren Leistungen zu erkennen gebe. Der Geist erlaube ihr nun mithilfe des Verstandes (raison) und der Empfindung (sentiment) - die einander als Fähigkeiten ihrer Seele (âme) bedingen - zu einer erhabenen Tugendhaftigkeit und aufgeklärten Weisheit zu gelangen.

In Semaine XII nimmt sie auf die ,moralische Anatomie‘ Bezug, die in der Moralistik des 17. Jahrhunderts eine verbreitete Methode zur Analyse des Menschen darstellte und bereits von Montaigne angewandt wurde (Van Delft 2005a, 167ff.). Madame la Spectatrice schließt hier vom Äußeren auf das Innere und denkt darüber nach, wie sich die laut einer Perückenverkäuferin divergierenden Kopfformen von Frauen und Männern auf ihren Verstand, ihr Verhalten und ihre Denkweise auswirken. Aus diesen Gedanken leitet sie auf die ,Wissenschaft ${ }^{\star}$ der Physiognomie über, die davon ausging, dass man aus den äußeren Zeichen eines Menschen (insbesondere seinem Gesicht) sein Benehmen, seinen Charakter, seine Laster sowie Tugenden ablesen könne. Ausgehend von der Begegnung mit der Perückenverkäuferin beginnt die Verfasserin also ihre nachfolgende Argumentation damit, dass sie Poulain de la Barres Aussage, der Verstand hätte kein Geschlecht, für falsch erachte. Allein durch die Formulierung ${ }^{72}$ ist für die Lesenden klar, dass sie die Position des geschlechtslosen Geistes unterstützt, allerdings beleuchtet sie diese erst im letzten Drittel der Nummer. Ihr Fazit lautet: Ungeachtet des biologischen Geschlechts, des Aussehens und körperlicher Einschränkungen sei jede kluge und tugendhafte Person vorurteilslos zu respektieren, wenn sie eine ehrenvolle und ehrbare Seele (âme) besitze:

72 Nach der Annahme, die Madame la Spectatrice mit einem ,vielleicht` beginnt, zählt sie die Eigenschaften des männlichen und des weiblichen Verstandes auf, wobei sie für den männlichen Verstand das Verb ,prétendre‘ (vorgeben, behaupten) benutzt, mit dem sie ihren Dissens ausdrückt: „Peut-êtr [sic] que ceux qui ont dit que les ames n'ont point de sexe se sont trompez. Ne pourroit-on pas dire au contraire, que la raison, qui est la principale partie de l'ame humaine, étant une raison d'homme ou de femme, elle est en quelque sorte de l'un ou de l'autre sexe ? Celle des hommes prétend raisonner mieux que la nôtre. [...] La raison de nous autres femmes, qui juge à sa maniere, \& qui, si elle n'est pas plus raisonnable que l'autre, est au moins plus modeste, dit que nous ne pensons pas moins bien que les hommes, $\&$ que nous penserions mieux, au moins quelque fois, si nôtre raison étoit aussi exercée, aussi cultivée par l'éducation \& par les affaires, que la leur“" (LaS XII, 268-270). 
Que celui qu'habite une ame si sage, si vertueuse \& si haute, paroisse avec toutes les infirmitez \& tous les défauts des corps ; il sera respectable pour moi, parce qu'il sera celui d'une ame que j'honore, que je revére, \& dont les beautés qui occupent mon esprit tout entier, effacent $\&$ absorbent toutes les laideurs de sa maison. (LaS XII, 279)

Wenn Madame la Spectatrice in weiterer Folge schließlich die Frage formuliert: „[Q]u'importe de quel sexe soit l'Auteur des pensées ?“ (LaS XII, 281), dann hinterfragt sie an dieser Stelle (ähnlich wie zu Beginn ihrer Zeitschrift) direkt das voreingenommene Rezeptionsverhalten ihres Publikums, das sich - wie im obigen Beispiel des mitangehörten Dialogs - vom Geschlecht der Person, die den Text verfasst hat, beeinflussen lasse.

In Semaine XIV gibt sie schließlich das Gespräch mit einem ihrer Cousins wieder, der im betrunkenen Zustand von seiner ,praktischen Philosophie‘ erzählt. In hedonistischer Manier bevorzugt der Cousin, im Hier und Jetzt genüsslich zu leben, anstatt sich über Gott und die Welt Gedanken zu machen, und konstatiert als ,praxisorientierter Philosoph` (philosophe pratique), der Welt nützlich sein zu wollen:

[J]e me charge d'être un Philosophe tranquile, heureux, aimable, utile à mes amis, à mes domestiques, à quantité de Marchands \& d'Ouvriers, \& à une partie du Public même. Je ne ferai ni livres ni réfléxions. Je ferai des choses ; je ferai un Philosophe pratique ; \& si je n'ai pas plus de partisans que vous, je consens que vous me mettiez au-dessous du plus creux speculatif de ces fous appellez Philosophes, anciens ou modernes, de quelle Secte il vous plaira. (LaS XIV, 326)

Diese ,praktische Philosophie‘ des Cousins knüpft durch seine Ausrichtung am gesellschaftlichen Leben (i. e. an der gesellschaftlichen Praxis) an eine der zwei aristotelischen Formen von ,praktischer Philosophie' an. Aristoteles, der (in der Nikomachischen Ethik) als Ziel jeglichen Handelns das Gute annimmt, unterscheidet zwischen solchem Handeln, dessen Ziel der Selbstzweck ist, und solchem Handeln, dessen Ziel in einem Werk oder Produkt liegt, das erschaffen werden soll. Während also die ,praktische Philosophie“ des Cousins auf sich selbst und sein Genussleben gerichtet ist, ist jene der Spectatrice darauf ausgerichtet, ein Werk - ihre Spectatrice - herzustellen. Inwiefern und mit welchen Argumenten Madame la Spectatrice auf das Plädoyer ihres Cousins mit einem Gegenplädoyer reagiert, bleibt sie ihren Leser*innen jedoch an diesem Punkt schuldig: „J'écoutai agréablement ce plaidoier, quoiqu'il me parût plein de sophismes. Je défendis les friandises de l'esprit \& le bonheur idéal. On verra mon plaidoier dans une autre Feüille [kursiv im Orig.]" (LaS XIV, 326). Sie verweist lediglich darauf, es in einer nächsten Nummer abdrucken zu wollen, worauf das Publikum jedoch vergeblich wartet, da die Publikation der Spectatrice mit der Nummer XV ihr Ende nimmt. ${ }^{73}$

73 Aus diesem Umstand heraus geht Rimbault (1999) in ihrem Eintrag zur Spectatrice in Sgards Dictionnaire des journaux mit hoher Wahrscheinlichkeit davon aus, dass die Spectatrice aus 16 Nummern bestünde. 


\subsubsection{Le Cabinet du philosophe (1734) - der gewöhnliche Philosoph}

Der Cabinet du philosophe ist die letzte Zeitschrift, die Marivaux gründet. Sie wird bereits von den Zeitgenoss*innen der Spectator-Gattung zugeschrieben, auch wenn diese Affiliation innerhalb der Schrift nicht ausdrücklich hergestellt wird (cf. Lévrier 2007, 59). Die Wochenschrift erscheint in Paris zwischen Januar und April 1734 in elf als ,feuilles' (Blätter) titulierten Nummern, wobei der digitalen Edition die Bandausgabe von 1752 zugrunde liegt.

Etwas mehr als ein Drittel der Nummern des Cabinet du philosophe weisen ein thematisches Frauenbild-Markup auf. Es finden sich hier vier Treffer zum Frauenbild (I, II, V, VI) und es liegt kein Treffer zum Männerbild vor, wobei die Nummer VI ( $D u$ Stile) nur peripher Geschlechterdiskurse transportiert. In diesem Blatt legt Marivaux seine Schreibstrategie offen und verteidigt seinen Stil. Er zitiert hier La Rochefoucauld, Montaigne, La Bruyère und Pascal, die den Basisdiskurs der Moralist*innen ausmachen, und stellt sich somit bewusst in die moralistische Tradition (cf. Lièvre 2003, 194).

Die Besonderheit der dritten Zeitschrift aus der Hand Marivaux' liegt in ihrer spectatorialen Verfasserfiktion, die bereits in den ersten Zeilen eingeleitet wird. Der Cabinet $d u$ philosophe wird vom (fiktiven) Herausgeber als zufälliger Fund im Hause eines bereits verstorbenen geistreichen, klugen Manns (homme d'esprit) präsentiert, der über Jahre seine Gedanken zu den unterschiedlichsten Themen auf losen Blättern niedergeschrieben und in einer Schatulle (cassette) aufbewahrt habe. Auch wenn nun diese Zeitschrift nur einen einzigen Verfasser hat, so verspricht der Herausgeber auf mehrfache Weise seinem Publikum ein lesenswertes, weil authentisches Werk. Erstens habe der Verfasser - wie die Verfasser*innen des Spectateur français und der Spectatriceseine Gedanken ungeordnet, also aus ihrem natürlichen Fluss heraus aufgeschrieben, womit auf der Mikroebene des jeweiligen Blattes eine Ästhetik des Zufalls verfolgt wird. Zweitens werden seine Reflexionen nicht als ehrwürdiger (umfangreicher) Band herausgegeben, sondern in Form von kurzen, leicht, verdaulichen' Blättern, die man nebenbei lesen könne. Drittens kündigt der Herausgeber an, durch die zufällige Anordnung der Blätter (nous les tirons au hazard) im Gesamtgefüge der Zeitschrift die Inhalte interessant und abwechslungsreich zu halten: „Commençons. Voici ce que contiennent les premiers papiers que nous trouvons à l'ouvierture de la Cassette ; car nous les tirons au hazard, ce sera toujours le même“ (CdP 1, 250). Damit herrscht auch auf Makroebene eine Ästhetik des Zufalls mit harten Schnitten vor.

Darüber hinaus liege laut Herausgeber der Mehrwert dieser Zeitschrift - die einer Kritik am Geltungsdrang der zeitgenössischen Autoren gleichkommt - auch darin, dass es sich hier nicht um die wohlüberlegten, stilvoll dargebrachten Gedanken eines Schriftstellers, sondern um die Gedanken eines gewöhnlichen Mannes handle - wie auch schon in Marivaux' vorangehenden Wochenschriften: ,[I]l s'est façonné à l'école des hommes, n'a rien pris des leçons de l'amour propre, c'est-à-dire de cette envie secrette que les autres Ecrivains ont de briller \& de plaire" (CdP 1, 247). Als oberstes Ziel erklärt der Herausgeber die authentische Darstellung der Inhalte, ohne den 
Leser*innen mehr zu versprechen (,n'en attendez d'avence ni plaisir ni dégoût“ [CdP 1, 249]), außer dass sie durch die Lektüre geschult würden, Inhalte zu beurteilen. ${ }^{74}$

$\mathrm{Zu}$ den narrativen Textsorten, die die Verfassungsinstanz des ,gewöhnlichen Philosophen' für die Vermittlung ihrer Gedanken wählt, zählen allgemeine Erzählungen (I, II), Dialoge (I, II, V), Fremdporträts (II, VI), Exempla (I, V) und Allegorien (I, II). Ebenso macht sie Gebrauch vom Traum (I) wie von der Utopie (II) und bedient sich bekannter Zitate (VI), um daran ihre eigenen Reflexionen anzuschließen. Metatextuelle Kommentare des Verfassers finden sich auch hier in allen vier Treffern.

Die Geschlechterdiskurse des Cabinet du philosophe entlarven das komplementär angenommene Geschlechterverhältnis als zugrunde liegendes gesellschaftliches Konstrukt, ohne hier jedoch Alternativen vorzuschlagen. Die Verfassungsinstanz zeigt sich in der ersten Nummer frauenfreundlich, indem sie die Frauen vor vermeintlich galanten Männern (hommes galants) warnt, hinter denen sich Libertins verstecken würden. Auch der Ratschlag aus der zweiten Nummer, mit dem Frauen nahegelegt wird, mehr als nur ihr Äußeres für den Ehemann zu kultivieren, kann als wohlwollend gegenüber Frauen und im Sinne der Zeit gewertet werden.

In den Blättern des Philosophen werden mehrere Charakterporträts von Männern und Frauen gezeichnet, zu denen der galante Mann (homme galant) (I) sowie die koketten und die verheirateten Frauen (V) zählen. Zur Vermittlung der Charakterporträts bedient sich der Verfasser eines formalisierten Aufbaus der Einzelnummern, der den Wochenschriftenleser*innen bereits aus dem Censeur (1714) geläufig ist und an jenen der Caractères (1688) des Moralisten Jean de La Bruyère (1645-1696) anschließt: Er beginnt meist mit einer inhaltlich und stilistisch pointierten Maxime, auf die eine Reflexion folgt. Schließlich wird das Charakterbild durch ein Personenporträt mit Anekdoten, Bildern und realistischen Details abgerundet.

Im Cabinet $d u$ philosophe wird also das Thema, das in einer Feuille zur Sprache kommt, anfänglich mit ein paar Sätzen abstrakt umrissen und im Anschluss mit Beispielen des Philosophen verdeutlicht, die vorrangig aus persönlichen Beobachtungen der Lebenswelt des Verfassers stammen. Immer wieder sind diese (Beispiel-)Geschichten aus dem Alltag durch Metareflexionen und rhetorische Fragen der männlichen Verfassungsinstanz unterbrochen, womit sich der Verfasser selbst zum Gesprächspartner macht und die für die Spectator-Gattung so typische Dialogizität aufrechterhält. Obwohl der Verfasser die im Cabinet du philosophe publizierten Reflexionen laut Herausgeber nie zur Veröffentlichung bestimmt habe, spricht dieser ab dem ersten Fragment (fragment) - auch mit dieser Bezeichnung rückt er die Wochenschrift in die Nähe von La Bruyère, der sein Werk ebenfalls als ,Fragment‘ beziehungsweise als ,fragmentarisch ‘ bezeichnete - seine fiktiven Leser*innen direkt an und imaginiert Unterhaltungen mit diesen. Durch die beschriebene Unmittelbarkeit und den

74 Marivaux bedient hier den gängigen Authentizitätstopos auf den Ebenen der Verfasserschaft, der ursprünglichen Genese des Inhalts sowie der Zusammensetzung des Inhalts innerhalb der Zeitschrift, um so mit den Leseerwartungen spielen und Spannung aufbauen zu können. Ganz besonders aber soll damit dem Publikum verdeutlicht werden, dass auch durchschnittliche Menschen in der Lage seien, über unterschiedliche Themen zu räsonieren und zu philosophieren. 
Appellcharakter erzeugt der Verfasser eine Nähe zum Publikum und animiert es gleichzeitig dazu, sich selbst Gedanken über die angesprochenen Themen zu machen. Durch seine inklusive Wortwahl und den Einschub von Interjektionen nimmt er das Publikum scheinbar mit auf seine Beobachtungstour, und zwar auch dann, wenn er aus der Beobachterperspektive über Dritte spricht, wie dieses Beispiel der zwei Koketten im Pariser Tuileriengarten veranschaulicht: „Menons nos deux Coquettes aux Thuilleries : vous les voyez qui s'y promenent; elles se tiennent sous le bras. Ah ! les bonnes amies! Que croyez-vous qu'elles pensent, \& que chacune d'elles dise intérieurement à l'autre“" (CdP 5, 332-333)?

Im ersten Blatt, in dem der Herausgeber zu Beginn nicht um eine Einleitung (samt Darlegung der Blattlinie) umhinkommt, wird eine der gängigen, negativ konnotierten, gesellschaftlichen Verhaltenspraktiken entlarvt. In einem Exemplum reflektiert der Verfasser darüber, dass ein galanter Mann (homme galant) einer Frau sein Verlangen (désir) nach ihr am effizientesten gestehe, indem er ihr kundtue ,je vous aime, qu'à cause qu'il signifie, je vous désire [kursiv im Orig.]" (CdP 1, 251). Es werden folglich die angesagten sprachlichen Codes der Gesellschaft gelüftet. Ferner wird zu verstehen gegeben, dass jedes Laster - und körperliches Verlangen (Sexualität) wird als solches dargestellt - durch eine Umformulierung höflicher erscheine, auch wenn es sich dabei nach wie vor um ein Laster handle: „Quand le vice parle, il est d'une grossierté qui révolte ; mais qu'il paroît aimable, quand la galanterie traduit ce qu'il veut dire“ (CdP 1, 252). Mit diesem kurzen Exemplum, das die linguistischen Versteckspiele der Galanterie entlarvt, werden gleichzeitig - wenn auch indirekt - alle Frauen davor gewarnt, nicht auf einen galanten Mann (homme galant) hereinzufallen, mit dem hier der lasterhafte Libertin gemeint ist, der nur auf die Befriedigung seiner (sexuellen) Bedürfnisse aus ist.

Hierauf folgt eine allgemeine Erzählung, die den Traum wiedergibt, den eine schwangere Frau dem Philosophen erzählt habe. In diesem Traum, der durch seine Feenfiguren einem Märchen gleichkommt, wollten verschiedene Feen ihrem ungeborenen Sohn positive Eigenschaften zukommen lassen, die jedoch gleichzeitig immer auch negative Eigenschaften nach sich ziehen würden, weshalb die Träumende sich jeglicher Feenhilfe verwehrte. Nach der Erzählung des Feentraums endet das erste Blatt mit einem Exemplum und einer Allegorie. Die dem Verfasser als Kommentar zum Traum dienenden Erzählformen zeigen dem Publikum schließlich auf, dass man im Leben nie alles haben könne, sondern immer Opfer (sacrifices) bringen müsse. Ferner nimmt der Verfasser diese Erkenntnis zum Anlass, um darauf hinzuweisen, dass die ehrenwertesten Opfer, die jede Person erbringen sollte, jene des Lasters an die Tugend, des Verbrechens an die Unschuld und der Unehrlichkeit an die Ehrlichkeit seien. Da Tugendhaftigkeit und Ehrlichkeit bereits einen Gutteil der Religion ausmachten, plädiert er im letzten Satz dafür, dass man auch die Religion (und eben nicht die Vernunft) opfere: ,[C]e sacrifice-là fait déjà plus de la moitié de la Religion. Le reste de cette Religion, ce sont ces Mysteres qu'il faut croire ; \& c'est-là où cette Religion crie à son tour : sacrifiez-moi, non votre raison, mais les raisonnemens d'un esprit si borné, qu'il ne se connoît pas lui-même“ (CdP 1, 261).

Im zweiten Blatt nimmt der Philosoph erneut Bezug auf die Liebe und legt seine Theorie über die Entstehung von Liebe zwischen zwei (heterosexuellen) Menschen dar. Dafür leitet er das Blatt mit den Worten ein, dass er stets den extremen Leidenschaften in der Liebe misstraut habe, und dass ,konstante Herzen“ (cœurs constants), 
also charakterfeste Menschen, emotional nur schwer von etwas berührt werden können, was er mit folgender Maxime resümiert: „Les gens faits pour être contans, destinés à cela par leur caractere sont difficiles à émouvoir“ (CdP 2, 264). Daraufhin unterscheidet er drei Manifestationsformen der Liebe: die flatterhafte, die beständige und die gekaufte Liebe, deren Ausprägungen er sukzessive beschreibt. Im zweiten Teil des Blattes verdeutlicht er die Maxime mit einer allegorischen Geschichte (,une fiction assez singuliere" [CdP 2, 271]), die er irgendwo gelesen habe und die darstelle, wodurch ein konstantes Herz bewegt, sprich erobert werden könne. Bei dieser im Repositorium lediglich mit Utopie und Allegorie gekennzeichneten Geschichte, die nach Boulard (2000) als exotische Erzählung einzustufen wäre, handelt es sich um den detaillierten Traumbericht eines Mannes, der in seinem Traum zwei loci amoeni besuchte: den ,Jardin de la beauté‘ (Garten der Schönheit) und den ,Jardin Je ne scais quoi` (Garten des gewissen Etwas). Zuerst ging er in den ,Garten der Schönheit‘, den er allein schon aufgrund seiner Bezeichnung anziehender fand. Im diesem wunderbar gestalteten Garten traf er eine auf einem Thron sitzende Frau an, die absolute Schönheit besaß und die er und eine Schar anderer Männer voller Bewunderung betrachteten. Schon nach einer kurzen Weile jedoch langweilte ihn (wie auch die anderen Männer, die in den Garten gekommen waren) die schöne Frau, die nie auch nur eine Miene verzog, geschweige denn Worte von sich gab. Nach diesem Erlebnis spazierte der Träumende (wie die anderen Männer zuvor) in den ,Garten des gewissen Etwas', der im Vergleich zum ,Garten der Schönheit‘ ungeordnet erschien und in dem viele Frauen emsig arbeiteten. Fasziniert von dem Trubel und den Frauengestalten an diesem Ort, hörte er plötzlich eine Frauenstimme. Er rief sogleich nach der Besitzerin dieser Stimme, die lediglich antwortete, sie befände sich in allen und allem des Gartens auch der Architektur, den Objekten und den Pflanzen:

Ne me cherchez point sous une forme ; j'en ai mille, \& pas une de fixe : voilà pourquoi on me voit sans me connoître, sans pouvoir ni me saisir ni me définir : on me perd de vue en me voyant, on me sent, \& on ne me démêle pas ; enfin vous me voyez, \& vous me cherchez, \& vous ne me trouverez jamais autrement : aussi ne serez-vous jamais las de me voir. (CdP 2, 282)

Die Oberflächlichkeit der Schönen wird hier der Tiefgründigkeit des Unbekannten im begehbaren Projektionsraum des Gartens gegenübergestellt, der die aufklärerischen Ideale veranschaulicht (cf. Niedermeier 2015, 323): Eine schöne Frau ohne Geist (esprit) langweile irgendwann, während eine Frau, die mehr zu bieten habe als nur ein hübsches Antlitz, ihr Gegenüber beziehungsweise ihren Ehemann auch noch nach längerer Zeit fasziniere. Was einen charakterfesten Menschen, in diesem Kontext folglich Mann, demnach wirklich bewege, sei das Überraschungsmoment, das über die fiktive Erzählung indirekt jeder Frau nahegelegt wird und womit auch hier letztendlich die Ausrichtung jeder Frau auf den Mann propagiert wird.

Das fünfte Blatt, ab dem jede Nummer Untertitel erhält und in kürzere Abschnitte gegliedert ist, besteht aus zwei übertitelten Abhandlungen, die sich zwei stereotypen Frauenbildern der Zeit in Form von mehreren Charakterporträts widmen. Diese sind allerdings nicht als solche codiert und hinterfragen die Frauenbilder zuerst eher indirekt, in der zweiten schließlich direkt: Sie beinhalten sowohl die Réflexions sur les Coquettes als auch Gedanken zu Des Femmes mariées, wobei beide Texte im gleichen 
Maße Männerbilder aufweisen. Durch ihre Aneinanderreihung sind sie in Opposition zueinander zu lesen. Situierte man die beiden angekündigten Frauenbilder auf einer zweipoligen Skala zum gesellschaftlichen Frauenbild der Zeit, so wäre das Bild der Koketten am Ende der negativen Seite und das der verheirateten Frau am Ende der positiven Seite zu verorten. Auf den ersten Blick erscheint es also, als ob das fünfte Blatt erst das negative und anschließend das positive Frauenbild nachzeichnen würde. Auf den zweiten Blick jedoch wird ersichtlich, dass auch der Abschnitt über die verheirateten Frauen von, weiblicher' Koketterie in der Ehe handelt und diese auch hier als Laster anprangert.

Anders als in Van Effens 70. Bagatelle, in der die unterschiedlichen Frauentypen nur durch ihr äußerlich wahrnehmbares Verhalten in Relation zur Männerwelt charakterisiert worden sind, wird bei Marivaux die kokette Frau auch aus der Innenperspektive präsentiert, wobei hier nicht mehr verschiedene Grade an Koketterie unterschieden werden. Nach einem Einleitungsstatement erörtert der Verfasser in den Réflexions sur les Coquettes anhand zweier Frauenfiguren die kompetitiven Verhaltensweisen von zwei Koketten. In deduktiver Ableitung belegt er folglich seine allgemeine Behauptung anhand zweier spezifischer Beispiele. Er imaginiert dabei auch die innere Gedankenwelt der beiden Rivalinnen, denen es ausschließlich darum geht, schöner und begehrenswerter als die jeweils andere zu wirken. Bemerkenswert ist in diesem Blatt die Tatsache, dass sich der Verfasser die Gedanken der beiden Frauen lediglich vorstellt, diese für das Publikum allerdings als faktische Innenperspektive erscheinen, da die Gedanken nach einer kurzen Einleitung als direkte Rede wiedergegeben werden.

Nach einer Reihe von Metakommentaren lenkt der Verfasser seine Reflexionen schließlich auf die Gesellschaft, die ein solch kokettes Verhalten hervorbringe: „La Coquette ne sçait que plaire, \& ne sçait pas aimer ; \& voilà aussi pourquoi on l'aime tant. Quand une femme nous [les hommes] aime autant qu'elle nous plait, pour l'ordinaire, elle ne nous plait pas longtems“ (CdP 5, 336-337). Das Thema der Gartenallegorie aus dem zweiten Blatt tritt hier in einer erkennbaren Variation zutage. Neu ist jedoch, dass sich der Verfasser am Ende dieses Abschnitts an die (männlichen) Leser wendet und an diese appelliert, koketten Frauen zu widerstehen: „Il seroit pourtant beau qu'un homme en pareil cas résistât ; encore seroit-ce du beau qui choqueroit la vue“ (CdP 5, 339).

Im Abschnitt Des Femmes mariées, der ebenfalls mit einem einleitenden allgemeinen Statement beginnt, hinterfragt der Verfasser - wie bereits in der ersten Nummer direkt die gesellschaftlichen Verhaltenspraktiken für Frauen und Männer, indem er in jedem Absatz metareflexive Interrogativsätze einstreut und diese danach in der Rolle des jeweilig befragten Geschlechts beantwortet. Vermittels der kontrastiven Darstellung einer Verhaltensweise - hier geht es um außereheliche Liebesabenteuer (also nicht um außereheliche Liebe, sondern um eheliche Untreue) - erörtert er die gesellschaftlichen Folgen der Koketterie für Frauen beziehungsweise der Libertinage für Männer und deckt dabei in jedem Absatz aufs Neue die für Frauen und Männer unterschiedlich geltenden gesellschaftlichen Normen auf. Dies endet mit dem Fazit, dass Frauen für ihre Liebesaffären bestraft, Männer für dasselbe Laster als Helden gefeiert würden: „Son libertinage, ou plutôt sa galanterie le rend illustre ; elle en fait un Heros qu'on est curieux de voir" (CdP 5, 343).

Daraufhin geht der Verfasser auf die paradoxe ,Verteilung ' der Laster für Männer und der Tugenden für Frauen ein, aus der heraus Frauen ein verführerisches, schel- 
misches und heuchlerisches Verhalten als lasterhaft angekreidet werde, womit er das immer mehr als komplementär angenommene Geschlechterverhältnis als diskursives gesellschaftliches Konstrukt zu entlarven versucht. In einer scharfen Replik aus weiblicher Perspektive führt er das Verhalten der Frauen auf das autoritäre Macht- und Abhängigkeitsverhältnis (le fruit de la dépendance) zwischen den Geschlechtern zurück und lässt die Koketterie als einzigen möglichen selbstbestimmten Ausweg erscheinen:

Nous [les femmes] sommes méchantes, dites-vous [les hommes] ? Osez-vous nous le reprocher? Dans la triste privation de toute autorité, où vous nous tenez; de tout exercice, qui nous occupe ; de tout moyen de nous faire craindre, comme on vous craint ; n'a-t-il pas fallu qu'à force d'esprit \& d'industrie, nous nous dédommageassions des torts que nous fait votre tyrannie ? Ne sommes-nous pas vos prisonnieres ; \& n'êtes-vous pas nos geoliers ? Dans cet état, que nous reste-t-il, que la ruse ? Que nous reste-t-il, qu'un courage impuissant, que vous réduisez à la honteuse nécessité de devenir finesse ? Notre malice n'est que le fruit de la dépendance où nous sommes. Notre Coquetterie fait tout notre bien. Nous n'avons point d'autre fortune que de trouver grace devant vos yeux. Nos propres parens ne se défont de nous qu'à ce prix-là ; il faut vous plaire, ou vieillir ignorées dans leurs maisons : nous n'échappons à votre oubli, à vos mépris, que par ce moyen ; [...]. (CdP 5, 345-346)

In dieser anklagenden Passage entlarvt der Verfasser die patriarchale Gesellschaftsordnung, in der Frauen von Männern abhängig sind, was an die Argumentation in der fünf Jahre zuvor erschienenen Spectatrice denken lässt. Demnach bleibe den Frauen als einzige Möglichkeit zur Rückgewinnung eines gewissen Maßes an Selbstbestimmtheit die Koketterie. Die kausale Argumentation, also die Herleitung der Verhaltensweisen von Frauen aus dem Verhaltenskodex von Männern, schließt an Poulain de la Barre an, der die schwächere Rolle der Frau innerhalb der Gesellschaft mit den Gesetzen der Männer erklärte.

Marivaux, der unter den Forscher*innen für seine proto-feministischen Ansichten in vielen seiner Werke bekannt ist (cf. Mason 1979; Gaudry-Hudson 1991, 36-37), tritt hier jedoch nicht als Vorkämpfer von Frauenrechten in einer gleichberechtigten Gesellschaft auf. Vielmehr untersucht er auf spielerische Art, unter dem Deckmantel einer Verfasserfiktion, die bestehenden gesellschaftlichen Werte, Normen und Praktiken auf ihre Validität und ihre Artifizialität hin. Ohne also Ratschläge für ein verändertes, egalitäres Miteinander zu geben, überlässt er es den Rezipient*innen selbst, geeignete Konsequenzen aus seinen Beobachtungen zu ziehen.

\subsubsection{La Spectatrice danoise (1748-50) - die vermeintliche Proto-Feministin}

Die Spectatrice danoise kommt zwischen September 1748 und April 1750 wöchentlich in Kopenhagen heraus. Von ihren 29 als ,Amusements“ (Vergnügungen, Späße) bezeichneten Nummern ${ }^{75}$ werfen $17,2 \%$ ein dezidiertes Frauenbild auf. Zu den fünf im

75 Es muss hier darauf hingewiesen werden, dass die Spectatrice danoise aus zwei Bänden besteht (cf. Lauriol 1999), wobei der erste ebenfalls in einen ersten Teil (Amusements 1-29) und einen zweiten Teil (Amusements 30-60) unterteilt ist. Zum Zeitpunkt der quantitativen 
Repositorium mit Frauenbild ausgewiesenen Nummern zählen die Amusements I, IX, ${ }^{76}$ XV, XIX, und XXVII, wobei das letzte Amusement (XXVII) mit einem Männerbild zusammenfällt.

Ebenso wie bei der 20 Jahre früher entstandenen Spectatrice verweist der feminisierte Titel der Zeitschrift auf eine weibliche Verfassungsinstanz aus Dänemark. Der volle Titel La Spectatrice danoise, ou l'Aspasie moderne, ouvrage hebdomadaire führt eine Frau namens Aspasie als ihre Verfasserin an, was auf mehrere Gründe zurückgeführt werden kann: (1) Aspasie ist eine bekannte Frauengestalt der Antike, ${ }^{77}$ die über die Jahrhunderte hinweg immer wieder in Kunst und Literatur rezipiert wird. ${ }^{78}$ (2) Auch wurde bereits in Addisons und Steeles 1713 publiziertem Guardian (Nr. 2, 14) Lady Elizabeth Hastings' vorbildhaftes Verhalten mit jenem von Aspasie verglichen und in die französische Übersetzung von Van Effen im Mentor moderne (1723) mitübernommen, wobei hier von einer klugen, verwitweten Aspasie die Rede ist:

Aspasie est une Dame, qui a beaucoup de génie, \& une grande Elevation dans l'esprit dans les sentimens : elle a passé tout le tems de son veuvage dans une [sic] retrait convenable, qui fait honneur à son Epoux defunt, qui donne de la réputation à ses Enfans. Comme elle en a plusieurs de l'un \& de l'autre sexe en âge de se marier, cette considération lui attire beaucoup de visites ; mais es [sic] vertus, \& les agrémens de sa conversation, lui en attirent encore d'avantage. Il n'y a presque point de circonstance de la vie humaine qui n'entre dans la vie de cette Dame considerée dans toutes ces differentes relations ; \&, par conséquent, sa conduite me fournira une infinité d'incidents, dont le public pourra tirer les préceptes les plus utiles. (Le Mentor Moderne II, 18)

Analyse war lediglich der erste Teil (i. e. Nummern 1-29) des ersten Bandes aus dem Jahr 1749 im Repositorium zugänglich, dessen Teile bereits Aufschluss über die Geschlechterdiskurse innerhalb der Zeitschrift ermöglichen.

76 Im 9. (und im 5.) Amusement wird das einzige Mal die weibliche Form ,lectrices‘ für die Publikumsanrede innerhalb der im Repositorium verfügbaren französischsprachigen Moralischen Wochenschriften verwendet (Stand: Januar 2019).

77 Aspasia von Milet ist eine Zeitgenossin von Sokrates, die Mitte des 4. Jahrhunderts v. Chr. wirkt und als Fremde nach Athen kommt. Da die Informationen über ihr Leben nicht gesichert sind, findet sich ein ambivalentes Bild von Aspasia in der Geschichte: entweder als Kurtisane und Prostituierte oder als gute Ehefrau. Ihre vermeintliche Tätigkeit als angesehene Hetäre lässt Rückschlüsse auf ihren hohen Bildungsstatus und ihre Unabhängigkeit sowie ihren Status als unverheiratete Frau im antiken Athen zu. Als Lebensgefährtin des Staatsoberhauptes Perikles fungiert sie als seine Beraterin und führt in ihrem Salon philosophische Konversationen mit Sokrates und Platon (cf. Henry 1995).

78 „Her presence in medallion books, in Tarabotti's defense of women, and in the influential Historia Mulierum Philosopharum would have made Aspasia known (if not well known) to literate Europeans interested in women's history. Dictionaries and encyclopedias also mentioned her; these were heavily dependent on Plutarch, with ,spice' from Athenaeus [kursiv im Orig.]" (Henry 1995, 89). Eine Verserzählung über Aspasia findet sich auch im Deutschen Merkur (cf. Wieland 1773). Im Jahr 1789 komponiert André Grétry (1741-1813) die Oper Aspasie und Marie-Geneviève Bouliar (1763?-1825) porträtiert sich 1794 selbst als Aspasia. 
(3) Da der gesellschaftliche Diskurs der Zeit insbesondere die tugendhaften Seiten der antiken Aspasia gegenwärtig hält, eignet sie sich als nachahmenswerte Identifikationsfigur für das weibliche Publikum. Welche Absichten die Produzentin der Spectatrice danoise jedoch genau mit ihrem Pseudonym hegt, verrät sie selbst gegen Mitte der ersten Nummer. Zuvor sei noch darauf hingewiesen, dass die weibliche Verfassungsinstanz vom Publikum alsbald als fiktiv erkannt und die Spectatrice danoise dem französischen Schriftsteller Laurent Angliviel de La Beaumelle (1726-1773) zugeordnet wird (cf. Lauriol 1999), ${ }^{79}$ der hier eine „,narrative Strategie der literarischen Travestie“ (Gronemann 2013, 156) beziehungsweise der ,Transsexuation` anwendet:

[L]e procédé, auquel Gérard Genette donne le nom de 'transexuation', est également utilisé par certains imitateurs de Steele et d'Addison, tel l'auteur de La Spectatrice parue en 1728 et 1729. Une quinzaine d'années plus tard, La Beaumelle choisira même de combiner changement de sexe et de nationalité dans La Spectatrice danoise [kursiv im Orig.]. (Lévrier 2007, 154)

Der narrativen Strategie der ,literarischen Travestie', die sich nachweislich intentional zumindest auch in der spanischen Pensadora gaditana (1763-1764) wiederfindet, liegt die Annahme zugrunde, Frauen hätten gegenüber anderen Frauen mehr Überzeugungskraft, auch wenn die Inhalte der Spectatrice danoise nicht ausschließlich, aber doch mehrheitlich an ein weibliches Publikum gerichtet sind. Darüber hinaus ist die Strategie der Transsexuation als eine Strategie der Publikumsbindung und Absatzsteigerung $\mathrm{zu}$ verstehen. Nicht nur außerhalb der Zeitschrift, sondern auch innerhalb wird über die Mutmaßungen in Bezug auf die geschlechtliche und nationale Identität von Aspasie gesprochen. Insbesondere das Rätsel um Aspasies Geschlechtsidentität trägt dazu bei, dass die neugierigen Leser*innen vermehrt über den Schreibstil der Verfasserin und über das von ihr vermittelte Wissen nach Indikationen hinsichtlich ihres biologischen Geschlechts suchen. In der 9. Nummer wird die Vermutung, die Verfasserin sei ein Mann, im Brief von Monsieur Fursman, dem Empfänger und Vermittler von Aspasies Leser*innenbriefen, kundgetan. Dieser ist bereits sichtlich verärgert darüber, dass ihm mittlerweile so viele Menschen auflauern, nur um etwas über die Geschlechtsidentität der Verfasserin herauszufinden: „Elle [une lectrice] n'est pas la seule, qui vous métamorphose en Homme. Presque toutes vos Lectrices ont donné dans cette idée. Je ne puis pas faire deux pas en ville, que je ne sois environné de curieux, Je crains, qu'on ne me suive pour découvrir mes liaisons, [...] [kursiv im Orig.]“ (LaSd IX, 66).

Die gängigen - und im Repositorium mit Markups hinterlegten - narrativen Textsorten sind in den fünf mit Frauenbild ausgezeichneten Nummern der Spectatrice danoise kaum vorzufinden. $\mathrm{Zu}$ diesen zählen einige metatextuelle Kommentare (I, IX, XIX, XXVII) und die beinahe jede Nummer zierenden initialen Zitate, die den nachfolgenden Inhalt pointiert vermitteln (I, IX, XV, XIX). Daneben sind in den fünf Amusements lediglich zwei Leser*innenbriefe (IX, XIX), zwei allgemeine Erzählungen (IX, XXVII), ein Dialog (XXVII) sowie das Selbstporträt der Verfasserin (I) eingestreut.

79 Zum französischen Einfluss auf die dänische Literatur im 17. und 18. Jahrhundert siehe Eaton (1931). 
Thematisch fokussieren die angetroffenen Nummern einige wenige Sujets: Sie behandeln die Rolle der Frau in der Gesellschaft, die insbesondere in der Ehe verortet wird, sowie ihre Bildung(sfähigkeit). Auch wenn die Verfasserin selbst am Ende des 9. Amusements Themenvielfalt und assoziative Schreibweise als Besonderheit ihrer Zeitschrift preist, so gesteht sie im 27. Amusement die thematische Gleichförmigkeit ein: „J'aurois pu le [le récit] rendre plus intéressant \& plus varié, mais j'ai mieux aimé m'attacher au vrai“" (LaSd 27, 223). Zwar verweist die Verfasserin mit dem Pronomen ,le‘ hier auf die einförmige nummernfüllende Geschichte (récit), die sie gerade erzählt hat, die Aussage trifft aber ebenso auf die geringe inhaltliche Abwechslung innerhalb ihrer Wochenschrift zu. Beide - die thematische Uniformität auf Mikroebene (Einzelnummer) und auf Makroebene (Zeitschrift) - werden darauf zurückgeführt, dass sie sich an die Wahrheit halte (attacher au vrai) und dies schlicht nicht mehr Abwechslung zulasse. Aspasie bleibt mithin über ihre Zeitschrift hinweg innerhalb der (thematischen) Grenzen der weiblichen Sphäre verhaftet, auch wenn sie - insbesondere in ihrer ersten Nummer - emanzipatorische Töne laut werden lässt, die im Folgenden thematisiert werden.

Wie bereits Madame la Spectatrice in La Spectatrice beginnt auch Aspasie ihre Zeitschrift damit, ihre Geschlechtsidentität von Anfang an bewusst zu thematisieren und sich für ihr Schreiben zu rechtfertigen. So lautet bereits das Motto ihres ersten Amusements, das - wie sie selbst gleich daraufhin bemerkt - aus dem Munde eines Mannes stamme: „Femmes ! quand Vous pensez, Vous pensez mieux que nous [kursiv im Orig.]“ (LaSd I, 1). Entgegen den so antizipierten Vermutungen des Publikums will sie sich nach diesem Eingangsstatement allerdings nicht mit der Beweihräucherung der Leistungen ihrer Geschlechtsgenossinnen aufhalten, wie es bei den Verteidiger*innen der Querelles des sexes in den Frauenapologien oft der Fall ist, sondern sie legt ihre eigenen Beweggründe für das Verfassen der Zeitschrift dar. Diese seien nicht inhaltlicher, sondern vielmehr geschlechtlicher Natur. Aus Protest will sie schreiben, weil oder gerade obwohl sie eine Frau ist: „Le Public sera sans doute surpris de voir une femme s'ériger en Auteur. Mais pourquoi“ (LaSd I, 1)? Dass es sich in den Augen der Gesellschaft um eine Dreistigkeit ihrerseits handle, sich als Autorin etablieren zu wollen, lässt sich nicht nur im Ausdruck ,s'ériger en Auteur' (sich als Autor aufspielen) ablesen, sondern auch im weiteren Verlauf ihrer Argumentation, in der sie gleichzeitig die stereotypen Frauenbilder ihrer Zeit aufgreift und sich selbst davon abgrenzt allerdings ohne diese in irgendeiner Weise zu hinterfragen.

So zählt die Verfasserin eine Palette an Argumenten auf, warum sie sich als Frau dem Schreiben anheimgibt, anstatt sich Haushaltstätigkeiten wie Sticken oder Teppichknüpfen zu widmen. Im selben Augenblick beklagt sie sich über die Männerwelt (un certain monde), die ihr zwar erlaube, sich zu bilden, aber nicht zu schreiben: „Vous pouvez étudier, tant quil < sic> vous plaira; mais écrire, c'est trop“ (LaSd I, 2). Danach führt sie, wie in den traditionellen Frauenapologien üblich, dann doch zumindest namentlich bekannte Frauen aus Frankreich (z. B. Mademoiselle de Scudéry ${ }^{80}$ oder Mar-

80 Madeleine de Scudéry (1607-1701) ist insbesondere für ihren Roman Artamène ou le Grand Cyrus (1649-1653) bekannt, der in zehn Bänden erschien und mit seinen 13.000 Seiten als längster Roman der französischen Literatur gilt. 
quise du Châtelet), ${ }^{81}$ Deutschland (Luise Gottsched), ${ }^{82}$ England (Elizabeth Carter) ${ }^{83}$ und Dänemark (Birgitte Thott ${ }^{84}$ an, die vor ihr den Schritt von der passiven Lektüre hin zum aktiven Schreibakt gewagt haben, und beweist somit bereits ihr umfangreiches Wissen. Allerdings bestreitet sie im selben ,Schreibzug', dass sie selbst so hoch hinauswolle wie die genannten Frauen, und bedient sich hier des geläufigen Bescheidenheitstopos. Ebensowenig wolle sie mit ihren männlichen Spectator-Vorgängern und -Nachfolgern konkurrieren und unterstreicht, dass sie das ,plaîre“ (Unterhaltung) ihrer Schrift über das ,instruire‘ (Belehrung) stelle. Auf semantischer Ebene stützt die Übertitelung der einzelnen Nummern mit ,Amusements` (Vergnügungen, Späße) die unterhaltende Absicht der Zeitschrift sowie die angebliche Leichtigkeit und Harmlosigkeit der Inhalte.

Für die Vermittlung ihrer unterhaltenden Inhalte verwendet Aspasie ferner einen einfachen, leicht durchschaubaren Satzbau mit eher kurzen Sätzen, womit Angliviel de La Beaumelle das Konstrukt der weiblichen Verfasserin zu untermauern sucht. Darüber hinaus versichert Aspasie dem Publikum, dass sie die Leserinnen - denen sie ein geringeres $\mathrm{Ma}$ an intellektuellen Kapazitäten unterstellt - nicht mit ihren Inhalten überfordern wolle (rien qui soit audessus de la portée d'une femme). Sie strebe mit ihrer Wochenschrift nur danach, über Sitten und Gebräuche (moral) oder scherzhaftes Geplänkel (badin) zu schreiben: „mais des bagatelles sérieuses, des réfléxions amusantes, des feüilles qui ne contiennent que du moral ou du badin, c'est-à-dire, rien qui soit audessus de la portée d'une femme, [...]“" (LaSd I, 2-3). Dass die Verfasserin mit ihrer Zeitschrift tatsächlich auch eine belehrende Wirkung verfolgt, lässt sie erst später im 9. Amusement erkennen. Ihrer Meinung nach sei die Ridikülisierung das einzige Mittel, mit dem man Menschen zu besserem Verhalten animieren könne, auch wenn manche meinen, es wäre ein Verbrechen (crime), sich über andere Menschen lustig zu machen: „Quelqu'un me disoit, qu'il y avoit du crime à s'en amuser ; cela seroit peutêtre vrai, s'il y avoit de la possibilité à corriger le genre humain“ (LaSd IX, 70). Insbesondere an den Männern will sie kein gutes Haar lassen. Solange Männer Menschen seien - sie zählt Narren, Schmeichler, Geizige, Ehrgeizige, Verleumder, Frömmler und Feiglinge auf -, werde sie immer etwas zu sagen haben, um diese lächerlich zu machen: „Tant que les hommes seront Hommes, c'est-à-dire, Fourbes, Flatteurs, Avares, Ambitieux, Médisans, Dévots, Laches, mon imagination ne sera point à sec. J'aurai toûjours quelque chose à dire pour les ridiculiser" (LaSd IX, 71). Hiernach stellt sie

81 Émilie du Châtelet (1706-1749), Mathematikerin, Physikerin, Philosophin und Übersetzerin. Sie ist mit Voltaire liiert und nach dem Ende ihrer Beziehung schreibt sie wahrscheinlich 1747 den Discours sur le bonheur, der 1779 posthum veröffentlicht und von Robert Mauzi 1961 neu editiert wird (cf. Châtelet 1961, LXXIV, LXXXIII). Für neuere Forschungen zu Châtelet siehe Hagengruber/Hecht (2019) Émilie Du Châtelet und die deutsche Aufklärung.

82 Luise Gottsched (1713-1762) bringt 1739 mit der Wochenschrift Der Zuschauer die erste vollständige deutsche Spectator-Übersetzung heraus (cf. Rau 1980, 171).

83 Elizabeth Carter (1717-1806), englische Schriftstellerin und Übersetzerin, Mitglied der Frauenvereinigung Blue Stockings um Elizabeth Montagu (1718-1800), die besonderen Wert auf Bildung und gegenseitige Unterstützung legt.

84 Birgitte Thott (1610-1662), polyglotte Schriftstellerin und Gelehrte, die vor allem für die Übersetzung von Seneca ins Dänische bekannt ist (cf. N.N. 2012). 
sich direkt in eine Linie mit dem lachenden Philosophen Demokrit (ca. 460-ca. 371 v. Chr.), der seinem Publikum ebenfalls Scherze, die immer auch ein Fünkchen Wahrheit beinhalteten, auftischte: „Outre que le Rôle de Démocrite est plus assorti à mon humeur, \& qui n'est pas asservi à la sienne ? le Badinage, assaisonné de sel, est, ce semble, plus propre à nous corriger, que ne l'est un sérieux effarouchant" (LaSd IX, 71-72).

In der ersten Nummer bekräftigt die Verfasserin dem Publikum allerdings durch eine argumentative Schreibstrategie, den gesellschaftlichen Praktiken und literarischen Konventionen ihrer Geschlechtsgenossinnen zu entsprechen. Denn insbesondere in gelehrten Kreisen (République des Lettres) sage man Frauen gerne einen eigenen Schreib- und Sprachstil nach, den man ihnen zudem gerne nachsehe (passer des négligences), woraus sich wiederum gewisse Privilegien für Autorinnen ergäben:

Dans la République des Lettres nous avons, de grands priviléges. On nous passe bien des négligences, bien des phrases louches, bien des raisonnemens gauches. Une vivacité saillante, des idées tirant sur le nouveau, des réfléxions plus ingénieuses que solides, quelques traits brillans, de la naïveté dans le récit, de l'enjoûment dans le style, de la finesse dans l'expression, voilà à peu près ce qu'on éxige de nous. Nous écrivons admirablement, si nous atteignons jusque-là ; nous écrivons divinement, si nous montons plus haut.

Il y a plus : Ce, qui ne seroit point gouté dans l'ouvrage d'un homme, fait beauté dans l'ouvrage d'une femme, \& ce, qui plait simplement dans l'un, charme, ravit, enchante dans l'autre ; voilà bien des prérogatives. (LaSd I, 6-7)

Ebenfalls noch im ersten Amusement erwähnt Aspasie jene dänischen Epochen, in denen Frauen sich geistig betätigen konnten, und beklagt die ,heutigen' Gesellschaftsnormen, die es Frauen nicht mehr, wie den dänischen Großmüttern, erlaubten, mit ihren Ehemännern auf der gleichen intellektuellen Stufe zu stehen: „La Lecture, les occupations qui tendent à orner l'esprit sont entiérement tombées“ (LaSd I, 3). Stattdessen seien die heutigen Däninnen zu langweiligen und unnützen gesellschaftlichen Verpflichtungen verdammt: „Mon séxe a dégénéré en Dannemarc ; Il étoit jadis, ou du moins paroissoit être plus spirituel : Poësie, Eloquence, Théologie, tout étoit du ressort de nos Grands-Méres. Elles partageoient avec leurs maris les plaisirs de l'amour \& la gloire des Lettres“ (LaSd I, 3). Umso weniger verwundert Aspasies gegen Ende der ersten Nummer vorgebrachtes Argument, mit ihrem einzig wahren Talent (dem Schreiben), ihrer dänischen Heimat nützlich sein zu wollen: „Me faire imprimer, n'est pas ma folie ; mais mon foible est de vouloir être utile à ma Patrie, que je ne puis servir que de ma plume“ (LaSd I, 7). Denn wenn sie sich schon nicht durch die Übernahme traditioneller Frauenrollen für ihre Gesellschaft nützlich erweise, so wolle sie mit ihrem Schreiben zumindest dem Gemeinwohl Dänemarks dienen.

Um den (willkürlichen) Zusammenhang von Geschlecht und Schreibtätigkeit (und Schreibfähigkeit) zu hinterfragen, kommt Aspasie gegen Mitte der ersten Nummer auf ihr Pseudonym zu sprechen, das sie für die Herausgabe ihrer Zeitschrift gewählt hat. Erneut nimmt sie mögliche Mutmaßungen des Publikums darüber vorweg, nur um sich anschließend von der griechischen Frauengestalt abzugrenzen und hernach allen Leser*innen nun doch eine erste Lektion zu erteilen. Subtiler als Madame la Spectatrice, die ihr Publikum explizit fragt: „,Q]u'importe de quel sexe soit l'Auteur des pensées ?“ (LaS XII, 281), deckt Aspasie hier durch die Aneinanderreihung mehrerer Interroga- 
tivsätze die Willkürlichkeit der Verbindung eines Namens - und in weiterer Folge eines Geschlechts - mit einem Verhalten auf:

Vous m'accusez de Coquetterie ; mais, je vous prie, depuis quand la ressemblance des noms établit-elle une ressemblance de mœurs? Qui vous a dit, que la vertu d'Aspasie ne fût point attaquée aussi calomnieusement que la mienne? Et puis, quand vous diriez vrai, Coquetter un peu, empêche-t-il de bien écrire ? (LaSd I, 4)

Im letzten Absatz offenbart sich schließlich doch das (vorgeblich) eigentliche Ziel der Zeitschrift. Sie will Frauen, die unter dem tyrannischen Joch ihrer Ehemänner (le joug tyrannique) leiden, durch nützliche Bildung aus dem ehelichen Macht- und Abhängigkeitsverhältnis herausführen, das sie mit Sklaverei (esclavage) gleichsetzt. Zuvor jedoch gibt sie noch an, wie glücklich sie selbst darüber wäre, wenn auch mehr Frauen an ihrer Zeitschrift mitschreiben würden. Sie hinterfragt einerseits, ob Frauen nie all ihre intellektuellen Fähigkeiten (talens) kennen würden, und andererseits, ob Frauen dauerhaft nur für das Schönsein und nie für ihre Gedanken und Überlegungen geachtet werden wollen:

Que je serois satisfaite, si mon séxe vouloit avoir part à mon travail ! Ne connoitra-t-il jamais tous ses talens ? préférera-t-il toûjours le mince mérite de plaîre à celui de penser \& de réfléchir? Nous avons tant d'empire sur l'esprit des hommes, qu'il nous seroit aisé de sécoüer le joug tyrannique qu'ils nous ont imposé. Mais le malheur est, que nous ne sortirons jamais d'esclavage, tant que nous bornerons notre étude à l'art de bien monter une coiffe, de décider auec $<$ sic $>$ goût d'une étoffe, de babiller éternellement sur une Juppe. C'est une manie, que j'aurois bien envie de détruire. (LaSd I, 8)

Insgesamt zeigt sich die Verfasserin in der ersten Nummer als selbstbewusste, emanzipierte Frau, die nicht für das Familienleben, sondern vielmehr für die intellektuelle Arbeit geschaffen sei: „Le Ciel ne m'a point accordé les sublimes talens, qui font une héroïne dans la noble science du Ménage“ (LaSd I, 1). Da Gott sie mit intellektuellen Fähigkeiten (talens) ausgestattet habe, beabsichtige sie wie andere gelehrte Frauen vor ihr, mit ihrer Zeitschrift für die Emanzipation der Frauen zu kämpfen. Wie sich jedoch im weiteren Verlauf der Zeitschrift herausstellen wird, handelt es sich hierbei lediglich um eine Strategie der Publikumsgewinnung und -bindung. Mit dieser Argumentation aus der ersten Nummer erreicht sie ein ganz bestimmtes Publikum, dem eine bestimmte Erwartungshaltung zu eigen ist. Obwohl Aspasie in der ersten Nummer eine proto-feministische Haltung an den Tag legt, setzt sie sich in den späteren Amusements für die Rolle der Ehefrau an der Seite des Mannes ein und macht (insbesondere im Amusement VII) die Frau für das eheliche Glück verantwortlich. Das Geschlechterverständnis, das die Verfasserin im weiteren Verlauf ihrer Schrift vertritt, ist somit ein komplementäres, ${ }^{85}$ auch wenn sie das Verhältnis von Frau und Mann, wie aus den

85 Das komplementär angenommene Geschlechterverhältnis der fiktiven Verfasserin lässt sich ebenfalls im Amusement XV auffinden, wenn sie ihre Leser*innen dazu anhält, ein nur aus Männern bestehendes Volk zu imaginieren, welches sie sich selbst mangels des 
obigen Beispielen hervorgeht, bereits als ein künstliches und hierarchisches Machtverhältnis ausmacht, ohne allerdings die Legitimität seiner Artifizialität anzuzweifeln.

Die nachfolgenden vier Amusements, die mit Frauenbild beziehungsweise Männerbild ausgezeichnet sind, tragen zwar keine Titel, im Inhaltsverzeichnis der konsultierten Bandausgabe von 1749 sind die einzelnen Amusements jedoch mit einer Betitelung aufgelistet, die auf ihre jeweiligen Inhalte schließen lässt: IX. Le Lecteur depaîsé, XV. Le Mariage, XIX. Apologie des Actrices, XXVII. Histoire Anglaise.

Das 9. Amusement beschäftigt sich aus der Sicht von Aspasie mit den Reaktionen des Publikums, das die unterschiedlichsten Spekulationen über ihre Person anstellt, vor allem hinsichtlich ihres biologischen Geschlechts, aber auch ihrer ,Nationalität' oder ihres Berufes. Viele Leser*innen glauben, dass die Zeitschrift von einem Mann oder sogar einem Pfarrer geschrieben werde, da der Stil zu ausgefeilt sei und zu viel Wissen in den Diskursen stecke: „Quelques-uns de mes Lecteurs me trouvent (c'est ce que je leur ai oüi dire) trop de sçavoir pour une femme, \& d'autres, trop pour une fille, de sorte que, sur ce pié-là, je ne suis ni fille ni femme“ (LaSd IX, 70). Offensichtlich amüsiert von den Mutmaßungen über ihre Person, rühmt sie sich damit, nachfolgenden Generationen von Frauen den Weg geebnet zu haben, damit diese selbst Schriftstellerinnen werden können: „Au moins pourrai-je me dire, que j’ai tenté de détruire le Préjugé où l'on est à l'égard de mes charmantes compatriotes, \& que je leur ai fraïé un chemin, dans lequel quelques-unes d'entre elles pourront marcher avec plus de succès que moi“" (LaSd IX, 70).

Das Amusement XV beschäftigt sich mit der Ehe. Darin unternimmt Aspasie eine allegorische Wanderung ins ,Land der Ehe' (pays du mariage), die sie sich wie eine Bergbesteigung mit freundlichen Wegen (avenues riantes), aber insgesamt auf dem Weg zum Gipfel des Glücks nicht besonders angenehm (désagreable) vorstellt:

Je me le [le pays du mariage] figure comme une Montagne, dont les avenuës sont riantes, mais dont le séjour est désagréable. La félicité réside au sommet; au pied l'on trouve la volupté, qu'on prend pour elle. Au milieu le dégout, plus loin le chagrin \& le repentir ; mais un peu plus haut l'espérance, qui malheureusement n'est visible, qu'à un petit nombre de yeux perçans. (LaSd XV, 113)

Mit dieser allegorischen Beschreibung der Ehe packt die Verfasserin den abstakten Ehebegriff in ein rational fassbares Bild. Während sie am Anfang ein eher idyllisches Bild der Ehe und des Eheglücks mit ewig glücklichen und sich liebenden Eheleuten zeichnet („Les deux Epoux, toûjours Amans, sont par conséquent toûjours heureux“ [LaSd XV, 114]), wird diese Idylle durch ihren Metakommentar zunichte gemacht, in dem sie danach fragt, ob es jemals ein so glückliches Ehepaar gegeben habe: „Mais n'est-ce point une belle chimère, que je viens de décrire ? Quel couple fortuné l'a réalisée“" (LaSd XV, 114)?

Die gesamte 15. Nummer erhält durch die verwendeten Stilmittel (Anaphern, Metakommentare, direkte Anrede der Leser*innen in Form von Interrogativ- oder Exklamativsätzen, parallele Strukturen) einen appellativen Charakter, der insgesamt eher

ausgleichenden (contrebalancer) weiblichen Charakters als Hölle (enfer) vorstellt und auf das weiter hinten in der Analyse näher eingegangen wird. 
gegen die Institution der Ehe als für diese spricht. Im Anschluss an die idyllische Beschreibung folgen vier törichte Heiratsgründe. Die Frage lautet also: Was bedeutet es, eine Ehe einzugehen?

Qu'est-ce donc que se marier? C'est en suivant le penchant secret de la Nature s'unir avec une personne, estimable par sa vertu, aimable par son caractère, choisie sans intérêt, cherchée à loisir, éxaminée avec discernement, nécessaire à la tranquillité du coeur. Ce n'est pas tout. Il faut que cette personne vous choisisse par les mêmes motifs, trouve en vous les mêmes qualités, soit guidée par les mêmes vûes. Voilà un véritable Mariage. Tous les autres n'en portent que le nom. (LaSd XV, 115)

Die Ehe wird hier als natürlicher Drang dargestellt, also als etwas, das dem Menschen innewohne und wonach Frauen wie Männer strebten. Obwohl Aspasie die Ehe vielmehr als nüchterne Verbindung zweier tugendhafter und liebenswerter Menschen zeichnet, die sich aus denselben Motiven einander zuwenden, rät sie allen Liebenden, nur eine Frau zu ehelichen, die sie ebenfalls zärtlich liebe: „Amans ! ne donnez jamais vore $<$ sic $>$ main à celle qui la refuse. On peut forcer les villes; on ne sçauroit forcer les cœurs ; \& le consentement du coeur est nécessaire au Mariage“ (LaSd XV, 117). Mit dem Appell an die Männer (Amans!) und dem Rückgriff auf die anschauliche Kriegsmetapher - man könne nur Städte erobern, niemals aber die Zuneigung eines Herzens erzwingen - spricht sich die Verfasserin für die Liebesheirat und gegen eine Vernunftehe aus.

In der Spectatrice danoise wird bereits Rousseaus Plädoyer für die Liebesheirat und somit die Glück verheißende moralische Verpflichtung der Frau als Gattin und Mutter innerhalb der Gesellschaft vorweggenommen. Auch durch einen zusätzlichen Blick in das 7. Amusement - das nicht mit Frauenbild oder Männerbild ausgezeichnet ist - wird deutlich, dass die Verfasserin ingesamt der Liebesheirat wohlwollender gegenübersteht. Dort schreibt sie eingangs, dass das Glück des Lebens von der Ehe abhänge und die Ehe wiederum von der Zuneigung der Bräute: „Le bonheur de la vie dépend de l'union du Mariage ; \& l'union du mariage dépend de la Sympathie des Mariées“ (LaSd VII, 51). Am Ende derselben Nummer erhebt sie das Eheglück und eine funktionierende eheliche (körperliche) Vereinigung (l'union) mit Nachdruck zur Obliegenheit der Frau:

Si l'union est bannie d'un ménage, j'en accuse la Femme. C'est sa faute, si elle ne raméne pas son mari. C'est q'elle $<$ sic $>$ ne veut pas s'en donner la peine. Nous autres femmes, nous avons tant de ressources, nous connaissons si bien la carte du cœur, que nous pouvons mener à notre gré l'homme le moins souple. L'union depend toûjours de nous. (LaSd VII, 58)

Wie bereits kurz erwähnt, geht aus dem 15. Amusement das komplementär angenommene Geschlechterverhältnis Aspasies hervor, wenn sie Jean-François Sarasin (16141654) zitiert, der sich oft fragte, ob jemals das Geheimnis gefunden würde, den Fortbestand der Welt ohne Frauen zu sichern (cf. Chaudon 1804, 110):

Ne trouvera-t-on jamais le secret de peupler le monde sans femmes, s'écrioit Sarrasin ? [...]. Figurez vous un peuple d'hommes. Autant voudroit-il vout $<$ sic $>$ figurer un peuple de Démons ; si la bonne humeur, si la gaieté de la femme ne servoit de contrepoids à vôtre caractère 
dominant, si vous ne vous humanisez a notre écôle, si votre férosité n'étoit contrebalancée par notre douceur, si par notre commerce vos mœurs ne prenoient insensiblement la teinture des notres, le monde ne seroit qu'un enfer. (LaSd XV, 118-119)

Anhand mehrerer aneinandergereihter Vergleiche kontrastiert Aspasie in diesem Beispiel weibliche mit männlichen Charaktereigenschaften. Spannungssteigernd wirkt im Absatz die Tatsache, dass sie erst nach dem dritten Vergleich zu erkennen gibt, wie eine nur aus Männern bestehende Welt ihrer Vorstellung nach aussehen würde: Ohne die ausgleichenden Eigenschaften von Frauen, zu denen sie Heiterkeit (bonne humeur, gaieté) und Milde (douceur) zählt, würde die Welt durch den dominanten Charakter (caractère dominant) und die Wildheit (férosité) der Männer einer Hölle (enfer) ähneln.

Insgesamt zeigt sich für die Spectatrice danoise, dass die vorwiegend proto-feministische Haltung der weiblichen Verfassungsinstanz in der ersten Nummer nur eine Strategie sein dürfte, um Leser*innen zu gewinnen, die genau eine ebensolche protofeministische Haltung vertreten. Nach der einleitenden Kampfansage, Frauen mit den Inhalten ihrer Zeitschrift vom tryannischen Joch (joug tyrannique) der ehelichen Sklaverei (esclavage) befreien zu wollen, lässt Aspasie ihre moralisierenden Botschaften zur nützlichen Rolle der Frau innerhalb der Gesellschaft einfließen. Ihre geeignete Rolle sei jene der Ehefrau, die Aspasie zudem dahingehend aufwertet, dass sie ihr die Verantwortung für das eheliche Glück überträgt. Mit der Stilisierung der Frau zum ,moralischen Geschlecht“ (Steinbrügge 1987) etabliert Aspasie die Vorstellung einer ,natürlichen' Gleichheit der Geschlechter mit dezidierten Rollen für die Frau wie für den Mann, was tatsächlich eine Aufwertung und gewisse Gleichstellung von Frau und Mann zur Folge hat, allerdings am grundsätzlichen Macht- und Abhängigkeitsverhältnis nichts ändert.

\subsubsection{Le Nouveau Spectateur und Le Monde comme il est (1758-60) - der strenge Erzieher}

Jean-François de Bastide (1724-1788) veröffentlicht zwischen 1758 und 1767 vier Zeitschriften, die zur Gattung der Moralischen Wochenschriften gerechnet werden können: Le Nouveau Spectateur (1758-1760), Le Monde comme il est (1760), Le monde (1760-1761) und Le Journal de Bruxelles ou le Penseur (1766-1767). Von diesen vier Zeitschriften waren zum Zeitpunkt der quantitativen Analyse (März 2018) die ersten beiden im Repositorium verfügbar. Aufgrund des von Bastide konzipierten Fortsetzungscharakters der Wochenschriften - Le monde comme il est gilt als Fortsetzung des Nouveau Spectateur, Le monde als Fortsetzung des Monde comme il est - werden die beiden Periodika in diesem Abschnitt gemeinsam behandelt. ${ }^{86}$

Die 108 Einzelnummern des Nouveau Spectateur, hier Diskurse (discours) genannt, ${ }^{87}$ erscheinen zwischen 10. September 1758 und Januar 1760. Bereits zwei

$86 \mathrm{Zu}$ den ersten umfassenden Studien dieser beiden Wochenschriften zählen Fischer-Pernkopf et al. (2018) und die Diplomarbeit zum Monde comme il est von Mussner (2016).

87 Die Bezeichnung ,Discours ‘ für die Einzelnummern ist erst ab der zweiten Bandausgabe anzutreffen. Im ersten Band sind die Einzelnummern weder als Diskurse bezeichnet noch mit einer Nummer versehen, sondern setzen direkt mit dem jeweiligen Textabschnitt ein. 
Monate später beginnt Bastide die Publikation der Zeitschrift Le Monde comme il est, deren 60 als Blätter (feuilles) ${ }^{88}$ bezeichnete Nummern zwischen 20. März und 5. August 1760 erscheinen. Beide Periodika werden in Bandausgaben zusammengefasst, wobei jene des Nouveau Spectateur aus acht Bänden und jene des Monde comme il est aus zwei Bänden bestehen. Wie an den umfangreichen Einzelnummern und mehrbändigen Gesamtausgaben der Periodika ersichtlich, ist Bastide ein sehr produktiver Produzent von Moralischen Wochenschriften. Neben den Bandausgaben der Marivaux'schen Periodika $(1752,1754,1755,1761)$ tragen also Bastides Zeitschriften ebenso dazu bei, dass die Spectator-Gattung auch noch in der zweiten Hälfte des 18. Jahrhunderts gern gelesen wird.

Beinahe die Hälfte (44 \%) aller 108 Diskurse des Nouveau Spectateur verfügt über eine Themenauszeichnung mit Frauenbild (48 Nummern). ${ }^{89}$ Von diesen sind 16 Nummern (14,8 \%) gleichzeitig dem Männerbild zugeordnet. ${ }^{90}$ Von den 60 Blättern des Monde comme il est weisen sogar mehr als die Hälfte der Nummern Frauen- und Männerbild-Markups auf. Hierin befinden sich 38 Treffer (63\%) für Frauenbild ${ }^{91}$ und zwölf Treffer (20\%) für Männerbild, wovon elf deckungsgleich mit der FrauenbildAuszeichnung sind. ${ }^{92}$ Diese hohe Trefferzahl wird zum Anlass für eine zusammenfassende Analyse der beiden Wochenschriften genommen, die anhand von Beispielen aus beiden Periodika gestützt wird.

Jean-François de Bastide verfolgt mit dem Nouveau Spectateur und seiner Fortsetzung, dem Monde comme il est, zwei Ziele: ein ökonomisch-finanzielles und ein sittenreformerisches. Als erster und einziger der (in der Studie behandelten) Wochenschriftenproduzent*innen deklariert Bastide unter Betonung seiner Ehrlichkeit im Vorwort zur Bandausgabe, dass sein Hauptinteresse an der Zeitschrift im ökonomischfinanziellen Nutzen für den Produzenten liege: „C'est [...] pour subsister honnêtement, pour m'épargner la honte de faire vainement pitié, [...]“ (NS2 I, Préface, 16). Durch diese Demonstration von Ehrlichkeit wolle er sich die Achtung und das Vertrauen des Publikums verdienen, denn, obwohl das Publikum tagtäglich belogen werde, könne

88 Jedes Blatt der Zeitschrift Le Monde comme il est umfasst genau zwölf Seiten, wogegen die Diskurse des Nouveau Spectateur alle verschieden lang sind. Hier umschließt der fünfte Diskurs des sechsten Bandes im Originalformat mehr als 200 Seiten (was im Repositorium 41 DIN A4-Druckseiten entspricht).

$89 \mathrm{Zu}$ den Diskursen mit Frauenbild-Markup im Nouveau Spectateur zählen: Vol. 1: II, VII, VIII, IX, XI, XVI; Vol. 2: I, II, V, VIII, XI, XV, XVII; Vol. 3: I, II, IV, V, XI, XV, XIX, XX, XXI; Vol. 4: I, III, VI, XIII, XV, XVII; Vol. 5: II, VII, VIII, IX, X, XII, XIII, XIV; Vol. 6: I, V, VI, IX; Vol. 7: II, III, XI, XIV, XVI, XVIII; Vol. 8: II, III. (Die Zitierweise der Einzelnummern folgt der Zitierweise im Repositorium.).

90 Vol. 1: II, VIII, IX, XI; Vol. 3: I, IV; Vol. 5: VIII, X, XII, XIII, XIV; Vol. 6: I, V, IX; Vol. 7: XVI; Vol. 8: II.

$91 \mathrm{Zu}$ den Feuilles mit Frauenbild-Markup im Monde comme il est zählen: Vol. I: 4, 7, 8, 10 , 11, 12, 21, 24, 26, 29, 30; Vol. II: 1, 2, 3, 4, 5, 6, 7, 8, 9, 10, 11, 12, 13, 14, 15, 16, 17, 18, $19,21,22,23,24,25,26,29,30$.

$92 \mathrm{Zu}$ den Feuilles mit Männerbild-Markup im Monde comme il est zählen: Vol. I: 3 und die folgenden elf Nummern, die ebenfalls mit Frauenbild codiert sind: Vol. I: 4, 10, 21, 30; Vol. II: 16, 17, 18, 30. 
man es ohnehin nicht täuschen: „On ment tous les jours au public, \& on ne le trompe pas. Je veux mériter son estime par ma sincérité“ (NS2 I, Préface, 16). Diese Selbstdarstellung als überaus ehrlicher Mensch kann als Strategie der Publikumsbindung gedeutet werden, denn einem vertrauenswürdigen, authentischen Verfasser schenke man auch bei eher unglaubwürdigen Inhalten noch Glauben.

Das zweite deklarierte Ziel der Bastide'schen Wochenschriften bezieht sich auf ihre allgemeine Nützlichkeit. Regelmäßige Verweise auf ein Allgemeininteresse bzw. Gemeinwohl (intérêt général) oder ein Nutzen für alle (utilité à tout le monde) gehören von Anfang an zum Grundtenor der beiden Periodika. Mit anderen Worten: Um die Leser*innen zu guten und nützlichen Bürger*innen zu erziehen, werden darin tugendhafte Verhaltensweisen als begehrenswert und lasterhafte als verwerflich dargestellt. Das edukative Ansinnen scheint gegen Ende des ersten Bandes des Nouveau Spectateur noch nicht das gesamte Publikum verstanden zu haben. Daher erklärt der fiktive Verfasser, der auch hierin unter dem Pseudonym des Monsieur le Spectateur auftritt, auf die dezidierte Frage hin, ob die Zeitschrift der Allgemeinheit zugutekomme, erneut die Blattlinie und informiert gleichzeitig über die spectatorialen Vermittlungsstrategien:

En premier lieu, il [le journal] renferme la critique des défauts; en second lieu, il peint jusqu'aux nuances des ridicules; en troisieme lieu, il fait l'éloge de la vertu en général, \& est un [sic] espece de centre où vont aboutir mille vertus particulieres par leur mouvement \& leur effet. S'il est ce que je dis, il est incontestable qu'il ne doive instruire \& plaire... (NS2 I, Fin du premier Tome, 420)

So umfasse die Wochenschrift in erster Linie Kritik an menschlichen Fehlern, in zweiter eine differenzierte Zeichnung des Lächerlichen. In dritter Linie geht es um eine Lobpreisung der Tugenden, sodass die Inhalte zweifelsohne gleichzeitig belehren (instruire) und erfreuen (plaire), womit sie sich in die Horaz'sche und in die SpectatorTradition einreihen. Die Strategie der Ridikülisierung von Lastern wird - wie die Verlautbarung des Zwecks der Wochenschrift - in variierender Wiederholung immer wieder aufs Neue vom fiktiven Verfasser verdeutlicht und auch relativ schnell vom (fiktiven) Publikum auf Briefebene imitiert, wenn es in selbstermächtigender Art die Fehler seiner Mitmenschen auszumerzen sucht. Die Weiterführung der Ridikülisierungsstrategie durch die Korrespondent*innen wird durch den Vergleich zweier aufeinanderfolgender Nummern deutlich: Am Beginn des zweiten Bandes ist es noch der fiktive Verfasser, der in seinem Kommentar zu einer Erzählung über einen Mann, der eine Frau durch die Lächerlichmachung von ihrem Laster befreite, die Leser*innen noch auf die Nützlichkeit dieses Vorgehens hinweist:

\footnotetext{
Le persifflage nous en délivreroit, \& fallût-il pousser jusqu'à l'impolitesse, il vaudroit encore mieux le livrer à un excès utile contre des sots qui importunent, que de tomber dans un autre excès fatal au genre humain, en les laissant, comme l'on fait, s'emparer de la conversation avec vigueur, mettre la raison aux fers par l'abondance de leurs bruyantes paroles, \& nous endormir, comme le vent, à force de nous étourdir. (NS2 II, 1, 33-34)
}

In der darauffolgenden Nummer ist es bereits der Korrespondent selbst, der die gegen die Herrschsucht einer Frau angewandte ,Heilungsstrategie“ beschreibt: „Non, Ma- 
dame, on les corrige [les défauts], on les tourne en ridicule, surtout lorsqu'ils prennent faveur dans les sociétés, \& qu'une femme impérieuse en prend droit de dominer, \& ne daigne pas distinguer ceux qui ne sont pas disposés à l'y souffrir“(NS2 II, 2, 69).

Insgesamt zeichnen sich Le Nouveau Spectateur und Le Monde comme il est durch den Entwurf eines komplementären, hierarchischen Geschlechterverhältnisses aus, das von den Vorstellungen seiner Zeit geprägt ist. Die spectatorialen Geschlechterdiskurse speisen sich vor allem aus der Gedankenwelt Jean-Jacques Rousseaus (1712-1778), auf den immer wieder auch explizit verwiesen wird. Beide Periodika entwerfen die Frau als Begleiterin des Mannes und richten die Erziehung der Frau ganz auf ihre Rolle als zukünftige Ehefrau und Mutter aus. ${ }^{93}$ Auch das Männerbild, das dem Idealbild des Honnête homme folgt, speist sich aus den Männlichkeitsvorstellungen Rousseaus, der den Mann als emanzipiertes und selbstbestimmtes Individuum entwirft, von dem Frau und Kinder abhängig sind und für die er als Familienoberhaupt Verantwortung übernimmt.

Die in den Bastide'schen Wochenschriften dargebotenen Geschlechterdiskurse stellen meist verwerfliche, lasterhafte Frauen- und Männerbilder dar, deren Inversion eine vom Publikum selbst zu erbringende kognitive Leistung - zum anzustrebenden (bürgerlichen) Rollenmuster führt. Durch die Sammlung der unterschiedlichsten Laster in all ihren ernsten wie erheiternden Facetten werden sie gleichzeitig zum Mittel der Unterhaltung (plaire) und der Belehrung (instruire), wie Monsieur le Spectateur in der ersten Nummer des sechsten Bandes erneut verlautet (cf. NS2 VI, 1). Die Notwendigkeit einer derartigen Zeitschriftenkonzeption ergibt sich für den fiktiven Verfasser dabei aus dem französischen Publikum selbst, welches - so seine Kritik - nicht so ernst und überlegt sei wie das seiner englischen Spectator-Vorgänger. Er bezeichnet es denn auch metaphorisch als verzogenes Kind, dem er (mit seiner Schrift) entschieden das Spielzeug entreißen wird, um es zur Schule zu bringen: ,[J]'y [dans le journal] employasse la force, la vigueur, l'air déterminé, l'air imposant, uniques moyens d'arracher l'enfant vif, étourdi, gâté, à l'amusement de sa poupée, pour le conduire avec fruit à l'école“ (NS2 I, Fin du premier Tome, 422). Der Vergleich des Publikums mit einem Kind überrascht hier keineswegs, ist doch die Neubewertung der Kindheit als wichtige Phase in der Entwicklung zum nützlichen Bürger und zur nützlichen Bürgerin in jener Zeit auf dem Vormarsch und findet mit Rousseaus Émile ou de l'Éducation (1762) ihr Programm. Mit dieser Metapher stilisiert sich der fiktive Verfasser selbst zum strengen Vater oder Erzieher - immerhin entreißt (arracher) er dem Kind das Spielzeug - und unterstreicht damit gleichzeitig den Autoritätsanspruch seiner Schrift. Dass der Verfasser seine Periodika als normative Erziehungsschriften ansieht, untermauert er zusätzlich am Ende des ersten Bandes des Nouveau Spectateur, wenn er sich (und die Zeitschrift) mit den Worten von Horaz in eine altruistische Tugendhaftigkeit hüllt: „meâ virtute me involvo [kursiv im Orig.]“ (NS2 I, Fin du premier Tome, 426) - ,Ich hülle mich selbst in meine Tugend'.

93 Die Einschätzung, dass Bastide (als Bewunderer von Marivaux) in vielen Textabschnitten eine „frauenfreundliche, nahezu emanzipatorische Haltung“ (Fischer-Pernkopf et al. 2018, 263; cf. ibid. 11, 26) pflege, ist für die mit Frauen- und Männerbild ausgezeichneten Nummern zu relativieren. 
Wie aus der hohen Trefferzahl zum Frauenbild abgeleitet werden kann, legt die Verfassungsinstanz zur Erziehung des Publikums zu guten und nützlichen Bürger*innen den Fokus ganz klar auf die Erziehung/Bildung der Frau. Damit geht die Entwicklung zur guten Mutter, die ihre Kinder zu erziehen weiß, einher - beides Anliegen, die ebenfalls in den Wochenschriften von Bastide thematisiert werden. Die gelehrte Frau (femme savante) spielt neben der Hausfrau, Ehefrau und Mutter überhaupt keine Rolle mehr, und ihre bereits in der ersten Hälfte des Jahrhunderts umstrittene Existenz wird durch die terminologische Absenz negiert, die bereits mit der Bagatelle (1718-1719) einsetzt und in allen weiteren französischsprachigen Wochenschriften fortgesetzt wird.

Die Themen, die in den mit Frauenbild und Männerbild ausgezeichneten Nummern immer wieder aus unterschiedlichen Perspektiven zur Sprache gebracht werden, beziehen sich auf das Familienleben (speziell auf die Erziehung/Bildung) und die Paarbeziehung (mit Fokus auf der romantisch-zärtliche Liebesbeziehung). ${ }^{94}$ Auf formal-ästhetischer Ebene werden die Erziehungs- und Liebesdiskurse vorrangig über fünf Textsorten vermittelt, die in zahlreichen Einzelnummern des Nouveau Spectateur und des Monde comme il est gemeinsam anzutreffen sind. Zu diesen zählen der metatextuelle Kommentar des Verfassers, das Fremdporträt, die allgemeine Erzählung (zumeist in Form der häuslichen Erzählung), der Dialog und der Brief, wobei eine Textsorte auch immer innerhalb einer anderen auftreten kann. ${ }^{95}$ So zum Beispiel wird durch die Wiedergabe von mündlichen und/oder brieflichen Dialogen innerhalb von Leser*innenbriefen, in die wiederum Porträts etc. integriert sind, die Kommunikationssituation der Wochenschriften besonders vielschichtig. Zahlreiche Einzelnummern des Nouveau Spectateur beginnen mit einem Zitat, das entweder aus einem zeitgenössischen oder einem antiken Werk stammt. Darauf folgt entweder ein Leser*innenbrief oder der Metakommentar des fiktiven Verfassers, in dem sich der Inhalt des Zitats in Form eines Beispiels oder anderweitiger Überlegungen widerspiegelt. Anschließend wird der Brief oder der Metakommentar durch einen weiteren Brief unterbrochen, wodurch die in den Wochenschriften übliche Dialogizität - auch durch die Verschachtelung der einzelnen Textsorten - deutlich in Erscheinung tritt. Eine Einzelnummer besteht demnach meist aus zwei verschiedenen Perspektiven, die zum voranstehenden Zitat in Relation stehen. Damit scheint sich Bastide Marivaux' Wochenschriften Le Spectateur français (1721-1724) und Le Cabinet du philosophe (1734) als Vorbild zu nehmen, in denen dieser eine ähnliche Vermittlungsstrategie anwendet.

Im Monde comme il est sind die Leser*innenbriefe oft in metatextuelle Kommentare des fiktiven Verfassers eingebettet, wodurch der Kommentarteil als Rahmen-

94 Neben Erziehung und Liebe ist der Authentizitätstopos einer der drei dominanten Themenbereiche in Bastides Le Nouveau Spectateur und Le Monde comme il est. Eine ausführliche Diskussion aller drei thematischen Aspekte ist in Fischer-Pernkopf et al. (2018, 72-134) nachzulesen.

95 In den 48 Treffern des Nouveau Spectateur befinden sich (mindestens einmal pro Nummer) metatextuelle Kommentare in 35 Diskursen, Fremdporträts in 19 Diskursen, allgemeine Erzählungen in 29 Diskursen, Dialoge in 22 Diskursen und Leser*innenbriefe in 36 Diskursen. In den 39 Treffern des Monde comme il est sind (mindestens einmal pro Nummer) Metatextualität in 32 Blättern, Fremdporträts in 11 Blättern, allgemeine Erzählungen in 32 Blättern, Dialoge in 19 Blättern und Leser*innenbriefe in 27 Blättern anzutreffen. 
erzählung fungiert. Diese Vermittlungsstrategie betont einerseits den belehrenden Charakter der Zeitschrift und andererseits erzeugt sie eine Spannungskurve für die Leser*innen. In seinen Kommentaren bespricht der Spectateur nicht nur die erzählten Beispielgeschichten, sondern erklärt gleichzeitig auch die Lehren, die seiner Ansicht nach aus ihnen zu ziehen sind und den Leser*innen bei der Persönlichkeitsentfaltung und der Entwicklung von Wertvorstellungen dienlich sein sollen. Zusätzlich versucht der Verfasser über rhetorische Fragen an das Publikum und eine scheinbar direkte Kommunikation mit ihm seine Aufmerksamkeit anzuregen, sprich den Unterhaltungswert der Wochenschrift zu steigern, um somit die Publikumsbindung und den Zeitschriftenabsatz zu erhöhen (cf. Fischer-Pernkopf et al. 2018, 38).

Insgesamt wird in beiden Bastide'schen Wochenschriften ein aktives Spiel mit den Kommunikationsebenen betrieben, indem der reale Autor (Bastide) immer wieder im Werk neben dem fiktiven Verfasser auftritt und somit die narrativen Ebenen überschritten werden. Diese ludische Komponente ist ebenfalls in der Anordnung der zahlreichen Leser*innenbriefe zu entdecken: Sie werden meist nicht einfach nur hintereinander abgedruckt, sondern treten innerhalb von Einzelnummern, aber auch zunehmend über mehrere Nummern und oft ineinander verschachtelt auf - womit Bastide auch hier eine ähnliche Vermittlungsstrategie wie Marivaux an den Tag legt und weiterentwickelt. Einer der Leser*innenbriefe im Monde comme il est erstreckt sich (kommentarlos) über nicht weniger als 12 Blätter (Feuille 31 bis Feuille 42), wodurch Bastides Wochenschriften in die Nähe des Briefromans gerückt werden können (cf. Fischer-Pernkopf et al. 2018, 107). Die Übergänge von einem Brief zum nächsten sind teilweise markiert, teilweise unmarkiert und meist an einem Punkt angesiedelt, der als Cliffhanger fungiert, also das Erzählte abrupt an einem packenden Moment abbrechen lässt. Diese Art des Perspektivenwechsels verfolgt einen spannungsaufbauenden Effekt, wie er später in den Feuilletonromanen des 19. Jahrhunderts, die in Zeitungen erscheinen, praktiziert wird. Zudem wird nicht davor zurückgescheut, eine Nummer auch mitten in einem Satz oder sogar mitten in einem Wort (!) abbrechen zu lassen (z. B. in LM II, 5; LM II, 14; LM II, 25; LM II, 29), was in dieser drastischen Art und Weise bei Marivaux noch nicht auftritt.

Um die Leser*innen zur Zusendung von Briefen zu animieren, erklärt Monsieur le Spectateur, dass er seine Augen nicht überall gleichzeitig haben könne und somit auf die (Beobachtungs-)Hilfe seines Publikums angewiesen sei: „Combien de choses à saisir dans le monde ! [...] si plusieurs spectateurs s'avisent de regarder de leur côté, [...] je ne doute pas que mon livre [i. e. le périodique] ne reçoive, [...], cette sorte de perfection que j'ai espéré qu'il auroit un jour, [...]“ (NS2 III, 15, 289). Durch die große Zahl an (als authentisch angenommenen) Briefen von Vertreter*innen der bürgerlichen Welt werden die Meinungen und der Alltag der Menschen hier viel stärker als in den bisherigen französischsprachigen Wochenschriften in die Zeitschrift transportiert. Mit anderen Worten wird das Private in dieser Wochenschrift mehr als je zuvor öffentlich gemacht. Dafür wird ganz bewusst eine komplexe Dialogsituation innerhalb der Wochenschriften geschaffen, die auf dem Wechsel zwischen der Themenpräsentation und der bewussten Unterbrechung von soeben geführten Gedankengängen und Gesprächen fußt. Im Sinne dieser Strategie der Abwechslung beendet Monsieur le Spectateur zum Beispiel seine theoretischen Überlegungen zur Selbst(er)kenntnis im Zusammenhang mit der (Er-)Kenntnis externer Objekte, um sich nicht dem Vorwurf auszusetzen, zu 
seriös zu schreiben: „Pour éviter le reproche, je vais recourir à la variété, en plaçant ici une lettre très-plaisante, $[\ldots]^{\prime \prime}$ (NS2 II, 1, 13).

Die moralische Erziehung des weiblichen und männlichen Publikums erfolgt größtenteils über (häusliche) Erzählungen und individualisierte Charakterporträts. Anhand dieser werden nicht nur die als angemessen erachteten Verhaltensweisen und Wertvorstellungen demonstriert, sondern es wird auch dargestellt, wie tugendhaftes Verhalten belohnt und lasterhaftes Verhalten gesellschaftlich sanktioniert wird. Die Strategie der Exemplifizierung an positiven und negativen Beispielen übernehmen die Leser*innen, die zudem das Beobachten alsbald als ihre eigene Aufgabe ansehen, gern selbst, wie aus dem Brief hervorgeht, der im Anschluss an das Eingangsstatement die persönliche Geschichte des Korrespondenten beinhaltet: ,[J]e crois qu'il est du devoir d'un Spectateur de les avertir [les femmes] que de toutes les séductions . . . [...]. Comme je suis persuadé qu'un exemple fait toujours plus d'effet qu'un simple raisonnement, je vous prie d'insérer dans vos feuilles l'aventure ci-jointe" (NS2 III, 5, 121-122).

Laster, so scheint es, werden dabei häufiger als Tugenden in konkrete Charakterporträts gepackt, wobei mitunter auch kurze, sozusagen eingestreute Charakterbeschreibungen in längeren Erzählungen auftreten können (z. B. in NS2 II, 1, 17; NS2 II, 1, 79). Zu den Fremdporträts, die anhand einer Person ein Laster exemplifizieren beziehungsweise ein Laster an sich thematisieren, zählen zum Beispiel die stereotypen Frauen- und Männerbilder der Koketten (coquette), der Frommen (dévote), der Heuchlerin (hypocrite), der verschwenderischen Ehefrau, der ,prude ${ }^{6}{ }^{96}$ der alten Frau/des alten Mannes (vieille femme/vieillard), des (verheirateten) Gecken (fat), des Betrügers (imposteur), des blasierten Mannes (homme blasé) oder des naiven und leichtgläubigen Mannes (homme crédule).

Um das Publikum von solch allgegenwärtigen Lastern zu befreien, gibt der Verfasser dezidierte Handlungsanweisungen, die bereits bei Van Effen Verwendung finden. In einem direkten Kommunikationsstil werden die porträtierten Individuen eingangs gelobt. Erst danach wird die als lasterhaft erachtete Verhaltensweise angeprangert und es werden Ratschläge gegeben, um sich des Lasters zu entledigen. Mit dieser rhetorischen Technik der Captatio Benevolentiae gewinnt der Verfasser die Sympathie seiner Leser*innen und kann hernach die positiv Gestimmten müheloser kritisieren.

Menschliche Tugenden werden dagegen nur selten in einem spectatorialen Porträt wiedergegeben. Im Monde comme il est wird am Ende einer Nummer beispielsweise zwar prominent mit „LES PORTRAITS DE PLUSIEURS FEMMES REMARQUABLES PAR LEURS VERTUS [Großbuchstaben im Orig.]“ (LM II, 14, 168) eine Reihe an Porträts von tugendhaften Frauen angekündigt, die jedoch nie folgt - auch in den darauffolgenden Nummern nicht. Die Enttäuschung der Leseerwartung rechtfertigt der Verfasser damit, dass durch solche Porträts nur neue Feindschaften zwischen

96 Die spectatoriale Definition der als ,prude ' bezeichneten Frau, von der sich die Briefschreiberin distanziert, lautet: ,[P]our mériter le nom de prude, il faudroit que j’eusse dans le cœur l'amour de leurs soins \& de leurs agrémens [des hommes], en même temps que je montre du mépris pour eux, \& ce contraste entre mes sentimens \& mes manieres, peut-on dire qu'il existe ? Y a-t-il quelqu'un en droit de m'en accuser? Me voit-on courir après les hommes, en même temps que je dis du mal d'eux ? Non assurément, \& observez encore que je ne veux pas dire que je n'aie jamais aimé ; [...]“ (NS2 II, 2, 89-90). 
weniger tugendhaften und bereits tugendhaften Frauen entstünden und diejenigen, die das Glück hätten, tugendhafte Frauen zu kennen, diese ohnehin zu huldigen wüssten: „[T] $]$ ant de vertus que l'on voit briller en elles pénetrent du respect le plus vrai“ (LM II, $15,174)$. Anstatt dessen fügt er eine Liste mit 13 Verhaltensregeln (règles de conduite) ein, die der von ihren Eltern vernachlässigten Jugend eine Stütze im richtigen gesellschaftlichen Umgang sein soll.

Erst in der darauffolgenden Nummer (LM II, 16) werden anhand der Geschichte zweier ungleicher Paare Tugenden und Laster explizit gegenübergestellt. Diese (allgemeine) Erzählung beginnt mit den Charakterporträts des Jünglings Dorimond und der jungen Frau Araminte, die beide die Eigenschaften eines Honnête homme aufweisen, wobei der Verfasser den Begriff ,honnête femme‘ aufgrund seiner negativen Konnotation nicht für die Frau verwenden kann. ${ }^{97}$

Dorimond avoit les qualités aimables de la jeunesse, \& les vertus solides de l'âge mûr. Il réunissoit tous les avantages qui peuvent faire une sorte de supériorité dans le Monde. naissance $<$ sic $>$, titres, fortune, grandeur d'ame, générosité sans faste, politesse sans fausseté, considération sans hauteur, tendresse sans folle jalousie, amitié sans légereté, sçavoir sans pédantisme, esprit sans frivolité : Dorimond étoit digne de toute sorte de louanges, \& ne pouvoit être bien loué que par les sentimens.

Araminte avoit été jeune sans folie, belle sans vanité, tendre sans foiblesse. Elle étoit devenue un honnête homme dans un âge où presque toutes les personnes de son sexe deviennent de malhonnêtes femmes, ou des femmes insupportables. Araminte enfin étoit l'image de Dorimond. (LM II, 16, 181-182)

Diesem Porträt folgt das zweier lasterhafter Charaktere, nämlich einer Koketten und eines Gecken, die ebenfalls durch eine Aneinanderreihung von Eigenschaften beschrieben werden:

Zirphile étoit jeune \& jolie, avoit beaucoup d'esprit, unissoit les talens aux graces, \& les connoissances solides aux idées agréables : mais elle étoit libertine \& coquette.

Moncade étoit un jeune fat, vicieux, caustique, tracassier, ingrat, volage, superficiel, suffisant, tel enfin qu'on auroit peine à le croire, si quelquefois il ne naissoit de pareils monstres : Mais il avoit l'avantage d'une jolie figure, \& sçavoit répandre sur sa personne un certain

97 Zahlreiche Geschichten in beiden Wochenschriften von Bastide beziehen sich auf den bürgerlichen Idealtypus des Honnête homme, der im nachfolgenden Ratschlag einer Freundin des Spectateur an ihre Freundin als idealer Ehepartner gepriesen wird: „Songez que je puis vous éclairer par des conseils éternellement utiles. Je crains que vous ne laissiez échapper le bonheur d'épouser un honnête-homme, \& je ne veux pas que vous fassiez ce tort à l'amie que j'aime si tendrement : ce seroit une perte \& un malheur irréparables, car j'ai toujours vû que les femmes qu'un véritable amour n'avoit pû toucher, finissoient par être dupes d'une imagination séduite ; \& malheureuses pour jamais“ (NS2 VI, 5, 247). In derselben Nummer wird erneut auf das Glück verwiesen, das mit der Wahl eines Honnête homme als Ehemann gesichert scheine: „Ce bonheur dépend de notre choix, \& il [n]'y a point de femme pour qui il n'y ait un honnête-homme sur la terre“ (NS2 VI, 5, 310). 
prestige par le jeu adroit de ses défauts : il plaisoit par-là à ces femmes qui n'ont pas ou le tems ou l'esprit de bien juger, \& de faire un bon choix. (LM II, 16, 182-183)

Nach dieser Exposition der Charaktere setzt die eigentliche Geschichte der vier jungen Menschen ein, die sich über drei Nummern erstreckt (LM II, 16 bis II, 18). Durch das im Vordergrund stehende Liebesthema kann diese allgemeine Erzählung - wie die meisten weiteren - der häuslichen Erzählung zugeordnet werden. Auffallend an Bastides Periodika ist nämlich, dass die Liebesthematik erstmals (!) so umfangreich in den Treffern der mit Frauen- und Männerbildern ausgezeichneten Wochenschriften zutage tritt. Eine mögliche Erklärung dafür ist in der veränderten Liebeskonzeption zu suchen, die in der zweiten Hälfte des 18. Jahrhunderts in Frankreich Einzug hält. Diese drückt sich durch ihren gefühlsbetonten Ansatz aus, der insbesondere die Beziehung zwischen Frau und Mann auf ein neues Fundament stellt. Ebenso manifestiert sich die Veränderung der Liebeskonzeption durch die semantische Erweiterung des Liebesbegriffs um emotionale Ausdrücke wie ,sentiment', ,affection“ oder ,sensibilité'. Wegbereiter der neuen Liebeskonzeption ist niemand anderer als Bastides Vorbild Rousseau, der diese anhand von Julie ou La Nouvelle Héloïse (1761) für das Publikum illustriert, auch wenn sich hier die aus adeligem Hause stammende Julie schlussendlich noch gegen ihre bürgerliche Liebe Saint-Preux und für die standesgemäße Vernunftehe entschließt:

[L'amour des protagonistes n'ignore pas] la prévalence du cœur, la maîtrise de soi, le sens du devoir dont l'accomplissement donne une certaine paix à Julie et Saint-Preux. Hors normes, les amours de ceux-ci n'en restent pas moins honorables. Quand Julie s'est donnée, elle était libre ; mariée, elle sait éviter l'adultère, même si sa noyade héröque arrive providentiellement pour éviter une rechute. Le livre a été important : Rousseau a prévenu, dans sa préface, de ses effets éventuellement subversifs. Il l'a été plus encore par le profond courant de pensée qu'il a suscité à travers l'Europe, qui s'amplifiera dans le premier tiers du XIXe s[iècle]. (Bernos 1997, 70)

Wie bereits an anderen Stellen (insbesondere in der Bagatelle-Analyse) erörtert, ist das Verständnis von ,amour' bislang auf der körperlichen Ebene angesiedelt, während für die zärtliche Zuneigung zwischen Frau und Mann - abseits des oft (nur) mit ,passions“ (Leidenschaften) umschriebenen sexuellen Verlangens - eher der Begriff der ,amitié (Freundschaft) gebraucht wird. Ehen werden zudem üblicherweise nicht aus Liebe der beiden Beteiligten zueinander geschlossen, sondern aus ökonomischen (z. B. um eine Familienfehde beizulegen) oder sozialen Gründen (z. B. zur Fortpflanzung oder um nach einer Witwenschaft den Kindern eine neue Mutter oder einen neuen Vater zu geben). ${ }^{98}$ Liebe (im Sinne von , amitié $)$ und Ehe werden demnach als zwei Komponen-

98 Die Ansicht, Vernunftehen wären gemeinschaftstauglicher, ,[...] gründet sich nicht nur in der christlichen Vorstellung einer keuschen und d. h. also relativ leidenschaftslosen Ehe, sondern auch und vor allem in der sich im Lauf des 17. Jahrhunderts - insbesondere bei Pascal, Nicole und La Rochefoucauld - ausbildenden moralistischen Psychologie. Deren Grundaxiom besteht ja darin, dass der Mensch vom Grundimpuls des amour propre beherrscht wird, was dazu führt, dass die sozialen Beziehungen sich ausschließlich als Macht- 
ten angesehen, die nicht miteinander in Zusammenhang stehen. Die Ansicht, dass es auch in der Ehe eine romantisch-zärtliche Liebe geben könne, entwickelt sich erst mit der im 18. Jahrhundert stattfindenden Aufwertung der ,sensibilité (Empfindsamkeit), wodurch die Ehe umgedeutet werden kann ,,als die in der Liebe vollzogene, vor allem psychische Verschmelzung der Ehegatten“" (Hausen 1976, 372; cf. Bernos 1997, 6871; Sauder 1992, id. 1997).

Die nach den Porträts einsetzende Liebesgeschichte über die vier jungen Menschen erzählt also, wie die Kokette Zirphile das Herz von Dorimond und der Geck Moncade das Herz von Araminte durch ein Täuschungsmanöver („la masque de la réforme“ [LM II, 16, 183]) erobert. Als sich die Kokette und der Geck in der Nacht vor ihrer Hochzeit kennenlernen, verfallen beide jedoch in ihr lasterhaftes Verhalten und geben sich ihren körperlichen Leidenschaften hin. Das kurze amouröse Abenteuer wird von Araminte und Dorimond entdeckt, woraufhin sich die beiden tugendhaften Herzen gebrochen von ihren Angebeteten zurückziehen. Nach vergeblichen Rückeroberungsversuchen treffen sich die Kokette und der Geck erneut und geben sich abermals ihrer körperlichen Anziehung hin, obwohl sie gar keine Leidenschaft (passion) mehr füreinander empfinden: „[I]ls se livrerent sans contrainte aux transports d'une passion qu'ils ne sentoient pas davantage" (LM II, 18, 205). Schon bald aber erkennen sie ihren Irrtum und trennen sich wieder: „Ils sentirent tous deux qu'ils ne s'inspiroient rien, qu'ils ne s'étoient jamais aimés, \& ils furent contraints de se rendre justice. Ils s'avouerent de bonne foi, leur erreur $\&$ leur indifférence, $\&$ se quitterent aussi singulierement qu'ils s'étoient pris“ (LM II, 18, 205-206). Die Erzählung endet schließlich mit dem Rahmenkommentar des Verfassers, der diese Geschichte als besonders lehrreich für die Frauenwelt - und nicht für die Männerwelt - erachtet: „Cette aventure ne paroîtra peut-être pas aussi plaisante qu'instructive à quelques femmes qui n'ont jamais eu des aventures plus honnorables. En la lisant, elles seront tentées de faire quelques réflexions sur l'infâmie de leurs mœurs \& de leur conduite, [...]“(LM II, 18, 206). Anhand dieser und ähnlicher Erzählungen wird das Publikum vor lasterhaften Menschen gewarnt. Ebenso wird aufgezeigt, wie sich ein solch getäuschtes tugendhaftes Herz zu verhalten habe und es wird durch die Demonstration des Lasters die romantisch-zärtliche Liebesheirat propagiert.

Insgesamt wird in Le Monde comme il est an mehreren Stellen dafür plädiert, dass der Wille zur Eheschließung von zwei selbstbestimmten (heterosexuellen) Herzen ausgehen soll. Die Ehe solle folglich auf Freiwilligkeit basieren. Um die neue bürgerliche Gesellschaftsschicht von der höfisch-aristokratischen Oberschicht abzuheben, stellt die Wochenschrift der Standesheirat die Liebesheirat zwischen Frau und Mann entgegen und befürwortet diese in ihren Inhalten. Die zahlreichen

[...] Geschichten, die der fiktive Autor in seiner Wochenschrift veröffentlicht, lesen sich wie ein Plädoyer für die romantische Liebe. Das Ideal von Liebenden, das er darin entwirft, zeigt vernunftbegabte und tugendhafte Menschen, die selbstbewusst auf ihr Herz hören und ihrem Weg folgen. Diesen Spiegel hält er seinen Lesern vor, die die Möglichkeit erhalten, sich

und Anerkennungskämpfe darstellen. Dies gilt auch für die Liebe, die ebenfalls durch eine nie zur Ruhe kommende Anerkennungsdynamik geprägt ist [...] und sich daher als prinzipiell instabil erweist [kursiv im Orig.]“" (Matzat 2015, 118). 
selbst darin zu betrachten und dieses Ideal zum Vorbild ihres Lebens zu machen. (FischerPernkopf et al. 2018, 100)

Das Engagement für die romantisch-zärtliche Liebesheirat ist gleichzeitig als Engagement gegen die Standesheirat und die Vernunftehe zu sehen, da letztere meist zu außerehelichen Liebesverhältnissen führte und somit den Zweck der Ehe, der für die ,philosophes“ in der Zeugung von Nachkommenschaft liegt, zu wenig verfolgten: „La fin du mariage est la naissance d'une famille, [...] [kursiv im Orig.]“ (Diderot/D'Alembert 2016, 10:104) - ,das Ziel der Ehe sei die Gründung einer Familie', wird auch im Encyclopédie-Artikel zur MARIAGE, S.M. (Droit naturel.) propagiert und in den Wochenschriften dem Lesepublikum indirekt über das Plädoyer für die Liebesheirat ,schmackhaft' gemacht.

Zur veränderten Konzeption der Ehe gesellt sich eine veränderte Konzeption der Ehetreue, die Bastide als wesentlich für die Ehe erachtet. In seinen Wochenschriften wird die Kritik an der gesellschaftlich geduldeten und in der Aristokratie üblichen Praxis der Mätressenwirtschaft und des, Liebhabertums' subtiler als im Misantrope (1711-1712) kundgetan. Hier empört man sich nicht mehr über diese Verfehlung, sondern sie wird exemplarisch anhand aberdutzender Beispiele vorgeführt und zum verachtenswerten Ehebruch, der als Verbrechen (crime) bezeichnet wird, stilisiert. Im Monde comme il est $(\mathrm{I}, 29)$ heißt es beispielsweise, dass die Treulosigkeit (infidelité) der Ehefrau den Ehemann schmerze und dieser Kummer ihn sogar in den Tod treiben kann: „Je suppose qu'il mourra de douleur, ou qu'il ira chercher dans la solitude l'oubli de l'objet, \& du crime“" (LM I, 29, 346). In ähnlicher Weise wie die Leiden der Männer an das Verhalten der Frauen gebunden werden, werden die Leiden der Frauen in Zusammenhang mit Männern als deren Verursachern gebracht. An vielen Stellen betont der fiktive Verfasser des Monde comme il est, dass die Leiden der Frauen „,vor allem darin bestehen, dass die Männer sie nicht ernst nehmen. Besonderes Leid erfahren sie, wenn sie von den Männern unterdrückt, von ihnen verlassen und betrogen werden“ (Fischer-Pernkopf et al. 2018, 105). Es wird demnach auch das männliche Publikum dazu angehalten, sich tugendhaft gegenüber der Frauenwelt zu verhalten und auch innerhalb der Ehe als Honnête homme aufzutreten. Mit den Liebes- und Beziehungsgeschichten kanalisiert Bastide sozusagen das Begehren seiner Leser*innen und propagiert das bürgerliche Ideal der Monogamie.

\subsubsection{Le Spectateur français avant la Révolution (1795) - der vorrevolutionäre Sittenmaler}

Bei dieser Wochenschrift im Repositorium handelt es sich um die zweite Neuauflage des Spectateur français, pour servir de suite à celui de M. de Marivaux, der vermutlich ab 1770 bis Ende 1772 wöchentlich von Jacques-Vincent Delacroix (1743-1831) in Paris herausgegeben wird. ${ }^{99}$ Die erste gebundene Neuauflage erscheint 1777 unter dem

99 Als Anwalt, Historiker, Lehrer und Journalist beobachtet Delacroix die gesellschaftspolitischen Verhältnisse seines Landes im Laufe seines Lebens sehr genau und bezieht sich in vielen seiner Werke auch ausdrücklich auf Addisons und Steeles Spectator, den er immer wieder nachahmt (cf. Pallares-Burke 2004, 146). Seinen Spectateur français avant la 
Titel Peintures des mœurs de ce siècle. Um sich jedoch ganz offenkundig wieder innerhalb der Spectator-Gattung zu positionieren, wird dieser Titel für die zweite Auflage erneut verändert, und zwar in Le Spectateur français avant la Révolution, für die Jean Sgard (1999b) als Erscheinungsjahr 1796 nennt (und nicht wie hier aufgrund der aus der Bibliothèque Nationale de France stammenden Repositoriumsvorlage angenommen 1795).

Die quantitative Analyse der 61 als ,Discours' (Diskurse) benannten Nummern des Spectateur français avant la Révolution legt offen, dass ungefähr in einem Viertel der Zeitschrift Frauen- und Männerbild-Markups codiert worden sind. 14 Diskurse (23\%) sind mit Frauenbild (I, III, IV, XIII, XV, XX, XXVII, XXXI, XXXVI, XLV, XLVI, L, LV, LIX), fünf (8,2 \%) mit Männerbild (XVII, XXVII, XXXI, XXXVI, LV) ausgezeichnet, wobei lediglich der Diskurs XVII mit Männerbild, die restlichen vier mit Frauenbild und Männerbild zugleich gekennzeichnet sind.

Das Ziel, das Delacroix mit seiner Wochenschrift verfolgt, lässt sich aus dem Titel der ersten Neuauflage Peintures des mœurs de ce siècle (1777) ablesen. Sein Anliegen ähnelt somit dem von Bastide ein Jahrzehnt zuvor, der darum bemüht war, in seinen beiden Wochenschriften das zwischenmenschliche Leben ,naturgetreu' abzubilden. Ebenso schließt Delacroix an Van Effens Intention aus dem Nouveau Spectateur français (1723-1725) an, mit dem dieser ein „Portrait naïf des mœurs“ zu zeichnen suchte. Das sittenmalerische Anliegen wird im ersten Diskurs des Spectateur français avant la Révolution expliziert, in dem der fiktive Verfasser Monsieur le Spectateur bekundet, nur ,echte‘ Porträts aus dem Leben seiner Leser*innen abbilden zu wollen. Gleichzeitig grenzt er sich hier von Marivaux ab, dessen Gesellschaftsporträt er für zu nachsichtig und milde hält: „Moins légers, moins agréables que lui [Marivaux], nous nous efforcerons de le surpasser par la vérité de nos portraits, par le naturel d'un style moins recherché que le sien“ (SaR I, 3).

Wie Michaela Fischer (2014) darlegt, gibt der Untertitel der Wochenschrift aus dem Jahr 1795 ,par le citoyen de La Croix‘ zusätzlich Aufschluss über die politische Haltung von Jacques-Vincent Delacroix, der sich hier bereits als Bürger vorstellt und sich somit nicht mehr als Untertan versteht. In seinem einleitenden Diskurs schreibt er von der Absicht, revolutionäre Gedanken in sein Werk einbringen und die Wahrheit um jeden Preis ans Licht bringen zu wollen. Wenig später klagt er jedoch ,über die politischen Zustände, vor allem jene, die Schriftsteller und philosophes betreffen [und] äußert zweifelsfrei Ideen, die die Revolution tragen [kursiv im Orig.]“ (Fischer 2014, 64): „Chaque citoyen, m’objectera-t-on, doit payer à la république le tribut de ses lumières ; il est beau de révéler sa pensée, de dire la vérité, même au péril de sa vie“ (SaR Discours préliminaire, xxvii).

Der Einfluss des Marivaux'schen Spectateur français (1721-1724) auf jenen von Delacroix ist aus der formalen Gestaltung der Einzelnummern ersichtlich, in denen

Révolution beginnt er ebenfalls damit, ihn in die englische Spectator-Tradition zu stellen: „Les feuilles du Spectateur Anglais furent reçues avec transport par un peuple qui aime la vérité, et qui est digne de l'entendre. Les hommes les plus célèbres, dont l'Angleterre s'honore, ont travaillé à cet ouvrage philosophique, Stéele [sic], le peintre de l'humanité ; le sage Adisson [sic], l'un des plus beaux génies de sa nation, l'ont enrichi de plusieurs discours qui le rendront immortel“" $(\mathrm{SaR} I, 1)$. 
persönliche Reflexionen mit Leser*innenbriefen abwechseln. Ebenfalls ähneln sich die Periodika aufgrund der moralisierenden Kommentare der Verfassungsinstanz, mit denen viele Nummern enden. Inhaltliche Ähnlichkeiten hinsichtlich des Geschlechterdiskurses sind jedoch gering. In den Nummern, die mit Frauenbild und Männerbild ausgezeichnetet sind, orientiert sich der Verfasser vielmehr an Rousseaus komplementärem Geschlechterverständnis und einer ,natürlich“ und hierarchisch gedachten Geschlechterdifferenz, auch wenn er sich für die Erziehung/Bildung der Frau ausspricht und indirekt den konstruierten Charakter der Geschlechterverhältnisse entlarvt. Die Einstellung zu Frauen im Spectateur français avant la Révolution mag der generell opportunistischen Grundhaltung Delacroix' geschuldet sein, denn wie Boons (2020) konstatiert, besteht seine Überlebensstrategie in der Zeit vor, während und nach der Französischen Revolution darin, teils im Sinne der Republik, teils im Sinne der Monarchie zu schreiben. Im ersten Blatt der 1794 erscheinenden Wochenschrift Le Spectateur françois pendant le gouvernement révolutionnaire verdeutlicht Delacroix seine Schreibstrategie, indem er sich mit einem kleinen Vogel vergleicht, der ängstlich am Boden dahinfliegt, um sein Weiterleben angesichts des bedrohlichen Adlers - der die Zeit der Grande Terreur (Schreckensherrschaft) symbolisiert - zu garantieren:

Semblable à l'oiseau timide qui rase la terre, elle [la nature] m'a refusé ce vol audacieux qui fend l'air et fait planer l'aigle superbe dans les hautes régions du firmament. Attaché à mon humble existence, je mets tous mes soins à la garantir le plus long-temps possible de la faulx de cet ennemi hideux qui tranche tout ce qu'il rencontre, et a établi son empire sur la destruction. (Delacroix, 1794, 3-4)

Die Inhalte der Wochenschrift rekurrieren auf eine Vielzahl an Themen, die durch die Instabilität des Tons der Epoche und dem Ende der Monarchie ein gutes Zeugnis abgeben (cf. Sgard 1999b). Die in den mit Frauenbild und Männerbild ausgezeichneten Nummern angesprochenen Themen sind dem Bereich zwischenmenschlicher Beziehungen, insbesondere der Ehe und somit den häuslichen Erzählungen zuzuordnen, wobei die Ehe dabei für Frauen und Männer als glücklicher Hafen dargestellt wird. So beklagt sich beispielsweise in der dritten Nummer ein Mann über die Geldgier seiner Mätressen und freut sich darüber, dass er jetzt endlich verheiratet ist. Insbesondere von der Frau sei der eheliche Hafen zielstrebig anzusegeln, denn die Verwirklichung jeder Frau könne nur an der Seite ihres Ehemannes stattfinden, der hierarchisch - wie in Discours XXVII anthropologisch begründet - über ihr stehe. Ganz in Anlehnung an Rousseau wird die Frau damit der privaten und der Mann der öffentlichen Sphäre zugeordnet sowie ein komplementäres Verhältnis der beiden Geschlechter zueinander entworfen. Am häuslichen Bestimmungsort komme der Frau zudem die verdienstvolle Aufgabe zu, als Garantin für eine gute und glückliche Ehe zu fungieren. Der fiktive Verfasser Monsieur le Spectateur lässt wissen, dass dies selbst dann der Fall sei, wenn der Ehemann seine Ehefrau betrüge. Die Betrogene hat sich in diesem Fall in der Öffentlichkeit nicht verletzt zu zeigen, sondern nach wie vor anmutig und liebenswert aufzutreten, sodass der öffentliche Ruf (le cri public) - die öffentliche Meinung - den Mann wieder zur Raison und zurück zu seiner Ehefrau bringe:

Un $<$ sic $>$ femme qui est abandonnée d'un mari qu'elle aime, n'a rien de mieux à faire pour le ramener $[\ldots]$ que de mettre encore plus de goût dans ses ajustemens, [...], que de déplorer 
ses peines dans la solitude, et de se montrer toujours aimable à la société. Bientôt il sera poursuivi par le cri public ; il entendra si souvent faire l'éloge de celle qu'il l'outrage, qu'à moins qu'il ne soit le plus méprisable des hommes, il redeviendra le plus tendre des maris. (SaR L, 391)

Wurde das Verhalten der Frauen am Beginn des Jahrhunderts (beispielsweise im Censeur und in Marivaux' Cabinet du philosophe, CdP 5) noch vom Verhalten der Männer abgeleitet und lag es somit an den Männern, in der Gesellschaft mit gutem Beispiel voranzugehen, so wird in dieser Passage das Verhalten des Mannes dezidiert in die Hände der Frau gelegt. Ganz deutlich wird sie hier zum ,moralischen Geschlecht` (Steinbrügge 1987) stilisiert, denn nur durch ihre stete Tugendhaftigkeit würden ihr Ehemann und sie selbst in den Augen der Öffentlichkeit Ansehen genießen können.

Die stereotypen Geschlechterdiskurse werden in den mit Frauenbild und Männerbild ausgezeichneten Nummern, wie bereits in den Wochenschriften zuvor, in Verbindung mit dem Tugendkodex der Zeit dargebracht. In variierender Wiederholung - also aus unterschiedlichen Perspektiven - wird nicht mit Kritik an den als lasterhaft angesehenen Verhaltensweisen und (Charakter-)Eigenschaften gespart. Zu diesen zählen beispielsweise Koketterie und Eitelkeit (III, XV), Eifersucht (IV, XV, L), Geiz (XV) und sein Gegenteil, die Verschwendung (I, III), eheliche Untreue (XXXVI, L), Rachsucht (XXXVI, XLVI) oder die Nachahmung von Modetrends (XIII - Vorliebe von Frauen für afrikanische (Pflege-)Kinder, XX - Vergnügungssucht). Ferner vermittelt der Verfasser seine Inhalte in prägnanter Weise, wodurch die meisten Nummern im Repositorium weniger als drei A4-Druckseiten umfassen. Teilweise bestehen sie nur aus den Reflexionen des Verfassers (XIII, XVII, XX, XXVII, L), teilweise aus seinen Reflexionen in Verbindung mit einem oder zwei Leser*innenbriefen (I, III, IV, XV [2 Briefe], XXXI, XXXVI, XLV, XLVI, LV [2 Briefe], LIX). Alle Nummern und Briefe tragen zudem einen Titel, der in resümierender Art und Weise den Inhalt ankündigt und die Wochenschrift durch diese Informationsschlagzeile in Richtung Zeitungsformat rückt.

Auffallend im Spectateur français avant la Révolution ist die geringe Anzahl an Markups für narrative Formen. In den insgesamt 15 Diskursen sind neben einem gekennzeichneten metatextuellen Kommentar (XXXI) zwei Fremdporträts (IV, XV), zwei Dialoge (XV, L) und drei allgemeine Erzählungen (XXXVI, XLVI, LV) anzutreffen. Überraschend ist dagegen die beträchtliche Anzahl an Briefen (I, III, IV, XXXI, XXXVI, XLV, XLVI, LV, LIX). Die zeitgenössischen Diskurse über die Geschlechter werden in den Nummern größtenteils in Form von Leser*innenbriefen wiedergegeben, in denen zumeist häusliche Erzählungen aus einem unglücklichen Eheoder Familienleben beschrieben und mit individualisierten Charakterporträts untermalt werden. Die Korrespondent*innen beklagen sich darin über die Verhaltensweisen ihrer Mitmenschen und wollen diese reformieren beziehungsweise andere Leser*innen durch die Erzählung ihres persönlichen Schicksals vor den lasterhaften und unheilvollen Verhaltensweisen warnen: So beschweren sich Ehefrauen und -männer über eifersüchtige und verschwenderische Gemahl*innen (I, III, XV); junge Frauen beanstanden die Vormundschaft ihrer Eltern (IV, LIX), oder es wird allgemeine Gesellschaftskritik geübt (XIII, XXXI, XLV). Die Bandbreite an Personen, die über die Briefzusendungen zu Wort kommen, erstreckt sich dabei von der Kurtisane (XV, XLV) bis zur ,femme honnête' (XV) und vom enttäuschten (Ehe-)Mann (I, III, XLVI) bis zum Pastor 
(XXXVI). Daran lässt sich ablesen, dass weibliche Stimmen in der zweiten Hälfte des 18. Jahrhunderts bereits zum alltäglichen Inventar der Moralischen Wochenschriften gehören.

Die Leser*innenbriefe, die allesamt an den Monsieur le Spectateur adressiert sind, weisen durch die Einbindung von Exklamationen, Interjektionen (z. B. Hélas!) und anaphorischen Wendungen einen mündlichen Stil auf. Mit dieser fingierten Mündlichkeit erhöhen die Korrespondent*innen die Nähe zum Publikum, das sich durch den vertrauten Stil emotional schneller angesprochen fühlt, und untermauern die Signifikanz des Geschriebenen. So erzählt die Briefschreiberin aus dem 15. Diskurs, wie sie dank der Wochenschrift, die ihr eifersüchtiger Mann lese, erstmals einen Augenblick Zeit für sich finde: ,[I]l a toujours les yeux fixés sur moi, comme l'avare sur son trésor. Je ne puis m'éloigner de lui sous aucun prétexte, et depuis que vos feuilles paroissent, voilà le premier instant que j'ai pu saisir pour vous écrire“ (SaR XV, 123). In einer unbeobachteten Minute spontan verfasst, habe sie keine Zeit gehabt, ihren Text zu überarbeiten.

Wie auch schon bei den meisten Spectator-Produzent*innen nach Van Effen finden sich bei Delacroix in den ausgezeichneten Nummern keine expliziten Referenzen auf die Antike in Form von Zitaten oder Motti. Generell wird in Delacroix' Wochenschrift auch eine klare Dichotomie zwischen dem lasterhaften, gewinnstrebenden, egoistischen Stadtleben einerseits und dem tugendhaften, die Moral verbessernden Landleben andererseits erkennbar. Wenn zum Beispiel einer der Korrespondenten (SaR III) sein lasterhaftes Junggesellenleben in der Stadt beschreibt und schließlich am Land seine Frau kennenlernt und damit den Mythos der guten, tugendhaften Frau vom Land fortschreibt, ${ }^{100}$ dann manifestiert sich auch hier Delacroix' Sympathie für die Schriften von Jean-Jacques Rousseau.

Von besonderem Interesse ist in dieser Wochenschrift der Brief, in dem sich eine Frau für die Einführung eines dritten Geschlechts ausspricht (SaR XXXI, 247-250). Dieses wäre ein ,sexe neutre' (neutrales Geschlecht), mit dem sie alle frivolen und lasterhaften Menschen bezeichnen würde. Bei diesem neutralen Geschlecht handelt es sich zwar ebenfalls um ein sozial konstruiertes Geschlechterkonzept - denn wer bestimmt, was frivol und lasterhaft ist? Gleichzeitig stellt dies jedoch auch ein vom als binär angenommenen biologischen Geschlecht losgelöstes Konzept dar, da es Frauen wie Männer inkludiert. Beeindruckend an diesem Brief ist darüber hinaus der vehemente Einsatz der Briefschreiberin für die Publikation einer Wochenschrift aus weib-

100 Der Topos der einfachen, tugendhaften Landleute in Abgrenzung zu den ,philosophes‘ oder Menschen aus höheren Schichten findet sich ebenso in der Encyclopédie im Artikel zur VERTU (Politique): „C'est souvent dans l'obscurité que brillent les plus solides vertus, \& l'innocence habite moins sous le dais que sous le chaume ; c'est dans ces réduits que vous méprisez, que des ames vulgaires exercent les devoirs les plus pénibles avec autant de simplicité que de grandeur ; c'est-là que vous trouverez avec étonnement les plus beaux modèles pour connoître la vertu; il faut descendre plutôt que monter, mais nous avons la plûpart des yeux si imbécilles, que nous ne voyons l'héroïsme que sous la dorure [kursiv im Orig.]“ (Diderot/D’Alembert 2016, 17:181-182). 
licher Hand. ${ }^{101}$ Die Leserin ist es sichtlich überdrüssig, dass Frauen von Männern beurteilt werden (être jugées), und vertritt die Meinung, dass die Beobachtungen von Frauen genauso viel zählen wie jene der englischen und französischen Spectateurs. Mit dieser Argumentation nähert sie sich hier dem Diskurs aus der Spectatrice an.

\begin{abstract}
Je ne sais pas pourquoi, nous qui avons le coup-d'œil si perçant, nous ne nous sommes pas encore avisés de faire un ouvrage dans le genre du Spectateur : certainement nos observations (je le dis sans vanité) vaudroient bien les vôtres, messieurs les Spectateurs Anglais et Français ? Pouvez-vous, par exemple, vous flatter de nous connoître ? Cependant vous ne cessez de parler de nous. Hélas ! souvent nous ne méritons pas plus vos éloges que vos reproches. Croyez-moi, Monsieur, les femmes ne peuvent être jugées que par elles-mêmes : elles n'y gagneront pas ; mais elles sauront du moins à quoi s'en tenir. Pour les hommes, ils n'ont jamais été plus observés et mieux connus que par nous : la manière dont nous les traitons le prouve assez bien.
\end{abstract}

Ne soyez donc pas surpris, Monsieur, si vous voyez tout-à-coup paroître sur la scène du monde une Spectatrice, dont les yeux ne seront point obscurcis par les préjugés ; qui, sans avoir égard aux distinctions, aux dignités, à l'opulence, et à tous ces signes extérieurs qui caractérisent les hommes et les femmes, mettra chaque individu à sa place. (SaR XXXI, 249250)

Die Briefverfasserin kritisiert ferner, dass Männer nicht gut über Frauen Bescheid wüssten und zudem oft ungerechterweise Lob beziehungsweise Kritik am anderen Geschlecht aussprächen, wohingegen Frauen sich laut ihr nur innerhalb der eigenen Reihen beurteilen können (les femmes ne peuvent être jugées que par elles-mêmes). Diese Beurteilung (jugement) durch andere Frauen falle zwar nicht unbedingt wohlwollender aus, sei aber zutreffender. Außerdem führt sie den Differenzdiskurs eines Jean-Jacques Rousseau oder eines Antoine-Léonard Thomas ins Feld, wenn sie davon ausgeht, dass Frauen ,von Natur aus` eine schärfere Beobachtungsgabe als Männer besäßen und über die Männerwelt besser Bescheid wüssten als die Herren Spectateurs und somit vorurteilsloser über beide Geschlechter schreiben könnten. Es solle also niemanden verwundern, wenn eines Tages eine Spectatrice auf der spectatorialen Zeitschriftenbühne erscheine.

Der Grundtenor, der alle Leser*innenbriefe durchzieht und sich in den Reflexionen des fiktiven Verfassers widerspiegelt, ist die Frage nach dem (Un-)Glück - ein Gedanke, der die ,philosophes' und die Revolutionäre im selben Maße beschäftigt. Insbesondere der 17. Diskurs, der mit „Sur le Bonheur“ übertitelt ist, enthält eine beachtenswerte Reflexion ausgehend vom individuellen Glück hin zur Idee des kollektiven Glücks, wie es im ersten Artikel der Erklärung der Menschen- und Bürgerrechte von

101 In ihrer Studie zur Präsenz von Frauen in der Presse des 18. Jahrhunderts zählt Suzanna van Dijk (1988, 11-12) zehn Frauennamen unter den 450 Zeitschriftenproduzent*innen im Dictionnaire des Journalistes von Jean Sgard (1976); insgesamt nennt sie 18 Journalistinnen. Die Durchsicht (Stand: Juni 2018) der erweiterten Online-Datenbank des Dictionnaire des Journalistes (Sgard 1999c) durch die Verfasserin ergab lediglich 14 Frauennamen unter den 810 eingetragenen Journalist*innen. 
1793 auftreten wird. ${ }^{102}$ Wenn Monsieur le Spectateur diesen Diskurs mit der Behauptung beginnt: „L'UNIQUE desir d'un être raisonnable est de parvenir au bonheur : c'est là le point où tendent tous les hommes“" (SaR XVII, 144), dann geht er von der Aristotelischen Glückstheorie ${ }^{103}$ aus, die als das einzig wahre Ziel eines Individuums sein Streben nach Glück annimmt, das wiederum durch das Streben nach dem Guten erreicht werden kann. Der nächste Absatz bezieht sich auf Jean-Jacques Rousseaus Überlegungen zum Naturmenschen, der nur im Naturzustand glücklich und gut - also mit einer ,bonté' (einer natürlichen Güte) ausgestattet - sei. Durch seinen Umgang in und mit der Gesellschaft entferne sich dieser Mensch allerdings vom idealen Naturzustand und entwickle sich zu einem korrumpierten und schlechten Wesen. So ist im Spectateur français zu lesen: „Dans l'état de nature (cet état n'est plus qu'un [sic] chimère) l'homme robuste, agile, est heureux jusqu'à ce qu'il rencontre un être plus fort et plus agile qui l'attaque“" (SaR XVII, 145). Konsequent verfolgt Monsieur le Spectateur den Rousseau'schen Idealtypus des Naturmenschen und erläutert, wie die Gesellschaft den Menschen entarte und wovon man sich entledigen solle, weil man es zum Glücklichsein nicht brauche. Nach der Beschreibung der individuellen Glücksfindung und des individuellen Glücks, das darin kulminiere, dass Seelenfrieden und Herzensfreude eins werden (,,[L]e bien le plus précieux est la paix de l'ame unie au plaisir du cœur" [SaR XVII, 148-149]), geht der Verfasser zur Beschreibung des kollektiven Glücks über:

102 Déclaration des Droits de l'Homme et du Citoyen (1793), Article premier (le but de la société): „Le but de la société est le bonheur commun. Le gouvernement est institué pour garantir à l'homme la jouissance de ses droits naturels et imprescriptibles".

103 Die Theorie vom Glück hat Aristoteles in seinem Werk Nikomachische Ethik dargelegt. Der Sinn des Lebens sei das Streben nach Glück, wobei dieses Glück auf das gute oder tugendhafte Leben verweist, das ein lebenslanges Projekt ist. Weiters beruht dieses Glück auf guten Handlungen und der Habitualisierung, ,activities that generate 'good character' and $[\ldots]$ on what is called habituation, 'the result of the repeated doing of acts which have a similar or common quality' [...]“ (Ahmed 2010, 36). Das gute Leben ist demnach das Leben, das in der richtigen Art und Weise gelebt wird, indem die richtigen Handlungen endlos wiederholt werden. Bei der Habitualisierung spielen Gefühle eine entscheidende Rolle, denn ein guter Mensch hat nicht nur ,richtige' Gewohnheiten, sondern weiß auch seine Gefühle und Wünsche richtig zu steuern. Er wünscht das Glück nicht einfach nur herbei, sondern er imaginiert das Glück als das, was er erhält, wenn er ,gut‘ wünscht: „It is not simply that we desire happiness but that happiness is imagined as what you get in return for desiring well“ (ibid., 37). Der Mensch lernt also bestimmte Dinge als gut zu erleben, wobei die Erfahrung selbst zur Wahrheit des Objekts (es ist gut) und des Subjekts (ich bin gut) wird. Die Habitualisierung ermöglicht es zum einen die Verbindung zwischen bestimmten Objekten und dem guten Gefühl herzustellen, zum anderen einen guten Geschmack zu entwickeln, wodurch das gute Gefühl und der gute Geschmack als von Natur aus vorhanden angesehen werden: „When history becomes second nature, the affect seems obvious or even literal, as if it follows directly from what has already been given. We assume that we experience delight because 'it' is delightful“" (ibid.). 
Persuadé que le meilleur gouvernement est celui où il y a le plus d'heureux, et qu'il est impossible que le grand nombre soit jamais [sic] le plus riche, il n'attacheroit point le bonheur aux richesses, mais à la vertu, à l'honneur, à l'industrie, aux grands talens. (SaR XVII, 149-150)

Aufgabe einer guten Regierung sei es nicht, alle reich zu machen, sondern die Grundbedürfnisse (Hunger, Durst) der Menschen zu stillen und ihnen Schutz (Kleidung, Behausung) und Arbeit zu bieten. Das Geheimnis dieses beständigen kollektiven Glückszustandes bestehe darin, Frieden zu erhalten und gerecht und menschlich zu regieren: „Tout le secret du législateur, pour entretenir la paix, sera de faire régner la justice et l'humanité“ (SaR XVII, 153). ${ }^{104}$ Dass Monsieur le Spectateur diesen Zustand jedoch noch lange nicht für gekommen sieht, für utopisch hält und (hier) wohl auch nicht ernst meint, geht aus seinem letzten Satz hervor, in dem er sich - wie so oft schon andere vor ihm - durch das Aufwachen aus diesem Traum von den vorangehenden Reflexionen distanziert.

Im Diskurs XX greift Monsieur le Spectateur den Glückstopos erneut, nun aber von seiner gegenteiligen Seite auf. In diesem Diskurs, der mit „Sur le malheur de la Beauté indigente" übertitelt ist, prangert er am Beispiel eines schönen und anmutigen Mädchens, das in die lasterhafte Umgebung eines Wausal ${ }^{105}$ eingeführt wird, die

104 Auch heute noch setzt sich der internationale Glücksindex aus wirtschaftlichen, sozioökonomischen und gesellschaftspolitischen Faktoren zusammen, zu denen das Bruttoinlandsprodukt eines Landes, die durchschnittliche Lebenserwartung seiner Einwohner*innen und die Freiheit, wichtige Entscheidungen selbst treffen zu können, zählen.

105 Damit wird auf die Londoner Vauxhall Gardens - parkähnliche zur Naherholung dienende Gärten (im Deutschen sogenannte Lustgärten) - Bezug genommen, die aufgrund ihrer Beliebtheit auch am europäischen Festland nachgeahmt werden. Eine der berühmtesten Lustgarten-Veranstaltungen, die jährlich zwischen Mai und August im Freien stattfinden, ist der Londoner New Spring Garden am Südufer der Themse. Auf einem Areal von acht Morgen Weideland kommen hier die Londoner Stadtbewohner*innen zwischen 1661 und 1728 zusammen, um der lauten Stadt mit ihren üblen Gerüchen zu entfliehen und die entspannte Atmosphäre zu genießen. Der Garten zieht dabei eine Vielzahl an Menschen unterschiedlicher Schichten an, inklusive Taschendieb*innen und Prostituierte. Im Spectator No. 383 vom 20. Mai 1712 erwähnt Addison den Spring Garden und kritisiert vor allem die dort herrschenden liederlichen Sitten. Ab 1729 übernimmt Jonathan Tyers (1702-1767) den teilweise verrufenen Lustgarten, den er von Prostituierten und unmoralischem Verhalten befreit und dort für „an 'innocent and elegant' entertainment“ (Coke 2017, 5) sorgt, „where respectable Londoners of all classes, with their families, could enjoy a civilised, enjoyable and even educational evening out“ (ibid.). Durch die sittlichen und architektonischen Veränderungen wird Tyers' Lustgarten zu einem „feast for all the senses“ (ibid., 11), dessen süßer Blumenduft, die herzerwärmende Musik und die hübsch gekleideten Besucher*innen einen erquickenden Kontrast zu den schmutzigen Londoner Straßen und den drückenden Alltagsproblemen abgeben: „The delicious sensory experience of being enveloped in a dream-world of perfumed flowers, charming music, fine design and beautiful works of art, especially at night, as well as eating and drinking good fare, and literally 
schwindende Tugend und mangelnde Sittlichkeit der Gesellschaft an. Da es Frauen sind, die das junge Mädchen in den ,Lastertempel ' bringen, zeigt sich deutlich, wie die gesellschaftliche Sittlichkeit an die Tugendhaftigkeit der Frau gebunden ist. Erneut nimmt der Verfasser hier Anleihe an Rousseau, der ,den Mangel an Moral in der mondänen Gesellschaft des 18. Jahrhunderts im Wesentlichen auf eine Denaturierung der Frau zurück[führt]“" (Pabst 2007, 67).

Neben dem Glück ergründet die Verfassungsinstanz auch die ,natürliche“ Ungleichheit zwischen den Geschlechtern im Bereich der allgemeinen Naturgeschichte. Der 27. Diskurs liest sich wie eine Zusammenfassung (der ersten Hälfte) des zweiten Diskurses von Jean-Jacques Rousseaus Discours sur l'origine et les fondements de l'inégalité parmi les hommes (1754) mit dem Fokus auf die Frau. Darin beschreibt Rousseau, wie sich der Mensch innerhalb von zwei einschneidenden gesellschaftlichen Veränderungen (révolutions) ${ }^{106}$ vom Naturmenschen (homme sauvage), der frei, friedlich und ohne Institutionen lebte, hin zum zivilisierten Menschen (homme policé) entwickelte, der von anderen abhängig sei. Im 27. Diskurs, der bereits durch seinen Titel „Sur les Révolutions arrivées dans l'existence des Femmes“ an Rousseaus ,Revolutionsschritte“ anknüpft, geht der Verfasser - wie bereits im 17. Diskurs - von einem Naturzustand aus, in dem Frau und Mann gleich gewesen seien und sich die Frau, frei und unabhängig, nur den Gesetzen der Natur beugen haben müsse. Hiernach folgt eine idyllische Beschreibung des nomadischen Lebens der prähistorischen Frau in einer idealen Naturwelt, in der es weder eine soziale Geschlechterdifferenz noch eine normierte Geschlechterhierarchie gab. Eines Tages habe die Natur schließlich den untätigen Menschen nicht mehr genügend Nahrung geliefert und es musste mit dem Ackerbau begonnen werden, für den die Frau - so die Argumentation - körperlich zu schwach war. Aus dieser evolutionären Unterlegenheit heraus musste sie einen physisch stärkeren Mann um Hilfe bitten. Durch diese familiale Vergesellschaftung wurde die Frau vom Mann abhängig und an das Heim gebunden: ,[E]lle passoit tout le jour dans la cabane du cultivateur qui la nourrissoit" (SaR XXVII, 219). Bei Rousseau liest sich die entsprechende evolutionär-soziale Begründung der unterschiedlichen Lebensweisen von Frau und Mann wie folgt:

Ces premiers progrès mirent enfin l'homme à portée d'en faire de plus rapides. Plus l'esprit s'éclairait, et plus l'industrie se perfectionna. Bientôt cessant de s'endormir sous le premier arbre, ou de se retirer dans des cavernes, on trouva quelques sortes de haches de pierres dures et tranchantes, qui servirent à couper du bois, creuser la terre et faire des huttes de

rubbing shoulders with elegant society, was a vivid, unforgettable and addictive experience which encouraged visitors to return again and again“ (ibid.).

106 Die Epoche der ,ersten Revolution“ sieht Rousseau in jener Zeit, als sich der nomadische Mensch in Gruppen, insbesondere Familienbande, zusammenschließt und es zu einer Art von Eigentum kommt, wodurch er eine neue Sichtweise auf sich selbst erhält und erstmals Eitelkeit und Verachtung sowie Scham und Neid gegenüber anderen entstehen können. Als zweite ,große Revolution“ betrachtet Rousseau Ackerbau und Hüttenwesen, woraus sich das Prinzip der Arbeitsteilung entwickelt und Ungleichheiten innerhalb von Gesellschaften entstehen, die in weiterer Folge in liberale oder illiberale Herrschaftsformen (Demokratie, Monarchie, Aristokratie, Despotismus) münden (cf. Rousseau 1754, 2. Diskurs). 
branchages, qu'on s'avisa ensuite d'enduire d'argile et de boue. Ce fut là l'époque d'une première révolution qui forma l'établissement et la distinction des familles, [...] et ce fut alors que s'établit la première différence dans la manière de vivre des deux sexes, qui jusqu'ici n'en avaient eu qu'une. Les femmes devinrent plus sédentaires et s'accoutumèrent à garder la cabane et les enfants, tandis que l'homme allait chercher la subsistance commune. (Rousseau 1754, 2. Diskurs)

Monsieur le Spectateur führt weiter aus, dass durch den Erwerb von Grundbesitz Neid entstanden sei; der Neid brachte Kriege zwischen Männern hervor, die wiederum zur Versklavung von Frauen führten und jegliche Gleichheit zwischen den Geschlechtern (und wenig später auch innerhalb beider Geschlechtergruppen) verschwinden ließen: „Alors, l'égalité disparut dans les deux sexes“ (SaR XXVII, 221). An diesem Punkt erklärt Monsieur le Spectateur, dass die geschlechtsspezifische Ungleichheit nicht innerhalb der gehobenen städtischen Schicht gelte, in der „ces femmes charmantes qui embellissent nos cités“ (SaR XXVII, 223) ihre Gleichheit zurückerlangt hätten, indem sie das ,Zepter der Liebe“ über ihre Geliebten, die als ,angenehme Untertanen“ (agréables sujets) bezeichnet werden, schwangen: „[Les femmes] sont chez elle [sic] d'aimables souveraines, tentant le sceptre que l'amour a mis dans leurs mains, environnées de leurs agréables sujets qui en reçoivent de douces loix .... [sic] et sont souvent leurs tributaires“ (SaR XXVII, 223). Mit der gewählten politischen Semantik (Herrscherinnen, Zepter, Untertanen, Gesetze, Vasallen), um die Beziehung zwischen Frauen und Männern der gehobenen Schicht zu benennen, deutet der Verfasser bereits an, dass es sich auch hier nicht um eine gleichberechtigte Beziehung handle. Ganz im Gegenteil hätten die städtischen Frauen bereits die Oberhand gewonnen und die Männer wären - wie im letzten Satzteil formuliert - von diesen Frauen abhängig (ils sont leurs tributaires). Durch die Gedankenpause, gekennzeichnet von vier Punkten, die den letzten Satzteil typografisch vom restlichen Satzgefüge entfernen, wird betont, dass es sich um einen kritischen Kommentar des Verfassers handelt. Er kritisiert, dass sich die Männer von diesen Frauen und ihren ,süßen Gesetzen“ (douces loix) abhängig machten. Würden die Männer nämlich - so eine mögliche weiterführende Interpretation der Verfasserin dieser Arbeit - die Herrscherinnenrolle der Frauen nicht dulden und unterstützen, so gäbe es diese Rolle schlicht nicht. Indirekt macht der Verfasser der Wochenschrift demnach die Männer für das Verhalten der Frauen verantwortlich. Darüber hinaus muss im Zuge der Betrachtung dieser Passage hervorgehoben werden, dass Frauen (einer gewissen Schicht) zwar eine Gleichberechtigung/Überlegenheit zugestanden wird, doch dass es sich hier nur um eine Gleichberechtigung/Überlegenheit in Liebesangelegenheiten, das heißt im privaten Raum, handle. Mit der Verwendung einer politischen Semantik wird somit über die weiterhin praktizierte Ausgrenzung von Frauen aus dem öffentlichen Bereich hinweggetäuscht. Fernerhin offenbart sich in dieser Passage erneut der konstruierte Charakter der Geschlechterverhältnisse.

Die Schönheit, insbesondere die vergängliche weibliche Schönheit, beschäftigt den Verfasser im 55. Discours, in dem er von der Begegnung mit einer schönen Frau erzählt, die durch eine Krankheit hässlich geworden sei. Glücklicherweise handle es sich jedoch um eine gebildete (nicht gelehrte) Frau, die aufgrund ihrer Bildung und ihres Geistes in der Gesellschaft noch geachtet würde: „[E]lle a des connoissances, de la facilité dans l'expression ; la sensibilité de son ame est exercée par de bonnes lectures“ (SaR LV, 427). Mit diesem wohlgemeinten Beispiel - das sich in ähnlicher Weise 
bereits im 3. Buch von Ovids Ars amatoria (Anweisungen für Frauen) findet - möchte der Verfasser allen Frauen anraten, sich nicht nur auf ihr Äußeres zu verlassen, und endet mit der folgenden, in eine Kriegsmetapher gekleideten Moral: „Cette réflexion me parut très-juste ; elle me fit regarder les femmes comme des guerriers, qui, pour conserver la victoire, doivent toujours avoir plus d'une arme à leur usage“" (SaR LV, 427).

Die Bildung der Frau wird im letzten Drittel des Jahrhunderts also wieder Thema und scheint eine gewisse - wenn auch nur eine geringe und in den ausgezeichneten Nummern nicht näher ausgeführte - Aufwertung zu erhalten, wenn sie (neben der Schönheit) zur ,Waffe‘ (arme) einer Frau erhoben wird. Das Bild einer gelehrten Frau (femme savante) - als Pendant zu den männlichen ,philosophes“- kommt aber auch hier niemandem mehr in den Sinn.

\subsubsection{Zusammenfassung}

Die Detailanalyse der 183 mit Frauenbild und Männerbild codierten Nummern der französischsprachigen Moralischen Wochenschriften belegt, dass das spectatoriale Geschlechterwissen von den Geschlechterdiskursen der europäischen Aufklärung inspiriert ist, diese ko-konstruiert, speichert und zirkuliert. Die spectatorialen Verfassungsinstanzen nehmen Bezug auf die Differenzbeschreibungen für das weibliche und männliche Geschlecht. Insbesondere betonen sie die Ungleichheit von Frauen und Männern auf physischer und charakterlicher Ebene, die zu unterschiedlichen Verhaltensidealen für Frauen und Männer führt. Obgleich im Misantrope (1711-1712) zu Beginn des Jahrhunderts zum Beispiel versucht wird, die Vorzüge beider Geschlechter hervorzuheben und die Mängel beider Geschlechter gleichermaßen auszumerzen, verfolgt die Verfassungsinstanz doch immer das Konzept einer ,natürlichen', hierarchischen Geschlechterdifferenz mit dezidierten Geschlechterrollen.

$\mathrm{Ab}$ der Mitte des 18. Jahrhunderts manifestiert sich in den französischsprachigen Wochenschriften zunehmend ein komplementäres Geschlechterverständnis, das den gesellschaftlichen Nutzen (utilité) von Frau und Mann in Verbindung miteinander konzipiert und jeweils andersgeartete, einander weitgehend ausgrenzende Wirkbereiche in der häuslichen und öffentlichen Sphäre entwirft. Als Leitbilder gelten für die Frau die stereotypen Rollen der Ehefrau, Hausfrau und Mutter, und für den Mann das stereotype Männerbild des Honnête homme. Darüber hinaus wird die Rolle der Frau aufgewertet, indem sie zum ,moralischen Geschlecht' (Steinbrügge 1987) idealisiert wird. Aus diesem Grund ist es nicht verwunderlich, dass alle französischsprachigen Wochenschriften die Verwirklichung einer jungen Frau an der Seite eines Mannes propagieren. Das bedeutet, ihren Wert erhält die Frau nicht über ihre eigenen Leistungen, sondern über ihren Ehemann. Damit sie sich ihrer gesellschaftlichen Bestimmung freiwillig hingibt, wird die eheliche Verbindung aufgewertet, was ab der zweiten Jahrhunderthälfte über die Valorisierung der romantisch-zärtlichen Liebe und des liebenden Herzens realisiert wird. Kommt am Anfang des Jahrhunderts in Van Effens La Bagatelle (1718-1719) das Thema der Liebesheirat nur ein einziges Mal in den analysierten Nummern zur Sprache (B XLVI), so sind Bastides Wochenschriften Le Nouveau Spectateur (17581760) und Le Monde comme il est (1760) 40 Jahre später übersät davon.

In Summe zeigt die Analyse der französischsprachigen Moralischen Wochenschriften, dass in diesen zunehmend - und ganz massiv ab Mitte des 18. Jahrhunderts - 
für eine Veränderung der Liebeskonzeption geworben wird, die ihre Vollendung in der bürgerlichen Liebesehe findet. Außerdem stellt sich heraus, dass der Frau immer mehr die alleinige Verantwortung für das eheliche Glück auferlegt wird, dessen Verwirklichung in weiterer Folge als Schlüssel für das gesamtgesellschaftliche Glück angesehen wird. Als ,moralisches Geschlecht' trage die Frau somit dieselbe Verantwortung für die Gesellschaft und das gesellschaftliche Gemeinwohl in der häuslichen Sphäre wie der Honnête homme in der öffentlichen Sphäre. 